\title{
Algerian Jewish Sign Language: its emergence and survival
}

\author{
by
}

Sara Lanesman

A thesis submitted in partial fulfilment for the requirements for the degree of

MA (by Research) at the University of Central Lancashire

January 2013 


\section{Student Declaration}

\section{Concurrent registration for two or more academic awards}

I declare that while registered as a candidate for the research degree, I have not been a registered candidate or enrolled student for another award of the University or other academic or professional institution.

Material submitted for another award

I declare that no material contained in the thesis has been used in any other submission for an academic award and is solely my own work.

\section{Collaboration}

Where a candidate's research programme is part of a collaborative project, the thesis must indicate in addition clearly the candidate's individual contribution and the extent of the collaboration. Please state below:

Signature of Candidate

Type of Award Master of Arts

School University of Central Lancashire 


\section{Abstract}

This thesis is concerned with Algerian Jewish Sign Language (AJSL) and the Algerian Jewish Sign Language community. AJSL developed naturally in the Jewish quarter of Ghardaia, a town in the sub-Saharan part of Algeria. A high percentage of deaf people lived in this quarter, and because of that a sign language emerged, and was used by both deaf and hearing members of the community. Many members of the AJSL community migrated to Israel in the middle of the twentieth century, where they have continued to use AJSL with friends and family members. As a result, AJSL has persisted alongside the dominant sign language of Israel, which is Israeli Sign Language (ISL).

This thesis uses data collected from nine members of the AJSL community to explore the sociolinguistic conditions of the AJSL community prior to, and following, the migration of AJSL community members to Israel. It considers how AJSL was used in Ghardaia, and how it has persisted in Israel alongside ISL, which is more prevalent and socially more powerful. The research participants shared narratives on life in Ghardaia and life in Israel, and were also asked about their attitudes towards AJSL and ISL. Specific recurring themes have been identified in their narratives, and these are used to build up a picture of the AJSL community in Ghardaia and Israel.

Analysis of these data shows that, once in Israel, AJSL and Algerian culture were perceived negatively by the mainstream Deaf community in Israel, and so AJSL was relegated to the status of a minority language, used only with friends and family members. Deaf Algerian immigrants began to learn ISL, and used this more in public, but hearing Algerian immigrants had no motivation to learn ISL, and remained sign-monolingual in AJSL.

For this study, just under 300 lexical items have been elicited from AJSL users in order to compare the lexica of AJSL and ISL. Lexical comparison suggests that AJSL has retained its own distinct lexical items over the past 60 years, and in this respect AJSL has been remarkably persistent. In light of the narratives shared by research participants, it is concluded here that the persistence of AJSL in Israel can be attributed to two main 
factors: its importance as a means of communication between deaf and hearing family members, and its rejection by the dominant community, the ISL users.

In spite of the remarkable persistence of AJSL, however, it is clear that AJSL is an endangered language, since intergenerational transmission of the language has all but ceased. This thesis presents evidence to suggest that AJSL is a moribund language, on the grounds not only of intergenerational transmission, but also the relocation and dispersal of the AJSL community, the size of the AJSL community, contact with ISL, and the low status of AJSL in the period immediately following migration to Israel.

The study of AJSL is interesting for many reasons. First, AJSL has characteristics both similar to and different from other village sign languages, and may shed light on the development and structure of such languages. Second, AJSL is unique as a sign language that has persisted in Israel, alongside a widely used sign language, where the sign languages of other immigrant communities have long since disappeared. The case is made in this thesis for the importance of documenting AJSL; language documentation is crucial, given that AJSL is now used only by older generations, and no longer acquired by younger generations. 


\section{Table of Contents}

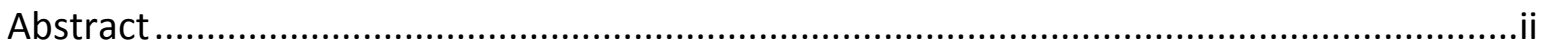

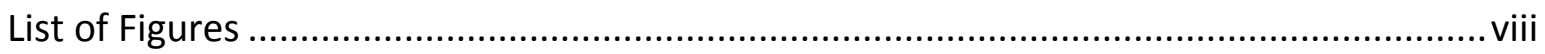

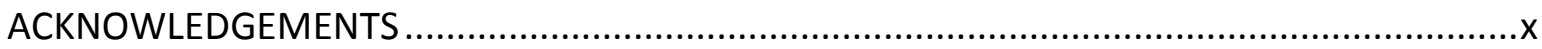

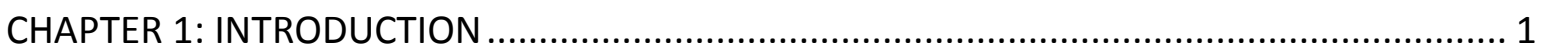

1.1 Sign languages and sign language using communities ...................................... 2

1.2 Urban sign languages and Israeli Sign Language .............................................. 4

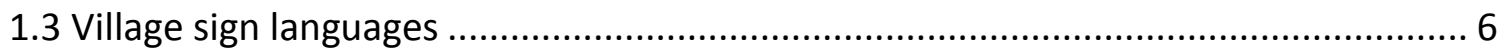

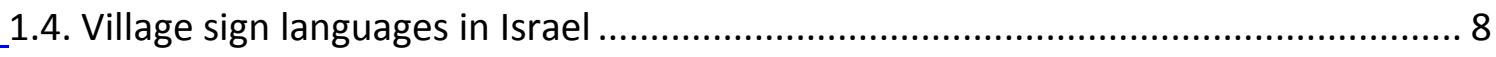

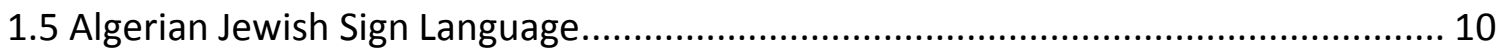

1.5.1 The origins of the Jewish community in Algeria ........................................... 10

1.5.2 The prevalence of deafness in Ghardaia, and the emergence of AJSL .............. 11

1.5.3 The migration of members of the Ghardaia Jewish community to Israel .......... 12

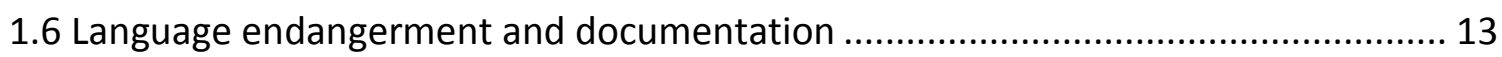

1.6.1 The transience of languages and the documentation of linguistic diversity ..... 14

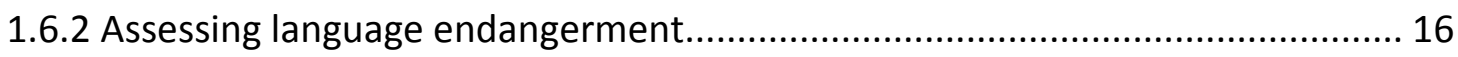

1.7 Research questions and structure of the thesis ........................................... 18

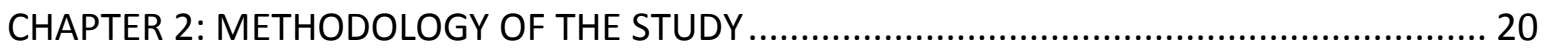

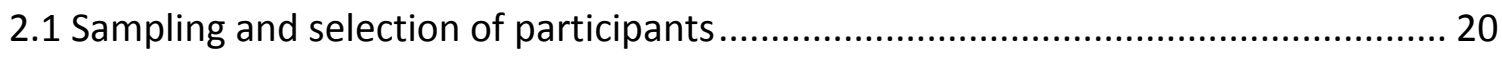


2.2 Data collection

2.3 Challenges encountered when collecting data

2.3.1 The influence of Israeli Sign Language and Hebrew 25

2.3.2 The Observer's Paradox 26

2.4 Types of data, and data analysis 28

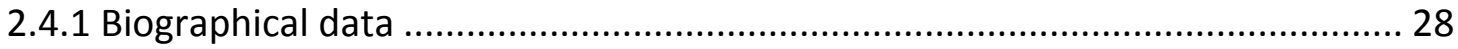

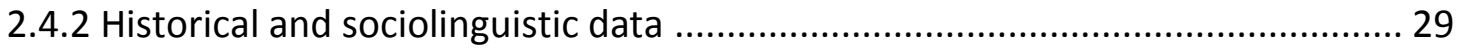

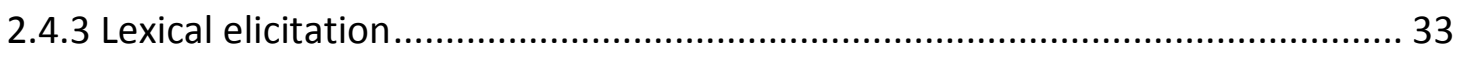

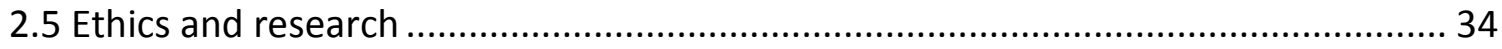

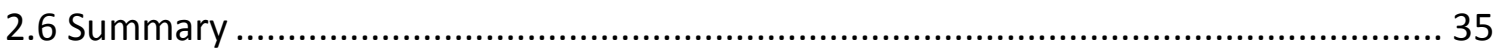

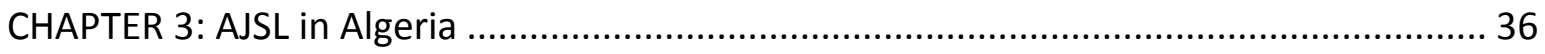

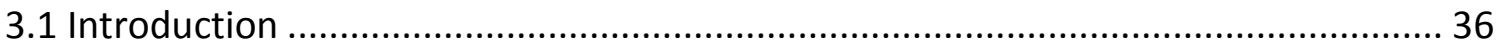

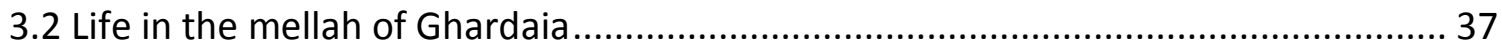

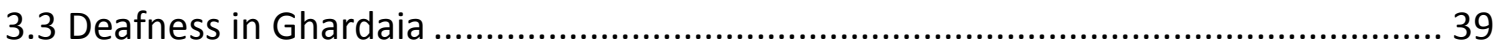

3.3.1 A myth about the origin of deafness in Ghardaia........................................ 39

3.3.2 The relationship between hearing and deaf people..................................... 40

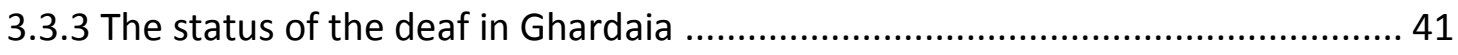

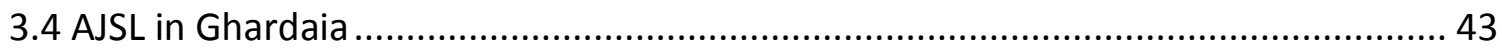

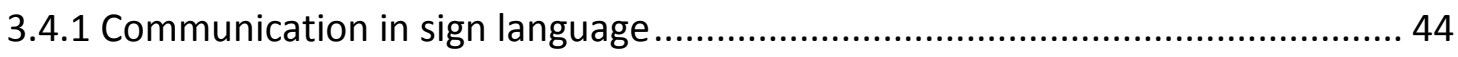

3.4.2 Acquisition of sign language (deaf and hearing) ......................................... 45 


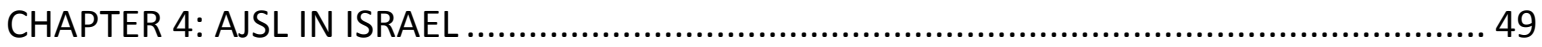

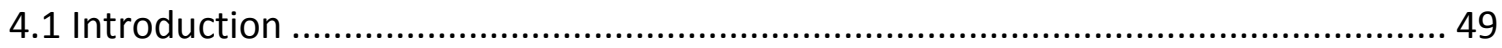

4.2 Relocation of people and dispersion of the population .................................. 50

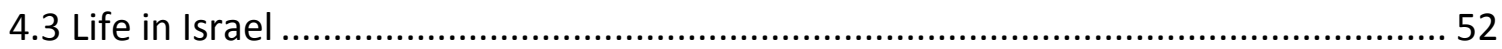

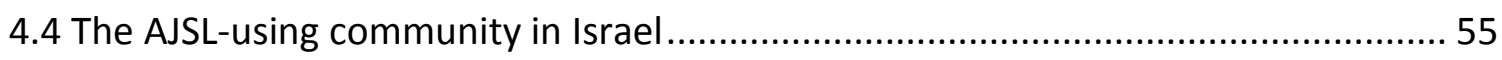

4.4.1 The attitudes of the Deaf community towards Algerian deaf people................ 56

4.4.2 The attitude of the Algerian immigrants towards the Deaf community in Israel 58

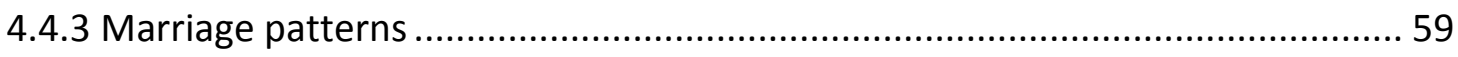

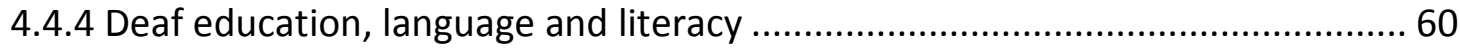

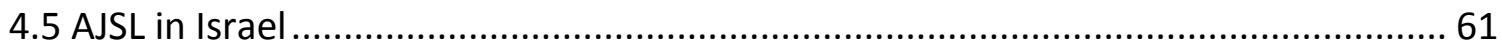

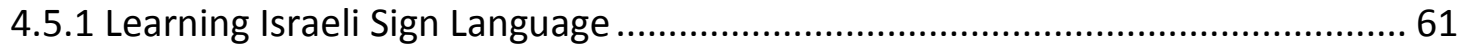

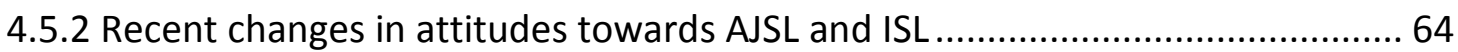

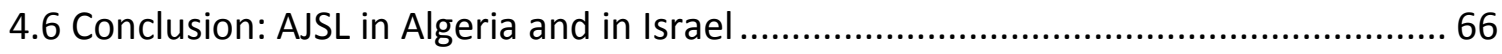

CHAPTER 5: LEXICAL COMPARISON OF AJSL AND ISL ............................................ 68

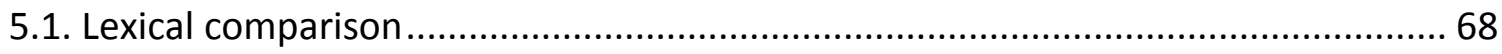

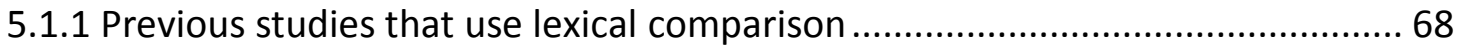

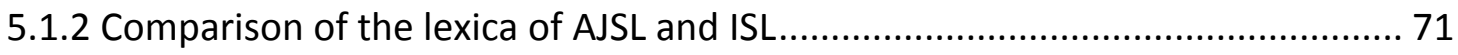

5.2 Sign from specific semantic domains within the AJSL lexicon ............................... 75 


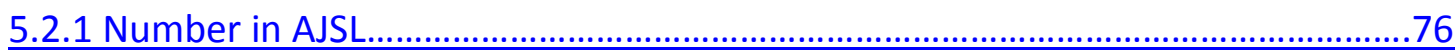

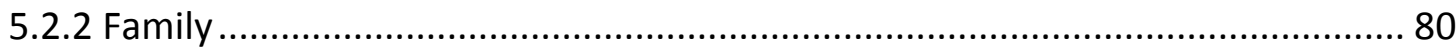

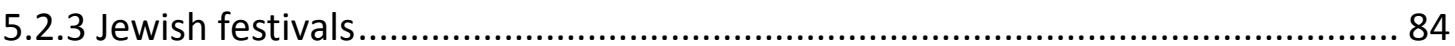

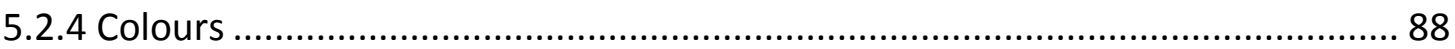

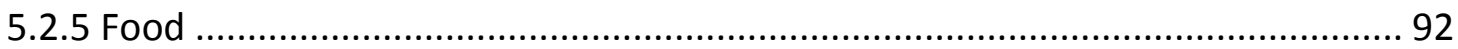

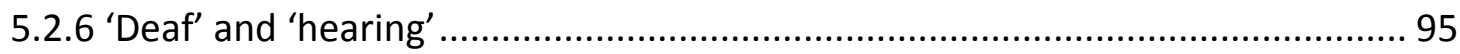

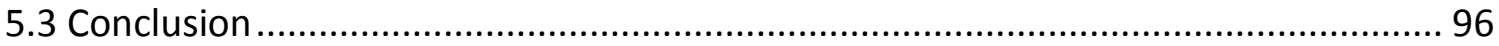

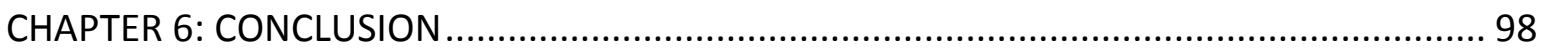

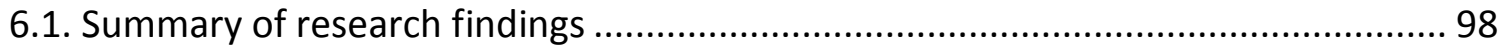

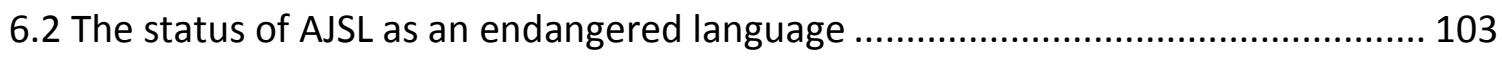

6.2.1 Evaluating the linguistic vitality of AJSL ................................................. 103

6.2.2 The function and transmission of AJSL ............................................... 106

6.3 Further research and the future of AJSL..................................................... 107

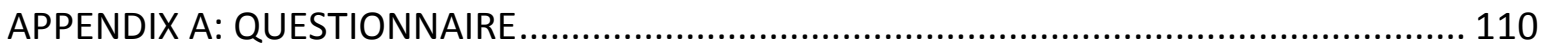

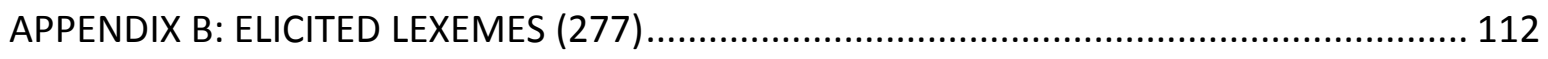

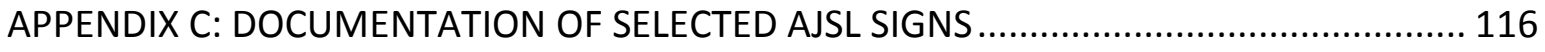

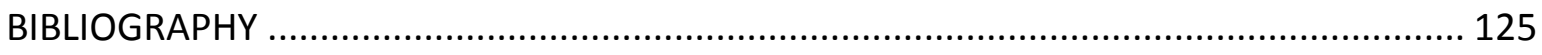




\section{List of Figures}

Figure 1.1 - A map showing the location of Ghardaia, in Algeria 11

Figure 1.2 - A photograph showing the marketplace of Ghardaia 11

Figure 1.3 - A map of Israel showing the four main areas

where significant populations of AJSL users are found

Figure 1.4 - A schematic representation of the terms used in this study, defining a continuum from healthy languages to extinct languages 17

Figure 2.1 - The relationships between the different participants 22

Figure 2.2 - A screen capture showing the excel spreadsheet that was

used to code the historical data 29

Figure 2.3 - The hierarchy of topics created for coding historical and sociolinguistic data pertaining to the AJSL community in Algeria 30

Figure 2.4 - The hierarchy of topics created for coding historical and sociolinguistic data pertaining to the AJSL community in Algeria 31

Figure 5.1 - KNIFE in AJSL and ISL 71

Figure 5.2 - Part of the table that was used for phonological analysis of signs in AJSL

Figure 5.3 - CHICKEN in AJSL and ISL 67

Figure 5.4 - MORNING in AJSL and ISL 73

Figure 5.5 - MOTHER in AJSL and ISL 73

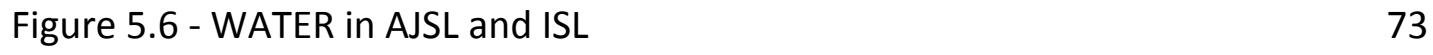

Figure 5.7 - COW in AJSL and ISL

Table 1 - The percentage of possible cognate signs in four pairs of languages $\quad 74$

Figure 5.8 - The number 5 in AJSL $\quad 72$

Figure 5.9 - The number 7 in AJSL 77

Figure 5.10 - The number 10 in AJSL

$\begin{array}{ll}\text { Figure } 5.11 \text { - The number } 14 \text { in AJSL } & 78\end{array}$

$\begin{array}{ll}\text { Figure } 5.12 \text { - The number } 20 \text { in AJSL } & 78\end{array}$ 
Figure 5.13 - The number 100 in AJSL 79

Figure 5.14 - MOTHER in AJSL and ISL 81

Figure 5.15 - BOY in AJSL and ISL 81

Figure 5.16 - GIRL in AJSL and ISL 82

Figure 5.17 - WEDDING in AJSL and ISL 83

Figure 5.18 - HENNA in AJSL and ISL 84

Figure 5.19 - ROSH-HASHANA (Jewish New Year) in AJSL and ISL 84

Figure 5.20 - YOM-KIPPUR (Day of Atonement) in AJSL and ISL 85

Figure 5.21 - HANUKKAH (Festival of Lights) in AJSL and ISL 86

Figure 5.22 - PESSACH (Passover) in AJSL and ISL 87

Figure 5.23 - SHAVUOT (Pentecost) in AJSL and ISL 88

Figure 5.24 - BLACK in AJSL and ISL 88

Figure 5.25 - RED in AJSL and ISL 89

Figure 5.26 - WHITE in AJSL and ISL 89

Figure 5.27 - BLUE in AJSL and ISL 90

Figure 5.28 - ORANGE in AJSL and ISL 90

Figure 5.29 - YELLOW in AJSL and ISL

Figure 5.30 - BREAD in AJSL and ISL 93

Figure 5.31 - COUSCOUS in AJSL and ISL 94

Figure 5.32 - WATER in AJSL and ISL 94

Figure 5.33 - DEAF in AJSL and ISL $\quad 95$

Figure 5.34 - HEARING in AJSL and ISL 96 


\section{ACKNOWLEDGEMENTS}

Many thanks to:

Professor Ulrike Zeshan - for her guidance, her support for the deaf world and for me, for pushing me to advance and for opening her heart and her home to me.

Dr. Irit Meir - for her guidance in the thesis process, and for sharing her experience and knowledge with me. It has been an intellectually, emotionally, and socially fascinating experience for me!

Assaf Israel - for his caring support at all times and assistance in adaptation of materials.

Christina Healy - for her help, translation, and editing, which was done with great diligence and patience.

Shai Davidi - for his great help in filming and picture editing.

Claire Perdomo - for her attention and generous willingness to host me.

Nicholas Barrie Palfreyman - For his willingness to share with me his knowledge, his constant help and support, his patience in explaining difficult theoretical issues over and over, and his kind hospitality.

Calle Börstell and Ryan Lepic - for their kind and very helpful assistance in editing

All interviewees - my heartfelt thanks for your cooperation with this research, enabling it to be conducted.

My dear family - for their support and patience at all times - David, Nadav and Ya'ara. 


\section{CHAPTER 1: INTRODUCTION}

This thesis focuses on a sign language that emerged in the town of Ghardaia, in Algeria, which had a high population of deaf people. Having been used there for several generations, the language moved to Israel when members of the Jewish community left Algeria in the second half of the twentieth century. The thesis describes the sociolinguistic situation of this sign language, Algerian Jewish Sign Language, both prior to and since the migration of members of the Jewish community to Israel, where it is still in use today.

Israel is a small country with a population of seven million. A rich variety of spoken languages are used in Israel, as a result of the diversity of its population, which includes Jews, Arabs, and their respective subgroups (Lewis 2009). Among the Jewish population there are many people who immigrated to Israel from many countries, including those in Europe, North Africa, and the Middle East. Among the Arab population there are Bedouins, who are historically a nomadic society; sedentary Muslims, both farmers and city dwellers; Christians; and Druze, a unique community that constitutes a sub-sect of Islam (ibid). However, the official language of Israel is Hebrew, alongside Arabic, which is used officially for the Arab minority. ${ }^{1}$ This diversity has a parallel in the sign languages that are used in Israel (Meir and Sandler 2008). While Israeli Sign Language (ISL) is the dominant sign language of Israel (see section 1.2.1), a number of other sign languages exist alongside it (section 1.3.1).

Algerian Jewish Sign Language - hereafter referred to as AJSL - is one of these, and was encountered recently, quite by accident, while conducting research into ISL (Lanesman and Meir 2012). While eliciting lexical items from members of the first and second generations of ISL users, a 65 year old deaf man, who had migrated to Israel from Algeria, asked "Do you want me to use the signs I use with my friends, or the signs I used with my mother?" It became clear that the Algerian signs he used were very different from ISL

${ }^{1} \mathrm{CIA}$, The World Factbook (www.cia.gov/library/publications/the-world-factbook/geos/is.html, accessed 28 May 2012). 
signs, and that he could remember the Algerian signs clearly. Given that this sign language emerged in the Algerian Jewish community, Lanesman and Meir termed it 'Algerian Jewish Sign Language' (ibid). Although AJSL has been used for several generations, it has not hitherto been the subject of research, because its existence has not been known to researchers until recently (cf. section 4.3.1). This study therefore presents the findings of the first research that has been conducted into AJSL.

Chapter 1 aims to provide key background details for this study, and begins by discussing the linguistic status of sign languages (1.1). Two distinct types of sign languages are identified - urban sign languages (1.2) and village sign languages (1.3) - and examples of these are provided in order to establish a broad sociolinguistic picture of sign languages and linguistic vitality in Israel. Several village sign languages exist in Israel, yet these are endangered due to the exposure of younger signers to Israeli Sign Language (section 1.4).

Algerian Jewish Sign Language - the focus of this study - is introduced in section 1.5, which includes information relating to the origins of the Jewish community in the Algerian city of Ghardaia, and the prevalence of deafness in the Jewish quarter of the city. The migration of AJSL users to Israel is also briefly described. Given the endangered status of village sign languages, key frameworks on language endangerment are reviewed in section 1.6, and key indicators are identified for analyzing the status of AJSL in Israel. Finally, given the considerable variety of labels that have emerged to describe processes and stages linked to language endangerment, four terms are proposed in section 1.6.3 that will be used to refer to the status of AJSL in this study.

\subsection{Sign languages and sign language using communities}

AJSL is one of many languages around the world that are produced with the hands, face, and body, and perceived visually rather than aurally. Section 1.1 provides a brief overview of evidence for the linguistic status of sign languages, describes the differences between urban and village sign languages, and explains how signed languages emerge naturally in signing communities. It is critical to understand these points in order to appreciate the history of AJSL, and to evaluate the current state of this language. 
The sign languages that are used by deaf people have received recognition as fully-fledged human languages since William Stokoe's study of the phonological structure of American Sign Language (Stokoe et al 1965). Stokoe's research demonstrated the existence of phonological organization in sign languages, which is one of the basic design features of human languages (Hockett 1960). Prior to the publication of Stokoe's research, it was generally believed that sign languages used holistic gestures to convey messages, and that this system of signs had no grammatical structure equivalent to the structure that characterises the grammar of spoken languages. However, Stokoe et al (1965) showed that signs in American Sign Language (ASL) are comprised of meaningless units, in much the same way as phonemes in spoken languages, and that signs may differ from each other in a single element. ${ }^{2}$

Stokoe's research was a breakthrough, opening the door for further research on the grammatical structure of sign languages (e.g. Klima and Bellugi 1979; Emmorey 2002; Meier et. al. 2002; Sandler and Lillo-Martin 2006). Further studies have found similar features in both signed and spoken languages, such as verb agreement (Meir and Sandler 2008; Rathmann and Mathur 2002; Fischer and Gough 1978; Friedman 1975; Padden 1988 , inter alia), the existence of a unit parallel to the syllable and the existence of larger prosodic units (Sandler 1999; Brentari 1998; Wilbur 2000), and complex words (Meir and Sandler 2008; Zeshan 2002). In addition, unique features of sign languages were found, such as facial expressions which are temporally linked with hand movements to produce a verb and its modifier simultaneously (e.g. Boyes Braem and Sutton-Spence 2001).

In addition to the linguistic contribution, Stokoe's study, as well as subsequent studies, had a tremendous social impact. The recognition of sign languages as natural human languages with complex structures and as a means of communication that is not inferior to spoken languages, contributed to the realization of the importance of sign languages as the native language of the deaf (Erting 1994).

\footnotetext{
${ }^{2}$ In other words, sign languages have minimal pairs. For example, the sign MOTHER and GRANDMOTHER in ISL are identical in all features except for the handshape. This is comparable to the words "cat" and "mat" in English, which are identical except for their initial consonants.
} 
Sign languages have developed in two different social settings. Those that have developed in the deaf communities of towns and cities can be described as 'urban sign languages', while those that emerge in isolated rural communities have been referred to as 'village sign languages' (Zeshan and De Vos 2012). These two types of sign languages differ both socially and linguistically (ibid; Meir et al. 2010) and are described in sections 1.2 (on urban sign languages) and 1.3 - 1.4 (on village sign languages).

\subsection{Urban sign languages and Israeli Sign Language}

Urban sign languages emerge alongside the formation of Deaf communities. These communities are created when deaf people from different places meet regularly over time (Padden and Humphries 1988). Such meetings most commonly occur through the educational system, with the establishment of schools for the deaf, although deaf communities can also emerge in social settings such as clubs, and through social events. A common language forms within the group as a result of the necessity to communicate (ibid.). While community members may have different linguistic backgrounds, the end result is a language formed by the society and the whole community within which it grows.

Deaf users of urban sign languages thus constitute the core of a linguistic and cultural minority community where sign language is the most important defining feature, despite the fact that these sign languages are also used by certain groups of hearing people, such as hearing relatives, friends, or sign language interpreters. To reflect this linguistic and cultural connotation, these urban minority communities are often referred to as "Deaf communities", and their members as culturally "Deaf" people, with a capital " $D$ ", as opposed to using "deaf" to refer simply to the hearing status of a person (Padden and Humphries 2005:1). Often an urban sign language used by a Deaf community becomes the national sign language of that country (Wheatley and Pabsch 2010). Communities that use sign language may be thought of as 'communities of practice' (Lave and Wenger 1991), as is explored in section 2.4 .2 below. 
Urban sign languages are often characterized by rapid changes and development, due to the different backgrounds and the diversity of sign language users, and the fact that new people join the sign community all the time (for example, Israeli Sign Language, Meir et al. 2010; and Nicaraguan Sign Language, Senghas et al. 2004).

Israeli Sign Language (ISL) is an example of such an urban sign language. ISL is the most prominent sign language in Israel, and is used by most members of the Deaf community in Israel. ${ }^{3}$ It emerged 75 years ago, when the Deaf community in Israel started to form in the 1930s, and is therefore still considered a young language (Meir and Sandler 2008). The Deaf community in Israel comprised immigrants from many countries: Europe (Germany, France, Hungary, Poland), North Africa (Morocco, Egypt, Algeria), Middle Eastern countries (Iraq, Iran), and others (Meir et al 2010:8). These immigrants brought their respective sign languages with them from their countries of origin (Meir and Sandler 2008:218). The deaf community in Israel currently numbers around 10,000 people (Meir et al 2010:8).

Israeli Sign Language emerged alongside the formation of the Deaf community in Israel, as a result of contact between these different languages. This contact was stimulated by social activities, where Deaf people from different immigrant communities met each other on a regular basis (see section 4.4 for more details). The first school for the deaf in Israel was founded in Jerusalem in November 1932, and this school - along with others that were founded subsequently - further contributed to the development of ISL (ibid:198).

Research on Israeli Sign Language began in 1967, when Izchak Schlesinger and his team, from the Hebrew University, began studying Israeli Sign Language (Meir and Sandler 2008:199), and this work led to the publication of a dictionary of ISL (Namir, Sella, Rimor and Schlesinger 1977). More recently, studies of ISL have focused on verb agreement

\footnotetext{
${ }^{3}$ In the remainder of the thesis, "Deaf" with a capital " $D$ " is used when talking about the ISL community, as it meets the definition of "Deaf community" as used in much of the literature. The AJSL users, on the other hand, do not clearly match the criteria for this usage because of the very different sociolinguistic setting and therefore, deaf AJSL users and the AJSL community are not referred to as "Deaf" with a capital " $D$ " in this thesis.
} 
(Meir 1998), prosody (Nespor and Sandler 1999), interrogatives and negatives (Meir 2004) and non-manual expressions (Dachkovsky 2008). The most comprehensive overview of Israeli Sign Language to date has been published by Meir and Sandler (2008). They assess the relationship between the lexicons of ISL and German Sign Language, noting that ISL absorbed vocabulary from German Sign Language as a result of the large number of immigrants from Germany and the crucial role they played at the establishment of the Deaf community. They find that the rate of similarity between the 2,000 signs included in the study is $38 \%$ (ibid:220). That is, $38 \%$ signs are identical or similar in both form and meaning. This demonstrates the historical connection between the two languages.

\subsection{Village sign languages}

Village sign languages typically develop in rural communities with high incidences of hereditary deafness (De Vos 2012; Nonaka 2011:194). These communities are often isolated geographically or socially, so that deaf people in the community have not attended schools for deaf children, and have not had contact with any wider deaf community. This means that they have not been exposed to the urban sign language varieties of their country (Zeshan and De Vos 2012). One feature that usually distinguishes village sign languages from urban ones is the social integration of the deaf within the hearing community. In rural communities the deaf people are part of the village community, whereas in urban settings deaf people tend to be more separated from hearing people (Groce 1985; Meir et al 2010). An important factor that contributes to this social integration in rural deaf communities is the use of sign language by both deaf and hearing members of the community. Kisch (2008) refers to such a community as a 'shared signing community' - all sign language users, whether deaf or hearing, live in a small and intimate cultural and social setting, enabling easier communication. However, as Kusters (2010) notes, 'village sign languages vary in detail with respect to various social factors such as the causes and incidence of deafness, community size, the ratio of deaf and hearing signers, time depth, et cetera' (cited in De Vos 2012).

A famous example of integration between deaf and hearing members of a community is the case of Martha's Vineyard, an island located off the coast of Massachusetts. Several 
villages with a high percentage of deaf people existed on this island for more than 200 years (Groce 1985). According to this study, the cause of genetic deafness was endogamous marriage patterns characteristic of these communities - families had settled in one place for many generations and married within the community. Deafness was not considered to be a disability or a reason for segregation, and deaf people were fully integrated into the community, with deaf and hearing people alike using a local sign language (Groce 1985). The study on Martha's Vinyard is the first detailed account of a "village sign language" situation, though this term is not used in Groce (1985). Because of the striking absence of barriers between deaf and hearing people, situations such as in Martha's Vinyard have also been called "assimilative deaf communities" (cf. the discussion in Marsaja 2008:12-30).

There are several other examples of rural communities where a village sign language has emerged, and is used by hearing community members as well as deaf ones. In the Balinese village of Bengkala, there are currently 48 deaf individuals in a village of approximately 2,100 members (De Vos 2012). According to local tradition there has been a deaf population in the area for several hundred years, and there is a local tradition of belief in deaf gods (Marsaja 2008:53-58). The local sign language - referred to as 'Kata Kolok', or 'Deaf Talk' (ibid.:84) - appears to have developed over five generations of deaf village members (De Vos 2012:46). Deaf and hearing residents have lived together in one community for generations, and many families with no deaf members are proficient in the use of the local sign language as they acquire it through daily interaction with their neighbours (Marsaja 2008). Kata Kolok differs from the spoken language of the region, Balinese, in syntax and lexicon (De Vos 2012).

Another village sign language emerged in an isolated community on the island of Amami in Japan, which had a high percentage of deafness (between $1.4 \%$ and $2.7 \%$ ), probably caused by marriage within the community (Osugi, Supalla and Webb 1999). In the northern part of Thailand there are several small villages known as the Ban Khor community, where high rates of hereditary deafness have existed for three generations (Nonaka 2007). Additionally, several communities in Africa have given rise to a high 
percentage of people with deafness, one example being Adamarobe, a village in eastern Ghana (Nyst 2007). Deafness in this village has also been prominent for at least three generations. In each of these rural communities the sign language that has evolved is used by both the deaf and the hearing members of the society.

It is clear, therefore, that village sign languages differ from urban sign languages in terms of their social origins, but they also differ in the amount and type of attention that they have received by academics. Until recently, research has focused on national sign languages that are used in more formal, large urban communities. Nonaka (2004) called attention to the neglect of "indigenous" sign languages - that is, village sign languages used by isolated and small communities - in the linguistic discourse and to the lack of documentation, as well as discussing the importance of preserving these languages. For example, Nonaka demonstrates that the sign language originating from the Ban Khor community in Thailand has rare phonological features, such as signs in which the arm conceals the face of the signer, including the signs THERE and FOREIGN (ibid:745). Nonaka argues that ignoring the indigenous language of Ban Khor and other rural sign languages while conducting research will result in a deficiency of knowledge about the full range of possible phonological structures in sign languages. This argument for the importance of researching phonology of understudied signed languages is further supported by the unique use of space seen in Kata Kolok (De Vos 2012). Unlike many signed languages, Kata Kolok signers regularly extend their arms to the full extent, making use of a much larger space around their body than many signed languages previously studied (Marsaja 2008:161). These features, previously undocumented, offer insights into the languages of the visual-gestural modality that may be overlooked if data from village sign languages are not considered.

\subsection{Village sign languages in Israel}

In addition to the urban sign language, ISL (described in section 1.2), Israel has several rural communities that have developed village sign languages of their own (Meir and Sandler 2008). Recently, attention has been drawn to a sign language used in the Bedouin community of Al-Sayyid, in southern Israel, which has been termed Al-Sayyid Bedouin Sign 
Language (ABSL). The Al-Sayyid community has a high occurrence of recessive nonsyndromic deafness (Scott et al. 1995). In this society, marriage takes place mostly between members of the same social group and, like other rural deaf communities, deaf members are fully integrated in the hearing community (Kisch 2000). The Al-Sayyid community was founded 200 years ago. Five generations (approximately 75 years) later, four deaf children were born to a single family (Aronoff et al. 2008). Deafness became prevalent in the following two generations, and because community members do not typically marry outside their tribe, there are currently 150 deaf adults, teenagers and children in a community of approximately 4,000 people (a prevalence of $3.7 \%$ ). The word order of ABSL differs from ISL, as well as other ambient languages, such as the local spoken Arabic and Hebrew (Sandler et al. 2005). In addition, ABSL differs in its vocabulary from other sign languages in the region, such as Palestinian Sign Language and Jordanian Sign Language (Al-Fityani 2007).

Hereditary deafness has also been discovered in the rural communities of Kfar Qasem, Ein Mahel and Arab El-Naim, resulting in the development of various sign languages. However, these languages have not been documented or studied so far. The only pilot study of village sign languages was conducted by Lanesman and Meir (2010) at the 'Onim' school, where students come from several villages. The subjects of this study came from both northern and southern regions of Israel, and the study attempted to discern whether there are similarities between signs of specific geographical regions. The data show a notable degree of homogeneity in the signs of those from the southern region of Israel, while signers from the north show much diversity. In addition, we found that signers from the north are more influenced by ISL, and tend to mouth Hebrew words while signing. Signers from the south rarely mouth words, and tend to move their mouths in ways specific to sign language, which is also characteristic of hearing signers in these villages (Lanesman and Meir 2010).

The short geographic distance from these villages to nearby cities allows members of these communities to have easy access to Israel's dominant sign language, ISL. Therefore, many signers from these rural communities - especially younger ones - are exposed to ISL 
both at school and through social events organized by the Institute for the Advancement of Deaf People in Israel (Lanesman and Meir 2012). This has resulted in a strong influence of ISL signs on the lexicons of the languages used by smaller communities, and all of these sign languages are endangered (ibid). Given the endangered status of village sign languages, a key question that will be considered in this study is the extent to which AJSL is endangered (cf. section 1.6).

Sign languages were also brought by new immigrants who migrated to Israel in the 1980s and 1990s from Russia and the former USSR (Yoel 2007), while immigrants from Ethiopia also brought their sign language with them. However, there does not seem to be significant effect on ISL from these sign languages. Many of these immigrants say that they have forgotten their first language and use only ISL now (Lanesman and Meir 2012). Use of Russian Sign Language has persisted among Russian immigrants, but Yoel (2007), who gives an overview of the Russian immigrant community in Israel, presents an analysis of attrition of Russian Sign Language among community members.

\subsection{Algerian Jewish Sign Language}

This section presents a brief overview of the history of AJSL, to explain the origins of the Jewish community in Algeria (1.5.1), the prevalence of deafness in Ghardaia, the emergence of AJSL (1.5.2), and the migration of community members to Israel (1.5.3). Details of the sociolinguistic setting of AJSL before and after the migration of AJSL users to Israel are not discussed here, as these details stem from the analysis of data collected from research participants (see Chapter 2), the findings of which are presented in chapters 3 and 4.

\subsubsection{The origins of the Jewish community in Algeria}

AJSL developed in several Jewish communities in the region of M'zab, Algeria, which is located in the northern part of the Sahara desert. This region is isolated from the more densely settled areas in the north of Algeria. The Jewish population in this region lived in several settlements, the largest of which is the city of Ghardaia (see Figures 1.1 and 1.2). 


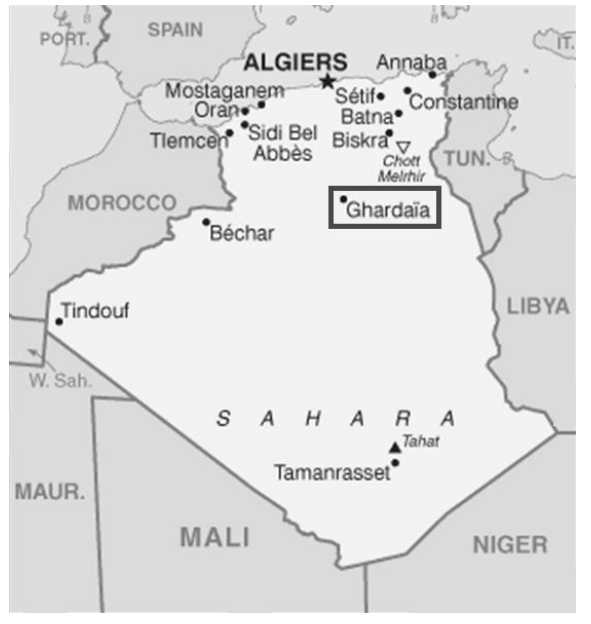

Figure 1.1 - A map showing the location of Ghardaia, in Algeria. (Source: CIA World Factbook.)

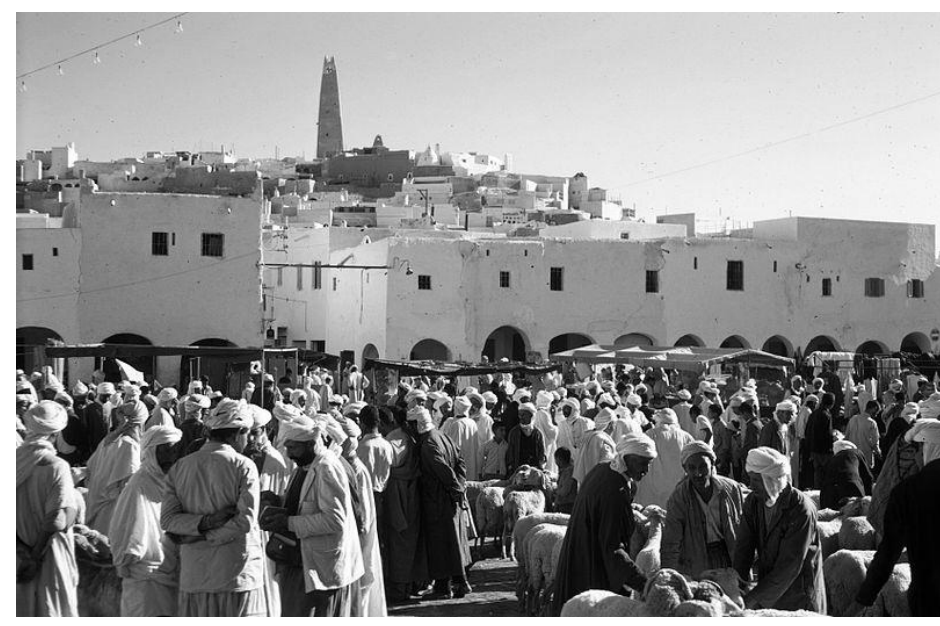

Figure 1.2 - A photograph showing the marketplace of Ghardaia (taken in October 1970). (Source: Wikipedia.)

According to historical evidence, Jews lived in this region at for least 700-800 years (Nagel 2004). Ghardaia had been founded in the eleventh century by Berbers who belonged to the Ibadiyya sect, a Muslim sect (Briggs and Guede 1964:9; Nagel 2004:27). According to M'zabite and Jewish oral traditions, four Jewish families of craftsmen came from Djerba around the fourteenth century, and worked in Ghardaia as jewelers and blacksmiths (Briggs and Guede 1964:10). In 1492, other Jewish families moved to Ghardaia from Tamentit, in the west of the Sahara, fleeing from persecution (Lanesman and Meir 2012).

Briggs and Guede (1964) provide some demographic data concerning the Jewish community in Ghardaia, which they found in the official archives in the office of the District Commissioner of the M'zab region. They report that the Jewish community did not exceed 2,500 people, and usually the overall population was much lower than this. In 1954 there were 1,091 community members (Lanesman and Meir 2012).

\subsubsection{The prevalence of deafness in Ghardaia, and the emergence of AJSL}

It was in the Jewish quarter, or mellah, of Ghardaia that a sign language developed, and according to Briggs and Guede (1964:12) this was due to the birth of deaf individuals into 
the community because of endogamous marriage patterns. ${ }^{4}$ Briggs and Guede write that $2.5 \%$ of the population were deaf (approximately 25 deaf people per thousand hearing people), and that 'nearly everyone had at least one deaf-mute among his close relatives or neighbor, and so everyone is fluent in sign language' (ibid:12). However, we do not know whether deafness was spread evenly throughout the Jewish community in Ghardaia, and it is impossible to construct social network data for Ghardaia (as, for example, is constructed for Ban Khor sign language, see Nonaka 2007), since the community does not exist anymore. ${ }^{5}$

Research into other 'deaf villages' has revealed information relating to the time depth of the sign languages used in those villages. For example, in the Balinese village, Desa Kolok, genetic testing and genealogical research has suggested that the sign language Kata Kolok emerged five generations ago (De Vos 2012). At present, it is not clear exactly when AJSL emerged (see further discussion in section 3.4.2).

\subsubsection{The migration of members of the Ghardaia Jewish community to Israel}

Between 1943 and 1962, all members of the Ghardaia Jewish community emigrated from Algeria. The first wave of migration took place between 1943 and 1950, when 500-600 Jews migrated to France and to the area that would become Israel in 1948 when it reemerged from the British Mandate in Palestine. This was due to growing tension between Berbers, Muslims and Jews (Briggs and Guede 1964). The tensions eased in 1950-1, but a second wave of migration took place in the 1950s, motivated by the establishment of the state of Israel in 1948, and the Algerian War of Independence with France (Lanesman and Meir 2012). The Jews were regarded as allies of the French, and felt increasingly unsafe. The final wave of migration was in 1962, and all Jews had left Ghardaia by this point (see Section 4.1 for details on these migration patterns).

\footnotetext{
${ }^{4}$ The social isolation of the Jews in Ghardaia lasted for at least 500 years, and resulted in several distinct physical characteristics, including a slight tendency towards blond or red hair (Lanesman \& Meir 2012).

${ }^{5}$ It seems that there were deaf people in other settlements as well as Ghardaia, since a deaf 85 year old man was born in Aflou - a smaller village, situated not far from Ghardaia - and married a deaf woman from Ghardaia. This man, YS, is the husband of MS, who is one of the research participants (see section 2.1) which suggests that there was contact between the communities.
} 
According to Nagel (2004), the more affluent Jews migrated to France, while less wealthy people moved to Israel. Those who migrated to Israel moved to different places, but there are four main areas where significant populations of AJSL users may be found: Haifa, Nazareth, Giv'at Schmu'el near Tel Aviv, and Dimona. These are indicated on the map in Figure 1.3.

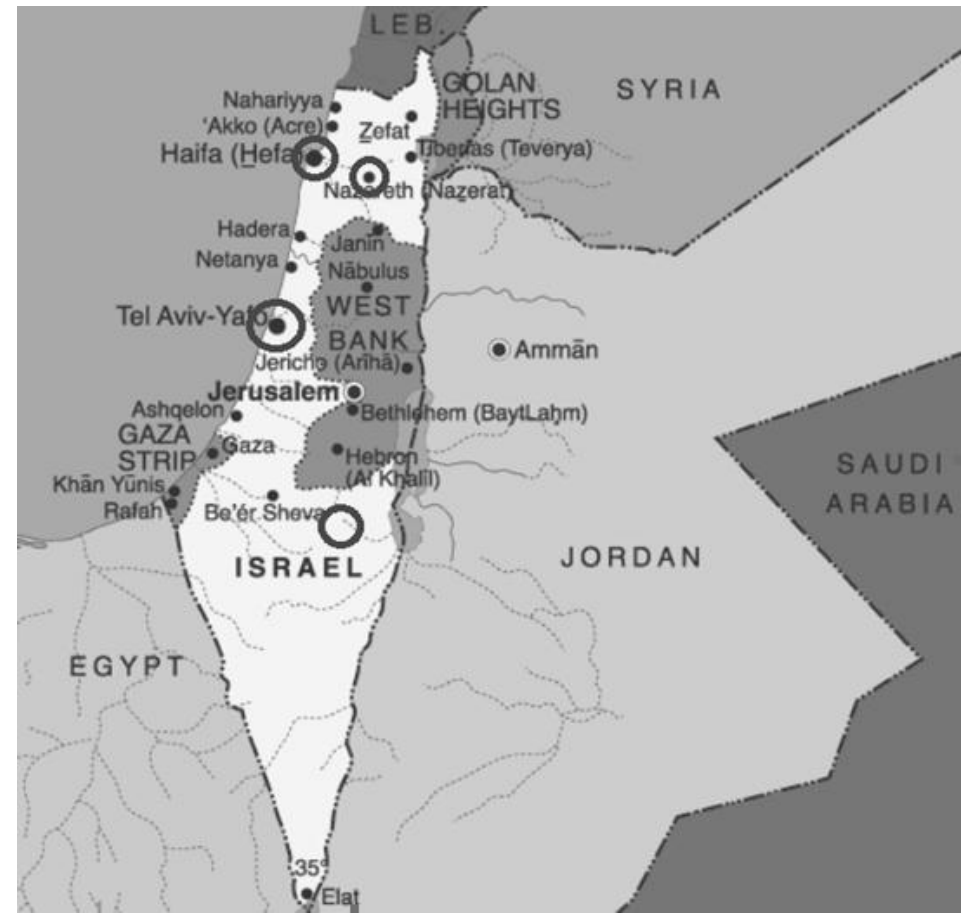

Figure 1.3 - A map of Israel showing the four main areas where significant populations of AJSL users are found (Source: www.justmaps.org).

\subsection{Language endangerment and documentation}

There are many possible reasons why languages can become endangered. For example, Lüpke notes that 'a large number of African languages... can be classified as endangered on diverse grounds, ranging from displacement due to wars or climate change to rural exodus for socioeconomic reasons' (Lüpke 2009:15). Other reasons, mentioned by Tsunoda (2005:57-63) include mixing of speakers of different languages, lack of language 
literature, spread of religion, decline or loss of population, language attitude, and destruction of the environment.

It has already been noted that village sign languages in Israel are endangered due to the exposure that younger village sign language users now have to the dominant urban sign language, ISL (section 1.4). It is argued here that the processes involved in language endangerment create a continuum stretching from a dynamic and healthy language to language death. However, any terms associated with language endangerment need definition. For example, what exactly is 'language death'? It may at first seem like a simple question, but different indicators have been proposed to determine whether a language has died (Tsunoda 2006).

A number of frameworks have been posited for assessing the degree to which a language is endangered, and these are referred to in section 1.6.2. This study aims to identify the extent to which AJSL is at risk of becoming extinct within the next couple of decades, and section 1.6.3 explains the terms that are considered the most appropriate to discussion of this issue. Before that, however, some reflections are presented on the transience of languages and the importance of documenting languages in order to understand linguistic diversity.

\subsubsection{The transience of languages and the documentation of linguistic diversity}

An important feature of human languages is their transient nature (Hale et. al. 1992; Himmelmann et. al. 2006). As humans move from one location to another and interact with diverse peoples, the languages they use influence each other (Sankoff 2001; Mufwene 2008). Other times, one language may carry more power politically than another, and have a great influence either to change the less powerful language, or to eradicate its usage. This process of languages interacting and changing has sometimes had the positive effect of creating linguistic variety around the world; however, because human languages live in the minds of those who use them for communication, the disappearance of communities with unique languages inevitably causes the extinction of those languages, decreasing global linguistic diversity (Crystal 2000; Skutnabb-Kangas 2003). Another common scenario is when a community continues to exist, but switches to 
a new language, as seen in Scandinavia with the Tornedalians, Kven, and Saami: these three groups switched language preference from their native language to the majority language, Swedish (Pietikäinen et al. 2010:129)

In civilizations around the world, as younger generations choose a majority language over the minority language of their parents, the language disappears when the older generation passes. One example of this common situation occurred in the final two decades of the eighteenth century in Nicaragua. While the Rama language was considered valuable for maintaining cultural identity, people mostly held negative attitudes toward it, with a strong preference toward Spanish. Consequently, younger generations did not learn the minority language, and in 1986 only a few dozen older men were still speaking Rama (Hale et al 1992:17). Linguists and the local government began a project to revitalize the language, but if the attempt proves unsuccessful, Rama will cease to be a living language when the last of the speakers die.

With the deaths of so many languages, we are gradually losing the existing linguistic diversity around the world. It is important to maintain, or at least document this valuable variety in order to understand various human cultures (Turin 2005) and in order to understand one of the unique characteristics of human beings - the natural ability to use language. The depletion of the world's linguistic diversity affects our ability to understand the existence of possible human languages, that is, the properties and characteristics of human language.

Documentation of indigenous languages is valuable to research. Linguistic research relies on the availability of documented materials when describing the use of a given language and its characteristics, and research that focuses on a relatively small number of languages belonging to a small number of language families limits the validity of linguistic models (Evans and Levinson 2009). Data from less well-known languages enrich the variety of features that linguists must relate to when constructing theories about language structure and use.

Documentation is especially important in the case of endangered languages. When a language disappears, its documentation may be the only proof for its existence, and the 
only way to learn about its structure and lexicon (Himmelmann et al. 2006). Additionally, documenting and analyzing an endangered language may stimulate interest in the language under study, promoting its use, and empowering the community which uses it. The promotion that research gives to a language is one way of supporting linguistic diversity (McWhorter 2001; Batibo 2009; Jones and Ogilvie, forthcoming).

\subsubsection{Assessing language endangerment}

A number of frameworks have emerged for assessing language endangerment, using different perspectives to assess the vitality of a language. An influential framework is the Major Evaluative Factors of Language Vitality, which were created by the Ad Hoc Expert Group on Endangered Languages at the request of UNESCO. According to UNESCO, 'no single factor is sufficient to assess the state of a community's language', but when considered together, these nine criteria can assess how viable a language is, and what its function is in society (UNESCO 2003).

The UNESCO World Atlas of Languages in Danger (Moseley 2010) currently lists 2,473 languages, as of April 2012. ${ }^{6}$ However, these do not currently include any of the world's sign languages, and discussion of sign language endangerment has been notably lacking from most of the literature on language endangerment (though see Van Steenwyk 2008 for comments on the status of Australian Sign Language as an endangered language). With this in mind, an important resource for considering sign language endangerment specifically is the UNESCO survey questionnaire for sign languages (Zeshan 2012). This is a version of UNESCO's Linguistic Vitality and Diversity that has been specifically adapted to suit the sociolinguistic setting of sign languages, and includes a consideration of how to apply the concept of the 'reference community' to sign languages. The survey questions are in two sections, on language vitality and endangerment within the reference community, and linguistic diversity.

\footnotetext{
${ }^{6}$ http://www.unesco.org/culture/en/endangeredlanguages/atlas, accessed 5 April 2012.
} 
Tsunoda (2006:57-63) summarises fifteen causes of language endangerment. These also include factors such as dispossession of the land, perhaps due to invasion or settlement, to destruction of the environment, as in the case of the Tokuyama-mura valley in Japan, which used a distinctive dialect, but was relocated when the government made the decision to build a dam there (Tsunoda 2006:58).

In his overview of the literature on endangered languages, Tsunoda (2006) highlights the vast number of terms that are used to refer to language endangerment. These include 'moribund', 'endangered', 'dying', 'sick', 'weakening' inter alia. In order to avoid confusion, the following terms are adopted in the current study to refer to different stages of endangerment. Following Schmidt (1990), healthy will be used to refer to a language which is not considered endangered, while extinct means that a language is no longer in use. Between these two points, the terms endangered and moribund will be used. These terms are presented schematically in the form of a continuum in Figure 1.5.

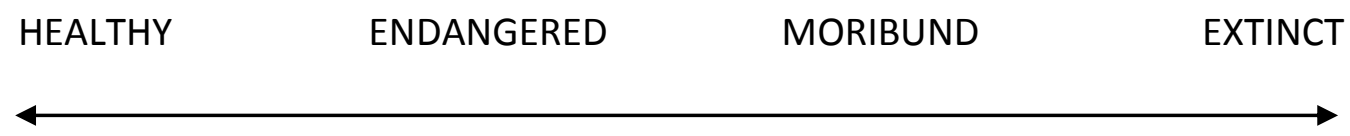

Figure 1.4 - A schematic representation of the terms used in this study, defining a continuum from healthy languages to extinct languages.

Of the frameworks in the area of language endangerment, a recurring concern is that of language function, and Fishman (1991) proposes eight stages - relating to language function - that indicate where a language lies on the endangerment continuum (figure 1.5). For example, languages that are used by governments and universities are in stage 1 (healthy), whereas languages that are only used by a few older people are in stage 8 (moribund).

A concern identified by several endangered language frameworks relates to intergenerational transmission, and Krauss (2001) refers to transmission patterns to propose indicators that determine whether a language is healthy, endangered or 
moribund. According to Krauss, a language is healthy, or safe, if it is likely that the language will still be used in 2100. A language is endangered if, by 2100 , children will no longer learn the language. Finally, a language is moribund if children no longer learn the language now.

The above approaches are used in Chapter 4 and Chapter 6 to explore those criteria that are most relevant to Algerian-Jewish Sign Language, given the history of that language. It should be noted all of the frameworks discussed here use exclusive terms that refer to spoken languages only and do not include sign languages. Therefore, the more inclusive term 'language users' is used in this thesis, rather than 'speakers', to encompass gesturalvisual modality and the vocal-auditory modality.

\subsection{Research questions and structure of the thesis}

Given the unusual situation of the development of AJSL in Algeria, the migration of AJSL users to Israel, and the persistence of AJSL in Israel alongside the dominant sign language (ISL), two research questions are posited:

1. What was the sociolinguistic situation of Algerian Jewish Sign Language (AJSL) before and after the migration of AJSL users to Israel?

2. To what extent is AJSL now at risk of becoming displaced by Israeli Sign Language?

Since these questions concern the language in its community of language users, this is mainly a sociolinguistic study. Chapter 2 sets out the research methodology, and includes details of the sampling of participants, the types of data that have been collected, and the ways in which the data have been analysed. Several challenges emerged during the process of collecting data, including manifestations of the observer's paradox, and some of the steps that were taken to overcome these challenges are explained in section 2.4. Finally, and importantly, details of ethical considerations are presented in section 2.5.

Chapters 3 and 4 present the results of historical and sociolinguistic data obtained from participants, in order to explore the sociolinguistic situation of AJSL before and after the migration of AJSL users to Israel, respectively. Chapter 3 uses elements of a 'community of 
practice' (Lave and Wenger 1991) approach to draw a tentative picture of the AJSL community as it existed in Algeria, prior to the migration of AJSL users to Israel. Chapter 4 makes reference to several of the language endangerment frameworks outlined in section 1.6, with a view to considering the progress of AJSL once its users had migrated to Israel.

Given the endangered status of languages such as AJSL, which exist alongside a dominant language (ISL), the documentation of AJSL is an important aim. Therefore, this study is also the first step to documenting the language, focusing specifically on the lexicon on AJSL. Chapter 5 presents an overview with key findings of a comparison of the lexica of AJSL and Israeli Sign Language. Lexical items were elicited from several semantic domains, including colour, food, religious festivals, and kinship terms. A key objective of this comparison is to see whether the lexicon of AJSL has persisted, or been influenced by the lexicon of ISL. A further selection of AJSL signs is presented in Appendix C.

Chapter 6 summarises the findings of the study (Section 6.1) and brings together the evidence that is needed in order to identify the extent to which AJSL is now at risk of becoming displaced by ISL (section 6.2). Once this question has been addressed, it is natural to move on and consider the future of AJSL, including the type and quality of documentation, and the possibility of language revitalisation efforts (section 6.3). Given that this study presents the findings of the very first research into AJSL, it is unsurprising that a number of ideas for future research have emerged during the course of the study, in the hope that they will stimulate further interest and lead to new linguistic and sociolinguistic discoveries linked to Algerian Jewish Sign Language. 


\section{CHAPTER 2: METHODOLOGY OF THE STUDY}

Chapter 2 describes the research methods that have been used, and explains why these particular methods have been judged the most appropriate for answering the research questions. This chapter describes how data have been collected (section 2.2), the challenges encountered when collecting data (2.3), what types of data have been collected, and how the data have been analyzed (section 2.4). Important ethical considerations are presented in section 2.5.

\subsection{Sampling and selection of participants}

Participants were selected in a way that has much in common with an ethnographic approach. Tagliamonte (2006:20) describes this as a methodological approach where 'the analyst integrates themselves within the community under investigation, either by engagement in local affairs and/or developing personal associations with members'. I am a deaf woman, and I am an active member of the deaf community in Israel. Given this, and that I was also born in Algeria - albeit not in Ghardaia - I was already acquainted with most of the participants in this research. My three sisters are also deaf, and are friends with most of the participants, and it was through these connections that I was able to meet other deaf Algerians and arrange initial meetings with potential research participants.

Other types of sampling would not have been suitable for this research. I noticed that it was not easy to engage people in discussion about AJSL when they were not previously known to me, which led me to the conclusion that random sampling would not have worked well, and additionally, it has not yet been possible to formulate an exhaustive list of the population of AJSL users in Israel from which such a random sample could be obtained.

Several criteria were used to select participants. The most important factor was that they still use AJSL extensively today, in order to best assure fluency. This criterion is critical. All 
deaf Algerians in Israel today are bilingual, using ISL to communicate with any deaf people who are not part of the AJSL community. AJSL is only used with family members and with others from the AJSL community. It was therefore important to select participants who regularly use AJSL today with a range of different people.

I decided to include hearing people in the study, because hearing people are an integral part of the AJSL community. In the Jewish community in Ghardaia, it seems that AJSL was used by many hearing people, as well as by deaf people (see Chapter 3) Therefore all community members, whether deaf or hearing, may have been significantly exposed to AJSL, and some continue to use AJSL today. Taking this into account, it is important to include hearing participants in order to understand their perception of deaf members of the AJSL community. This will enable a deeper understanding of the details and social intricacies of the AJSL community. However, hearing people participated only in the interviews, and were not involved in the lexical elicitation exercise (see section 2.4 on lexical elicitation, and also section 2.3 on challenges associated with data collection). 


\begin{tabular}{|c|c|c|c|c|c|c|c|}
\hline $\begin{array}{l}\text { Participant } \\
\text { code }\end{array}$ & Sex & $\begin{array}{l}\text { Deaf/ } \\
\text { hearing }\end{array}$ & $\begin{array}{c}\text { Age at } \\
\text { time of } \\
\text { interview }\end{array}$ & $\begin{array}{l}\text { Year of } \\
\text { migration }\end{array}$ & $\begin{array}{l}\text { Data } \\
\text { (mins) }\end{array}$ & $\begin{array}{l}\text { Place of } \\
\text { residence } \\
\text { in Israel }\end{array}$ & $\begin{array}{l}\text { Deaf family } \\
\text { members }\end{array}$ \\
\hline YZ & M & deaf & $70 \mathrm{~s}$ & 1958 & 139 & Haifa & $\begin{array}{c}\text { Two sons, wife, } \\
\text { father, four } \\
\text { brothers, others }\end{array}$ \\
\hline MG & $\mathrm{F}$ & deaf & $60 \mathrm{~s}$ & 1950 & 165 & $\begin{array}{c}\text { Ramat Gan, } \\
\text { near } \\
\text { Tel Aviv }\end{array}$ & $\begin{array}{c}\text { Father, brother, } \\
\text { others }\end{array}$ \\
\hline MS & $\mathrm{F}$ & deaf & $70 \mathrm{~s}$ & 1948 & 30 & $\begin{array}{c}\text { Nes Ziona, } \\
\text { south of } \\
\text { Tel Aviv } \\
\end{array}$ & $\begin{array}{l}\text { Sister, brother, } \\
\text { three children }\end{array}$ \\
\hline LP & $\mathrm{F}$ & deaf & $50 \mathrm{~s}$ & 1962 & 75 & Haifa & $\begin{array}{c}\text { Father, three } \\
\text { sisters, brother, } \\
\text { others }\end{array}$ \\
\hline ES & $\mathrm{F}$ & deaf & $50 \mathrm{~s}$ & 1956 & 79 & $\begin{array}{c}\text { Kibbutz } \\
\text { Sollelim, } \\
\text { near Haifa }\end{array}$ & $\begin{array}{c}\text { Father, three } \\
\text { sisters, brother, } \\
\text { others }\end{array}$ \\
\hline ZM & $\mathrm{F}$ & deaf & $50 \mathrm{~s}$ & 1957 & 55 & $\begin{array}{c}\text { Atlit, } \\
\text { near Haifa }\end{array}$ & $\begin{array}{c}\text { Grandmother, } \\
\text { others }\end{array}$ \\
\hline MA & M & hearing & $80 \mathrm{~s}$ & 1937 & 45 & Haifa & $\begin{array}{c}\text { Mother, two } \\
\text { uncles, daughter, } \\
\text { others }\end{array}$ \\
\hline SS & $F$ & hearing & $70 \mathrm{~s}$ & 1962 & 40 & Haifa & $\begin{array}{l}\text { Husband, sister, } \\
\text { brother, three } \\
\text { daughters, one } \\
\text { son, others }\end{array}$ \\
\hline YS & M & deaf & $60 \mathrm{~s}$ & 1948 & 30 & $\begin{array}{c}\text { Pardes Katz } \\
\text { near Tel } \\
\text { Aviv } \\
\end{array}$ & $\begin{array}{c}\text { Father, sister, } \\
\text { others }\end{array}$ \\
\hline
\end{tabular}

Table 2.1 - An overview of research participants. 


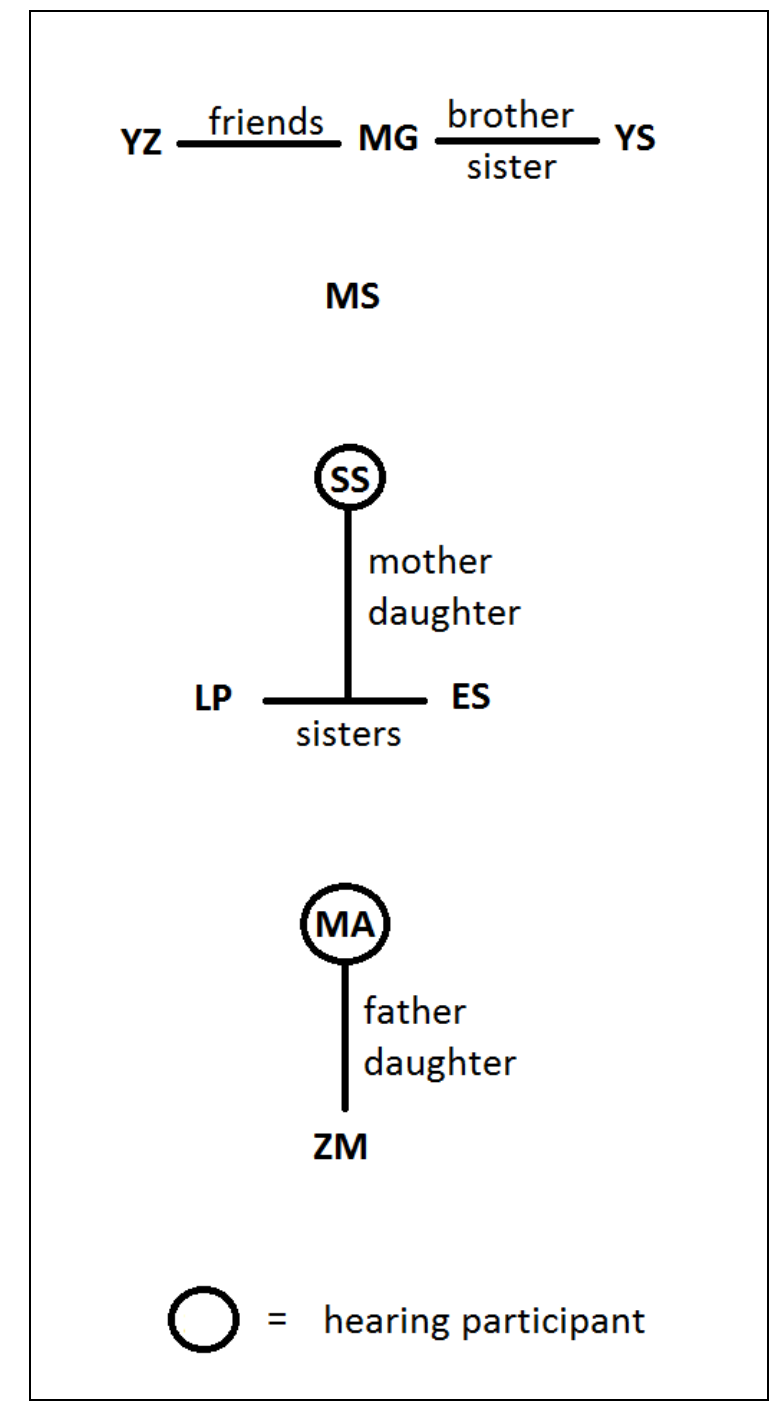

Figure 2.1 - The relationships between different participants.

Table 2.1 presents an overview of research participants, including the year they migrated to Israel, and the amount of data that has been recorded for that individual. Figure 2.1. presents the genealogical relationship between the participants. Each participant has been given a code in order to respect their anonymity. Of the nine participants, all were born in Algeria except for ZM, who was born in Israel, and all were between 50 and 89 years of age at the time of the interview. Seven are deaf and two are hearing, born of deaf parents. Six of the subjects are female and three are male. Their current area of residence in Israel is also noted. In terms of the representativeness of the sample, participants are broadly representative of two of the four areas where AJSL users have settled more densely (see section 1.5.3) - Haifa, and Giv'at Schmu'el (Tel Aviv) - but AJSL users from 
the areas in Nazareth and Dimona have not yet been sampled, because I have not yet had the opportunity to meet and befriend people from these communities. So far they have resisted establishing any contact with me.

While many sociolinguistic studies work with much larger samples of participants, for this particular study the use of nine participants is motivated and justified by several factors. As explained above, the criteria for suitable participants were such that the pool of eligible participants was not large in the first place, particularly as AJSL is already endangered with dwindling numbers of users. The approach here is largely qualitative, based on in-depth interviews, and is not uncommon in research on sign languages and Deaf communities to have relatively modest numbers of participants. For instance, a recent study by Eichmann (2009) involved interviews with eight participants in the UK and nine participants in Germany.

\subsection{Data collection}

All participants were met at least once, and meetings always included two participants. Figure 2.1 shows the relationships between different participants. It was considered advantageous to film participants, where possible, interacting with other participants who are known to them, for three reasons. Firstly, they were able to relax as much as possible with a person they know well (see also section 2.3.2 on the Observer's Paradox). If they were asked to interact with someone they did not know well, participants may have felt more apprehensive. Secondly, both participants know AJSL, and so this enabled free communication between the participants in AJSL. Thirdly, both participants are members of the AJSL community in Israel (see chapter 4) and it was hoped that their shared history, as immigrants from Algeria, and shared language (AJSL), would make it easier for them to share their memories and opinions.

Participants were filmed using two high quality cameras, with each directed at a participant in order to achieve optimal documentation. The two cameras were synchronized, and were later edited into a single screen format (see section 2.4). Each meeting lasted around three to four hours in total. Filming took place either in the 
participants' own homes, or at the Sign Language Research Laboratory at the University of Haifa. Some of the subjects were not able to travel to the Laboratory due to the distance involved, while other subjects expressed apprehension and were not comfortable about the idea of coming to the laboratory. These participants were filmed at home, where they felt more at ease.

\subsection{Challenges encountered when collecting data}

During the process of data collection, a number of difficulties emerged. First, it proved difficult to contact and set up meetings with participants. Initially, the participants were highly suspicious, especially regarding the necessity and purpose of the research, and of video documentation. Some of them expressed feelings of inferiority, as they are not skilled in reading and writing, and felt that they might not be suitable for the research. The participants asked many questions, and sometimes gave the impression that they lacked faith in the research project. Such obstacles have been noted by other field researchers (e.g. Vaux and Cooper 1999). In order to alleviate their concerns, I shared my views about the importance of the research and documentation of AJSL for the sake of the community, and for future generations. I emphasized the extreme importance of their role as the last generation, with the ability to preserve the language through the use of these interviews.

\subsubsection{The influence of Israeli Sign Language and Hebrew}

All of the interviewees are bilingual; they use both ISL and AJSL for communication. ISL is the dominant sign language of Israel, and Algerian immigrants use ISL to communicate with the members of the deaf community in Israel. At times, ISL is even used for communication with close family members. ISL is used naturally, especially when in the vicinity of people who do not understand AJSL. Several participants repeatedly translated what was said into ISL, for my benefit. The presence of a hearing researcher in the room at the time of the interview also caused several subjects to use spoken language, which interfered with their use of AJSL. 
In order to overcome these difficulties, several steps were taken. Firstly, video documentation always took place in pairs, so that participants were able to communicate with a fellow native AJSL signer. Filming in pairs encouraged subjects to use AJSL, so that the communication would be more natural and thoughts would flow more freely. The pairs consisted of siblings, parent-child, or close friends (see Figure 2.1).

Secondly, the subjects were asked to use signs from AJSL naturally, and not to translate for me during the conversation. In addition, on occasions when my presence appeared to be interfering with the process - for example, when participants interrupted their dialogue in order to include me - I tried to keep a distance from them by avoiding eye contact, and occupying myself with other things. This allowed the subjects to converse freely in AJSL without stopping the communication to translate what was being said. Additionally, to minimize these good-natured translations, I informed the participants that they would receive a copy of the film later on, giving them the opportunity to translate what was said for me, so as not to cause confusion between ISL and AJSL.

Participants were asked to talk about the history of Algeria; to share their childhood memories in Algeria; to explain their sign language; to talk about the people with whom they communicated in sign language; to share their struggles with deafness and communication; to tell the story of their migration to Israel; to talk about acquiring a new language (ISL); and to explain why they feel that AJSL has persisted to this day.

Interestingly, the two hearing participants found it difficult to participate in linguistic tasks in AJSL, and often switched to spoken Hebrew when trying to perform the tasks. Yet when they conversed freely with their deaf family members, they used AJSL fluently. For this reason, it was decided not to use these hearing participants for lexical elicitation. After initial meetings, several subjects expressed pride in their contribution to the important research, and agreed to take part in follow-up meetings where more data were collected.

\subsubsection{The Observer's Paradox}

The Observer's Paradox was first noted by Labov (1971), who observed that the act of collecting data can have an adverse effect on linguistic informants, causing them to use 
language differently to how they would normally use it. Labov describes 'vernacular' data as 'the style in which the minimum attention is given to the monitoring of speech' (Labov 1971:208), but notes that the Observer's Paradox can make it difficult to obtain such data, since the presence of a recording device can lead to hypercorrection, where language users seek to use a more 'perfect' register of language.

Craig (1997) observes that, for endangered languages, the influence of the Observer's Paradox can be even stronger. One characteristic of marginal speakers overlooked in the usual linguistic fieldwork, is 'their lack of linguistic confidence; this often translates into a heightened tension in the process of data gathering which is not to be underestimated and which has been widely reported in the literature on language death' (Craig 1997:265).

A number of subjects, especially older subjects, expressed much apprehension about being filmed. They were anxious about being in front of the cameras, and were concerned that their storytelling or explanations would not be 'sufficient' or 'accurate'. In addition, talking about the past and sharing their memories sometimes caused them to become excited, or emotional, and occasionally this made them appear confused or fearful. For some of the participants, this was the first time that they had ever shared their recollections, and so they showed a lack of confidence. Conducting research ethically not only means being concerned with matters of confidentiality and the physical well-being of participants, but also taking into account the potential effects of data collection on the emotional and mental well-being of participants.

In order to try and mitigate the influence of the Observer's Paradox, I took the following practical steps: participants were always filmed with at least one person known to them (see section 2.3.1). This helped participants to relax considerably, and to communicate more freely. In time, they learned to ignore the video cameras. Tagliamonte (2006:26) talks about the importance of common personal associations, such as ethnicity, religion, nationality, place of origin in trying to reduce the influence of the Observer's Paradox. In this case, there were several strong personal associations between myself and the participants: I am deaf, as are seven of the participants. Although I was not born in Ghardaia, I was born in Algeria, and my family migrated to Israel just as did their families. 
Such common ground was helpful in reducing apprehension and anxiety on the part of the participants.

\subsection{Types of data, and data analysis}

Three types of data were collected, and these are explained below: biographical data (section 2.4.1), spontaneous, conversational data on topics related to AJSL and the AJSL community in Ghardaia and Israel (section 2.4.2), and data that was elicited using a word list, with specific examples from the lexicon of AJSL (2.4.3).

Video data was transferred to a digital format and then saved on DVD. The conversations were then edited using a split screen format. This format enables the viewer to see both subjects in full view and to simultaneously follow both sides of the conversation.

Section 2.3.2 described the Observer's Paradox. As is typical of the behaviour caused by the observer's paradox, participants often withheld certain information until the cameras had been switched off and packed away. Throughout this thesis, quotes from recorded data have been used wherever possible to support the analysis. However, in some cases, the analysis relies upon information that was shared by the participants off-camera. This is an unfortunate though natural consequence of the Observer's Paradox.

\subsubsection{Biographical data}

Biographical data were collected in line with Section 1 of the questionnaire, which is presented in Appendix A. This data was collected by the researcher, who went through the questions in ISL. Participants responded in ISL, and the answers were recorded by the researcher on paper. The aims of the questions in this section were to collect metadata for the participants, and to establish that they are suitable participants for the research: that is, that they use AJSL on a regular basis. Participants were asked about their place of birth, the year they moved from Algeria, and their area of residence in Israel. They were also asked about deaf family members, and use of ISL and AJSL. Biographical data were used to create an overview of participants, which is presented in Table 2.1 (see section 2.1). 


\subsubsection{Historical and sociolinguistic data}

The questions in Section 2 of the questionnaire (in Appendix A) were developed based on what had been learnt about the AJSL community informally, prior to this research, through questions and answers with members of the AJSL community. Participants were asked about the conditions of the deaf in the Jewish community, and communication between hearing and deaf people in the community. Other questions focused on the migration to Israel, life in Israel and use of the AJSL in Israel. The questions were addressed to the subjects in ISL, and they replied in the same language.

Participants were also asked to share and discuss their life stories with another AJSL signer, this time in AJSL. The purpose of asking participants to use AJSL was twofold. Firstly, by association, the use of the language of the community - AJSL - may have led participants to mention or remember events or practices that are related to the AJSL community. Secondly, recording spontaneous conversations in AJSL will enable the analysis of the lexicon and grammar of AJSL; although such analysis is beyond the scope of the current investigation, it is hoped that this analysis will soon be undertaken. 


\begin{tabular}{|c|c|c|c|c|c|c|}
\hline \multirow[t]{12}{*}{ file name } & time code & Content & Level 1 & Level 2 & Level 3 & Level 4 \\
\hline & $15: 17$ & $\begin{array}{l}\text { Father shows and teaches all the time to Mother all signs - } \\
\text { peppers,tomatoes,potatoes,frying and thus she learnt all the signs and } \\
\text { sentences }\end{array}$ & Algeria & $\begin{array}{l}\text { sign } \\
\text { language }\end{array}$ & $\begin{array}{l}\text { Acquisition of } \\
\text { Sign } \\
\text { Language }\end{array}$ & $\begin{array}{l}\text { How did th } \\
\text { language? }\end{array}$ \\
\hline & $13: 58$ & $\begin{array}{l}\text { All the times I communicate only in Israeli sign language with friends but I talk } \\
\text { with my Mother immediately I switch to Algerian sign language }\end{array}$ & Israel & $\begin{array}{l}\text { Sign } \\
\text { language }\end{array}$ & $\begin{array}{l}\text { Algerian } \\
\text { JSI,ISL }\end{array}$ & $\begin{array}{l}\text { With whor } \\
\text { sign langu }\end{array}$ \\
\hline & $13: 31$ & $\begin{array}{l}\text { I talk with my deaf sister in AJSL but with Mother in AJSL and sometimes in } \\
\text { ISL.Every Saturday the family come to Mother and } 2 \text { hearing brothers and } \\
\text { one hearing sister and } 5 \text { deaf brothers and communicate in AJSL you see } \\
\text { and too some in ISL- mixed ISL and AJSL }\end{array}$ & Israel & $\begin{array}{l}\text { Sign } \\
\text { language } \\
\text { in Israel }\end{array}$ & $\begin{array}{l}\text { Algerian } \\
\text { JSI,ISL }\end{array}$ & $\begin{array}{l}\text { Did Algeri: } \\
\text { language } \\
\text { the Israeli }\end{array}$ \\
\hline & $12: 54$ & My children only in Hebrew as they are hearing & Israel & $\begin{array}{l}\text { Sign } \\
\text { language }\end{array}$ & Algerian JSL & $\begin{array}{l}\text { With whor } \\
\text { sign langu }\end{array}$ \\
\hline & $12: 28$ & $\begin{array}{l}\text { Once I spoke with my sisters all the time AJSL you see and today there was } \\
\text { already change because of the children but sometimes AJSL- depends }\end{array}$ & Israel & $\begin{array}{l}\text { Sign } \\
\text { language } \\
\text { in Israel }\end{array}$ & Algerian JSI & $\begin{array}{l}\text { With whor } \\
\text { sign langl }\end{array}$ \\
\hline & $11: 55$ & I love to talk in AJSL you see. Till today I use some signs of AJSL & Algeria & $\begin{array}{l}\text { sign } \\
\text { language }\end{array}$ & Algerian JSL & $\begin{array}{l}\text { Did Algeri } \\
\text { language }\end{array}$ \\
\hline & $11: 38$ & $\begin{array}{l}\text { I have } 2 \text { languages and I can use them. The special signs that are short. Also } \\
\text { private language and it seems that no-one catches me for secret. }\end{array}$ & Israel & $\begin{array}{l}\text { Sign } \\
\text { language }\end{array}$ & $\begin{array}{l}\text { Algerian JSL } \\
\text { Alutute UI }\end{array}$ & Who used \\
\hline & $10: 27$ & $\begin{array}{l}\text { littile sister heard that talking about it with swearing (on Algeria) -I told her not } \\
\text { to pay attention to it as everyone is stupid.I told her all the time that they are } \\
\text { gossiping about you.Some of people are not good but my friends are }\end{array}$ & Israel & $\begin{array}{l}\text { Deaf } \\
\text { community }\end{array}$ & $\begin{array}{l}\text { Algerians to } \\
\text { Israeli } \\
\text { community }\end{array}$ & $\begin{array}{l}\text { What was } \\
\text { community }\end{array}$ \\
\hline & 09:59 & $\begin{array}{l}\text { What is word "dangerous" as it is charactertistic of Algerian culture like } \\
\text { cursing -it is frightening and heard behaviour (B on B)-yes for example sign } \\
\text { cursing therefore people are frightened (against evil eye) very frightening } \\
\text { them-I talk nicely like my mother (as my family is cultured) depending with } \\
\text { which people? }\end{array}$ & Israel & $\begin{array}{l}\text { Deaf } \\
\text { community }\end{array}$ & $\begin{array}{l}\text { Attitute of } \\
\text { Algerians to } \\
\text { Israeli } \\
\text { community }\end{array}$ & $\begin{array}{l}\text { What was } \\
\text { community }\end{array}$ \\
\hline & 09:09 & $\begin{array}{l}\text { When talking AJSL you see (secret language) talking in secret other deaf } \\
\text { look and ask what it is? Is it AJSL? You see secret. I told them nothing can } \\
\text { be done it is language of AJSL }\end{array}$ & Israel & $\begin{array}{l}\text { Deaf } \\
\text { community }\end{array}$ & $\begin{array}{l}\text { Attitute of } \\
\text { Algerians to } \\
\text { Israeli }\end{array}$ & $\begin{array}{l}\text { With whor } \\
\text { sign langu }\end{array}$ \\
\hline & $08: 38$ & $\begin{array}{l}\text { I keep my tradition I came from Algerian family you see but I do not go to } \\
\text { synagogue-Day of Atonement but I go to events- bar mitzvah and weddings } \\
\text { Youre atevervwhere when I arew un ant married and changed but I still }\end{array}$ & Algeria & $\begin{array}{l}\text { Jewish } \\
\text { community } \\
\text { Jewish }\end{array}$ & $\begin{array}{l}\text { Family life } \\
\text { (celebrations) }\end{array}$ & What was \\
\hline
\end{tabular}

Figure 2.2 A screen capture showing the excel spreadsheet that was used to code the historical data.

Initially, the data were transcribed into Hebrew. The data were then split into short segments referring to a specific topic - each comprising one or two sentences. These were inserted into an Excel worksheet, along with a time code that could be used to refer to the data easily (see Figure 2.2). In order to analyse the data in terms of the research questions, I created a hierarchy of topics. This hierarchy was designed by surveying the data and using an inductive approach to create categories that reflect the key topics and sub-topics that occur in the data. On the first level, this involved identifying whether the segment related to life in Algeria or life in Israel. On the second level, sub-topics were identified: for Algeria, these were 'life in the mellah of Ghardaia', 'deafness in Ghardaia', and 'AJSL in Ghardaia'. Further to this, another level of sub-topics was created, and segments were then classified accordingly. The hierarchy is presented in figures 2.3 and 2.4 . 
The aim of this hierarchy was to enable the data to be organized in a way that enabled the answer to the first research question, which focuses on the sociolinguistic situation of AJSL before and after the migration of the AJSL community to Israel. This is reflected directly, in the way that the data are sorted into one of two categories on Level 1 ('Algeria' and 'Israel'). Data that has been classified as relating to 'life in Algeria' are presented and analysed in Chapter 3, while data that relate to 'life in Israel' are presented and analysed in Chapter 4.

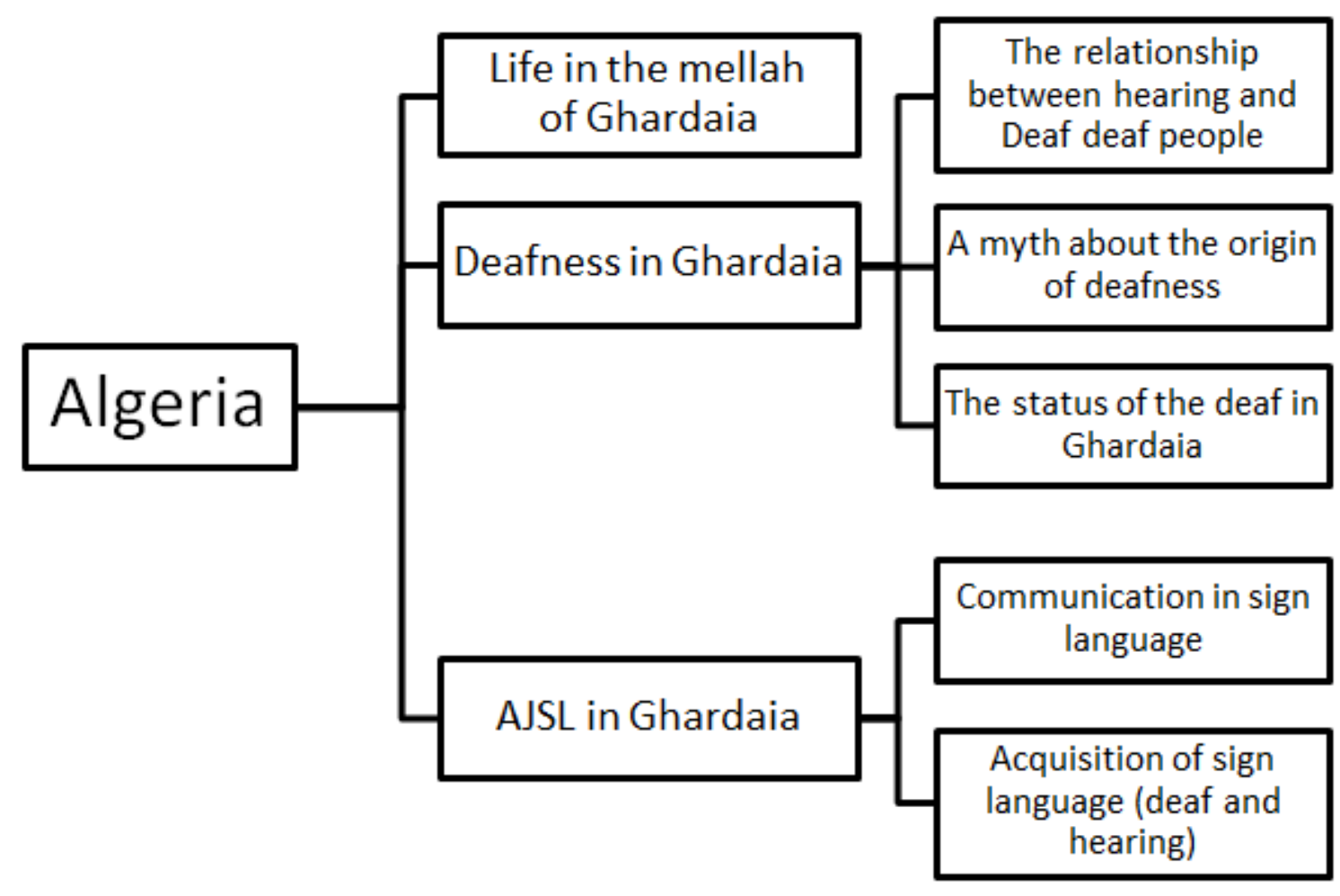

Figure 2.3 - The hierarchy of topics created for coding historical and sociolinguistic data pertaining to the AJSL community in Algeria. 


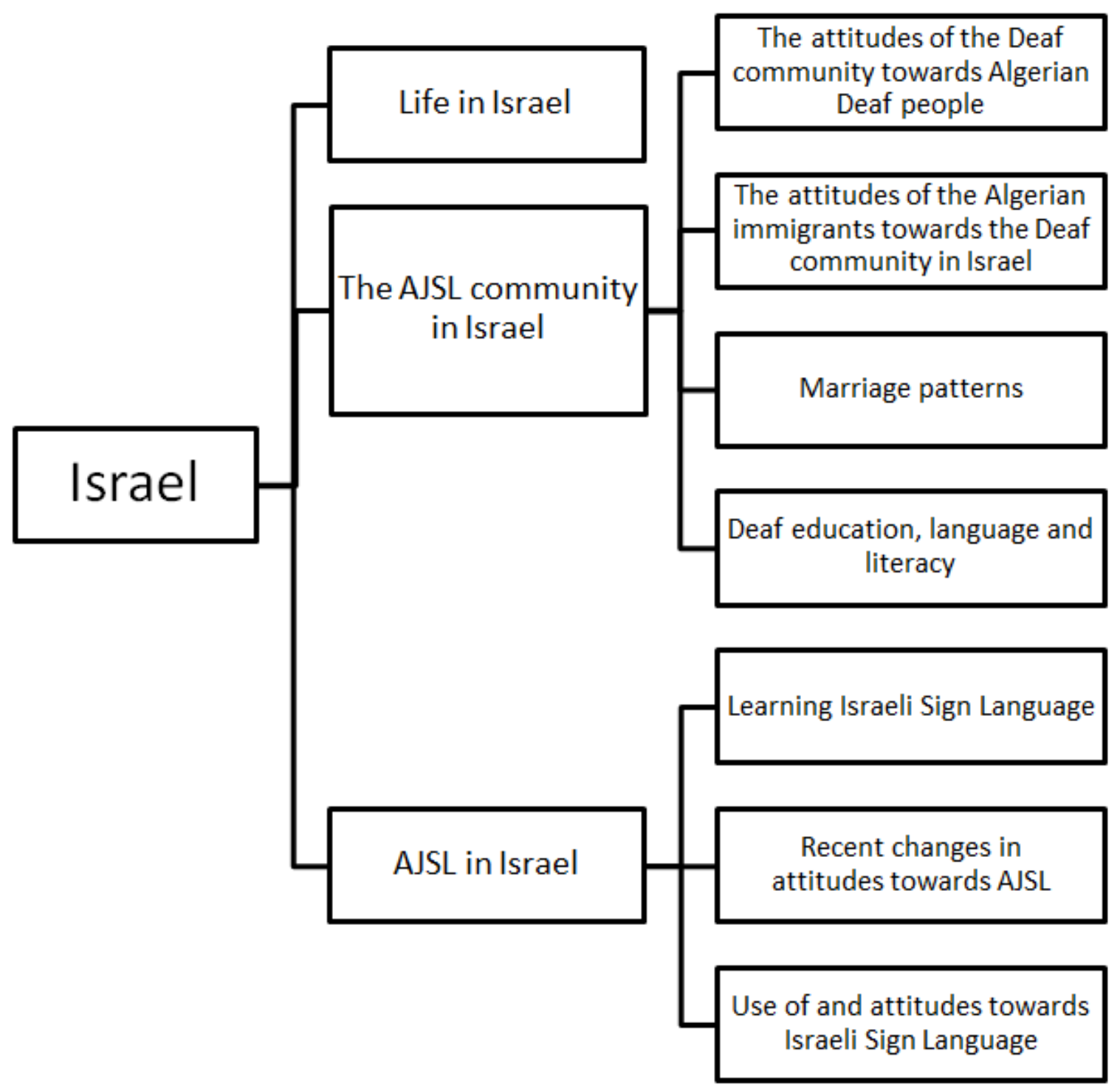

Figure 2.4 - The hierarchy of topics created for coding historical and sociolinguistic data pertaining to the AJSL community in Israel.

After coding and analyzing the data according to the topics presented in Figures 2.3 and 2.4, I analysed the themes that recurred in the database, and related them to theoretical constructs in socio-linguistics, and compared them to what is known about other village sign languages and their communities. 
In order to understand the process of development and growth that AJSL underwent within the community in Algeria and in Israel, we must first examine the community itself. Language is bound to a community, and it is possible to learn a great deal about its development and growth through examining the community that uses it. 'Community of Practice' is a theoretical construct that can help to analyse different language communities. This concept was developed by Lave and Wenger (1991) and first applied to language and gender as a social construct by Eckert and McConnell-Ginet (1992), who use the following definition:

'A community of practice is an aggregate of people who come together around mutual engagement in an endeavour. Ways of doing things, ways of talking, beliefs, values, power relations - in short, practices - emerge in the course of this mutual endeavour' (Eckert and McConnell-Ginet 1992: 464).

Ideas from community of practice theory have informed some of the analysis of the data that participants have shared pertaining to the community of people that used, and continue to use, AJSL (Chapter 3 and Chapter 4). Indeed, the differences between the AJSL community of practice in Ghardaia and in Israel are particularly important in explaining the trajectory of the vitality of AJSL, and there is a comparative element to this analysis (see Chapter 4).

\subsubsection{Lexical elicitation}

In order to elicit vocabulary items, the target lexemes were signed to participants in ISL, and the subjects translated them into AJSL. Just under 300 signs were included on the list, from various semantic domains including family, food, festivals and holidays, emotions, occupations, colours and numbers. For a complete list of elicited words, see Appendix B. More information about lexical elicitation can be found in Chapter 5 . The motivation for lexical elicitation is given in section 5.1.1, the creation of the wordlist is explained in section 5.1.2, and the analysis of some of the words is presented in 5.2. All of the words were elicited from YZ and MG. With most other people, only 50-80 words were elicited, 
because it soon became clear that most of the AJSL signs that they gave were the same, and so it was not necessary to repeat the activity in full with all of the participants.

An Excel worksheet was created to analyse the elicited lexemes. Signs were analyzed according to the main phonological parameters of signs as seen in previous sign language research: handshape, orientation, movement (both path movement and internal movement), and location (Stokoe et al 1965). Once the phonological analysis had been completed, the signs in AJSL were compared with the corresponding signs in ISL according to criteria of similarity and difference in sign structure, based on the criteria used in Guerra Currie, Meier and Walters (2002). A screenshot of the resulting worksheet is presented in Figure 5.2 in Chapter 5.

\subsection{Ethics and research}

I empowered my potential subjects and validated them as qualified consultants by explaining the significance of documenting their unique language and emphasizing the extraordinary fact that the language has survived for 60 years in a foreign country. I explained that because the language does not have a written form, we must capture it on video, to ensure that the language is documented for future reference. I clarified the importance of their contribution to the preservation of the language, and in this manner I succeeded in gaining their cooperation and assistance with the research.

Several other steps were taken to ensure that the research is ethical. Firstly, informed consent was obtained from the subjects. Specifically, participants were asked to indicate whether or not their data could be used in different formats, such as a photograph in a scientific paper, a video clip at a conference, or the publication of a story in a book, or on DVD. The data is held securely at the Sign Language Research Laboratory, which is part of the University of Haifa. I plan to archive the data in the corpus at the International Institute for Sign Languages and Deaf Studies in the near future.

Finally, all participants received a letter of appreciation, and a DVD with the video documentation of their life stories, as a token of our gratitude and respect for their participation in the research, for their language, and for their willingness to further the 
research of AJSL. In order to acknowledge the time that participants gave, and the data that they were sharing, participants were also remunerated.

\subsection{Summary}

Chapter 2 has outlined the methodology that has been used to collect data from the participants. This methodology has been determined by the two research questions for the study. In particular, it has been necessary to collect different types of data. In order to examine the sociolinguistic situation of AJSL before and after the migration of AJSL users to Israel, historical and sociolinguistic data have been collected (2.4.2). This has been supplemented by lexical elicitation (2.4.3), which is the first step towards documenting the language; it may also shine more light on the extent to which AJSL is now at risk of becoming displaced by Israeli Sign Language, as will be discussed in chapter 6 .

The process of coding the data has also been explained, along with some of the challenges that emerged while collecting the data, and the ways in which these challenges have been overcome (section 2.3). In particular, the Observer's Paradox influenced the behaviour of the participants, sometimes unavoidably (2.3.2), but several steps were taken to alleviate the effects of the Observer's Paradox, and the researcher's own personal associations with the participants was helpful in this respect. Ethical considerations - such as obtaining informed consent and protecting the data that have been collected - have also been discussed (2.5).

Of course, some of the findings of this study are limited, in that they rely on the recollections of participants. In particular, data about the AJSL community in Ghardaia has been collected in Israel, many years after the participants emigrated from Algeria. However, such recollections are incredibly valuable, and are becoming rarer year by year, as the size of the immigrant community decreases. Moreover, by gathering narratives from many community members, it is possible to corroborate the data, and construct a likely picture of the sociolinguistic setting where AJSL thrived in Ghardaia, how it came to Israel, and what happened to AJSL after the migration of the Jewish community. 


\section{CHAPTER 3: AJSL in Algeria}

\subsection{Introduction}

Chapter 3 presents an in-depth account of the AJSL community prior to migration to Israel. The description and analysis in this chapter are based on data obtained from nine members of the Algerian Jewish community, of whom eight were born in Algeria, and all of whom continue to use AJSL. Three sub-topics are covered, relating to Ghardaia: life in the mellah (the Jewish quarter of Ghardaia where AJSL developed); deafness in Ghardaia; and AJSL in Ghardaia. In each of these sections, data are presented on different aspects of the sub-topic. The summary at the end of chapter 3 considers what the data reveal about the community in which AJSL emerged and developed.

Given the importance of the unique sociolinguistic setting of AJSL, Section 3.2 considers life in the mellah, or Jewish quarter, of Ghardaia. This includes discussion of the homes and family lives of participants, and the preservation of tradition and religion.

Section 3.3 considers the existence of deaf people in Ghardaia, and includes references to an origin myth that describes the causes of deafness in the community. It then compares the status of the deaf members and the hearing members of the community, and discusses the attitude of the hearing members towards deaf people and deafness.

Section 3.4 focuses on the sign language that emerged in this community, AJSL. It investigates the possible origins of the language (although no definite answer can be supplied), the users of the language (both hearing and deaf) and the transmission of the language across generations, a process in which the hearing members played an important role.

Section 3.5 forms the conclusion, and provides a comparison of the special socio-linguistic situation in Ghardaia to those reported on other village sign language communities. 


\subsection{Life in the mellah of Ghardaia}

All of the research participants lived in Ghardaia in the M'zab region. The Jewish community lived in one neighbourhood - the Jewish quarter, enclosed by walls. The Muslim residents lived outside of these walls. Most families enjoyed a reasonable economic situation and were well established. Some of them lived comfortably in large houses.

"Our house was large and lovely, with 12 big rooms." (ES)

"Jews and Arabs lived near each other, like friends". (LP)

Generally speaking, it seems that Jewish families in Ghardaia were large, with 7 or 8 children. Women married at a very young age - for example, SS married at the age of 14 .

"His [my husband's] father was deaf and dumb, and he had a wife and children, seven girls and one boy". (SS)

Some families, however, appear to have lived in more impoverished conditions, facing economic difficulties (see section 3.3.3).

The Algerian Jewish household was patriarchal; it seems that the father usually set the tone, and held the power. It was customary for the father of a household to have more than one wife.

"My father had two wives because his first wife was too old. He wanted to marry a younger wife and did not want to divorce his first wife. He has 8 children." (LP)

"Father educated us very well. My brothers and sisters were well-disciplined according to whatever Father said. If I went out with a boy he forbade him to enter my house and pinched me on my ear so that I would return home early... We had to serve him his meals on time and launder his clothing, he was very tidy." (ES)

In Algeria, men worked outside the home in order to support their family. They had various trades, such as jewellers, porters, steelworkers, and glaziers. They also worked as 
clerks for the rich Jewish traders. According to evidence in the archives at Beit HaTfutsot\#73772, all tax collectors in Ghardaia were Jews.

SS comments: "People earned money from work - they had various trades - glaziers, steelworkers" (SS)

Women, in contrast, remained at home.

"Women were only at home and the men could go out. It was forbidden for women to go out..." (SS)

"Women never attended schools. The women stayed at home and cleaned all the time..." (ES)

From what the participants say, it seems that Algerian Jewish households adhered strictly to the laws and commandments of the Torah, as required by Judaism. Most families were very religious - they attended synagogue, celebrated the Jewish festivals and holidays (such as Passover, Rosh Hashana, and Yom Kippur), and held fast to traditions, such as wedding traditions, bar mitzvahs and circumcisions.

"We were religious people who practiced their mitzvoth (commandments), said the blessings, prayed on the Sabbath, and put on the tefillin (phylacteries)" (SS)

"I practice the traditions that have been passed down from generation to generation in my family from Algeria. My father is religious; he practiced these traditions and customarily attended synagogue" (ES)

From the data presented above, it is clear that the Jewish community in Ghardaia had its own clearly-defined geographical space, within the Jewish quarter. From the economic activities that have been described, it is likely that the members of the broader Jewish community had shared economic aims, and a joint negotiated enterprise - both of which can play a role in creating a community of practice (Lave and Wenger 1991), as mentioned in section 2.4.2. Additionally, several participants mentioned the fact that women stayed at home in large households, and it is likely that they too shared tasks and engaged in 
joint, negotiated enterprises. Finally, the Jewish population kept their religion and traditions well-guarded, and it is likely that these also had a part to play in the AJSL-using community of practice.

\subsection{Deafness in Ghardaia}

As explained in section 1.5.2, the number of deaf people in the mellah of Ghardaia was notably high, and it is likely that this occurred due to marriage within the community, which was rather small. Table 2.1 in chapter 2 includes information that the participants shared concerning which members of their family are deaf.

"My paternal grandmother was deaf. Part of my family on both sides is deaf. Part of my family is deaf... In the second and third generations there are many deaf people." (ZM)

\subsubsection{A myth about the origin of deafness in Ghardaia}

Another participant, SS, mentioned a local belief that was used to explain the existence of the high number of deaf people in Ghardaia. According to Judaism, in order to maintain purity, it is forbidden for a woman to have sexual intercourse with her husband for the week of her menstruation until she has been purified in the ritual bath. When a woman is menstruating, her husband must refrain from touching her and from sleeping with her. Once the seven days are over, the wife must go to the ritual bath - a place where there is a pool of unfiltered water, where one can immerse oneself in order to reconcile various impure states of being. The woman must soak in the ritual bath and cleanse herself in order to be with her husband.

According to a popular superstition existing in the Jewish community of Ghardaia, sexual intercourse that takes place during menstruation may result in the birth of deaf children, as it is a serious offence. This superstition was only related to me by hearing members of the community, and although deafness was labelled a punishment, the participants did not seem to regard it with any great concern. Deafness was seen as a consequence of sin which one must simply accept, rather than a tragedy. 
"When a woman is menstruating she must be separated from her husband. If she has her period and wants her husband she will not be able to have [hearing] children. It is forbidden, that is how you have deaf children, that is what causes deafness. If a wife wants her husband, she must separate herself from him when she has her period, bathe in the ritual bath, and only then will she be allowed to be with her husband." (SS)

It seems that such origin myths are relatively rare across rural communities with hereditary deafness. Among the communities compiled in Zeshan and De Vos (2012), only one other village sign language, Kata Kolok in Bali, is associated with an origin myth. The interaction between such beliefs and the status of deaf people and sign language in the AJSL community thus deserves further study.

\subsubsection{The relationship between hearing and deaf people}

From what participants have said, it seems that hearing members of the mellah accepted deaf people as a part of the community. Communication between deaf and hearing people often happened freely, without major difficulties.

"All the family members from Ghardaia know AJSL very well. The hearing also used AJSL well, just like the deaf." (LP)

Although it seems that deaf people in the Jewish community of Ghardaia were largely accepted as members of the community, deafness does appear to have had some negative associations. For example, one of the participants mentioned being 'hurt' by the fact that her children were deaf.

"It hurt me to bring my deaf children into the world." (SS)

Interestingly, the production of the AJSL sign DEAF describes the act of 'cutting the tongue'. This sign reflects the strong connotation between deafness and an inability to speak. 


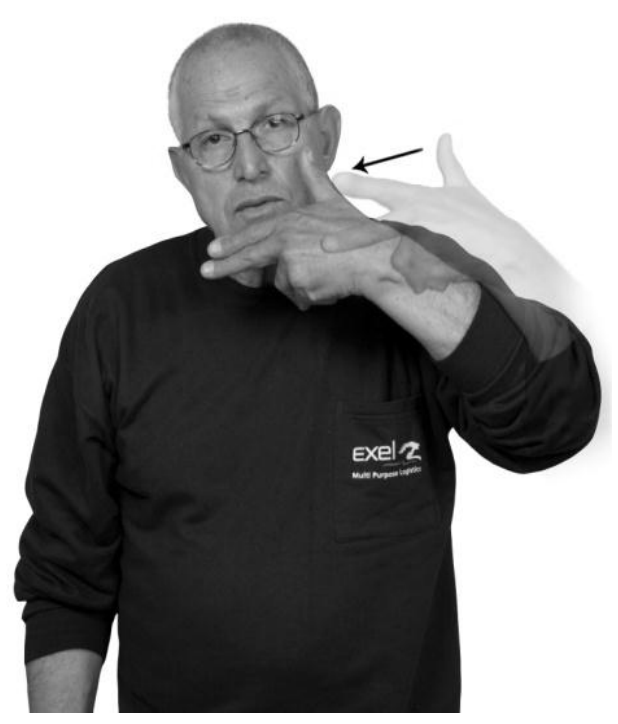

Figure 3.1 The sign for DEAF in AJSL

The participants in this study reported that marriages between hearing and deaf spouses were common. While this may be an indication of acceptance of deaf people into the society, there is also a less positive connotation in terms of providing "help" for the deaf spouse, as detailed in the next section.

\subsubsection{The status of the deaf in Ghardaia}

Similar to hearing people, the status of the deaf depended on factors such as the economic and social status of the family. From an economic standpoint, at least, there were no differences between deaf and hearing members of the society. It also seems that deaf people were expected to marry, just as hearing people were. However, deaf people always married hearing spouses, which could indicate that deaf people were considered in need of the assistance of a hearing spouse in everyday life; however, further historicalsociological research would be required to bear this out, and that is beyond the scope of the present study. Nevertheless, the fact that deaf people married suggests that deaf people were accepted as valid societal participants by the Jewish community in Ghardaia. 
"Getting married is important anyway, and it does not matter - deaf, ugly, hearing, disabled - it is important for Jews to get married" (MG)

"There, deaf women and hearing women were the same. Both the deaf and the hearing got married..." (SS)

Additionally, there were some deaf people of a high status who enjoyed a good economic position, and could marry many wives. For example, ES's father was wealthy and honourable and had five wives. However, there were also deaf people who had a lower social status. For example, YZ's family suffered from poverty.

"My house in Algeria was three floors high and it was very big. I had two maids. My father held a very good position and was rich. We had lots of food and he gave food to the poor... Everyone came and he gave them food: nuts, dates and wine..." (ES)

"My family was very poor, we did not have money and we had a hard life..." (YZ)

During the first half of the twentieth century, there was no awareness of the special educational needs of deaf children; teachers did not know how to teach the deaf and how to communicate with them. Only the hearing sons of the Jewish families attended schools. The only available schools were French, and it was there that boys acquired French. It seems that deaf boys did not attend school because communication was difficult and suitable deaf education was lacking. Deaf boys stayed at home and looked for work during the day while hearing children attended schools. Because of this, they sometimes experienced frustration and boredom.

"In Algeria I played with a rope and a football and that was all. It bored me terribly. There was no deaf school. It was boring and I sat outside and wandered around all the time, playing marbles" (YZ)

Girls, whether hearing or deaf, did not attend school; they stayed at home and assisted with the housekeeping and cleaning. As far as this aspect was concerned, the status of the deaf girls did not differ significantly from the status of the hearing girls. 
"Women stayed at home at all times to clean...the hearing boys studied at the French schools, reading and writing..." However, later she adds: "Some of the hearing girls studied at the French schools" (ES)

"No deaf people went to school; all of them were mutes. Deaf boys and girls did not go to school." (ES)

Although deaf men in the community sometimes enjoyed a higher social status, their lack of literacy skills prevented them from reading prayer books and understanding their content. Nor was there access to religious events, in the form of sign language interpretation. Therefore, deaf people in Ghardaia did not have access to several aspects of cultural life and education, which later impacted on them when they moved to Israel.

"I was a new immigrant and although I studied I could not understand how to write on the blackboard... it's a shame that I did not attend the school in Algeria." (YZ)

Deaf people in Ghardaia usually held simple jobs. Those who worked as jewellers enjoyed a high status, as explained by ZM, whose father worked as a jeweller. It is likely that the lack of literacy skills had a negative effect on the status of some deaf men.

"I left school in the second grade [to work] because my parents could not support themselves. When I was in the second grade I went out to support my family. I had all kinds of jobs including jewellery-making and anything that was available....I worked in any job that was available to me." (MA)

\subsection{AJSL in Ghardaia}

AJSL emerged as a result of the high incidence of deafness within the Jewish families in Ghardaia, and in answer to the necessity to communicate within these families. It is not clear how the language developed, and whether it was influenced by other sign languages, since it is not at all clear whether other sign languages or signing systems existed in the same region of Algeria. Also, we do not know whether there were deaf Muslim people in the vicinity. As pointed out above, deaf children in the community did not attend deaf schools and the Jewish community did not have regular contacts with the 
Muslim communities. Therefore it is reasonable to assume that AJSL was developed independently of influence from other languages, but this remains a hypothesis rather than a fact.

Additional evidence supporting the hypothesis that AJSL developed within the Jewish community comes from U.B., a deaf person living in Israel who originated from Morocco. U.B. has a Muslim Algerian friend, who uses Algerian Sign Language. He also has friends who use AJSL and knows some AJSL signs. U. B. points out that when comparing signs from AJSL and the Algerian Sign Language his Muslim friend uses, it looks as though these are two different languages.

\subsubsection{Communication in sign language}

Many Jewish families were mixed, with both deaf and hearing family members. The reality that existed as a result of this composition made the development and use of a visual language necessary and so most deaf and hearing family members were fluent in AJSL. It is likely that this local sign language was viewed as critical for communication, and may have been respected and valued equally with other local languages.

"The whole family from Ghardaia knows AJSL excellently and the hearing have full command over AJSL, exactly like the deaf." (LP)

In addition to the Algerian Jewish deaf people and their hearing family members, this language was also known and perhaps used by those who lived in the close surrounding areas, including their Jewish and Arab neighbours.

"In my neighbourhood in Ghardaia we had Arab neighbours and we always spoke in AJSL. They knew our language. But outside the village the situation was absolutely different, not the same. Only the neighbours know and recognize that this is local AJSL... My uncle knows AJSL very well." (LP)

As mentioned in Section 1.3, the use of sign language by both deaf and hearing people is a hallmark of all communities with hereditary deafness where a similar development of a local sign language has taken place. 


\subsubsection{Acquisition of sign language (deaf and hearing)}

As mentioned in Chapter 1 , it is unclear when the first deaf people were born in the Jewish community of Ghardaia.. The participants interviewed for this study include deaf members of the community in their 70 s and 80 s, and some participants mention deaf individuals in previous generations.

"My father was deaf and he passed away 14 years ago. He was 96 years old." (LP)

Another AJSL user who was born in Ghardaia, and is 80 years old, reports that his grandmother was deaf. It is possible to tentatively conclude that deafness has existed in this community for at least five generations, and it is likely that AJSL emerged concomitantly.

Children born into families with deaf adults acquired the sign language from their deaf family members. When deaf children were born to hearing families, they acquired the language from deaf adults in the vicinity - extended family members, neighbours or friends - or from hearing family members who knew how to communicate in sign language.

Hearing people who married deaf people acquired the language from their spouses if they did not know it previous to marriage. Because the majority of the people in the community had contact with deaf people, and AJSL was used in the community to some extent, acquiring the sign language naturally was not problematic.

"I can hear and I speak and understand the language well. Once I did not know how to use AJSL and now I know...my husband is deaf. He taught me AJSL and I began to learn and grasp the signs slowly. I did not work outside the home. I was only at home..." (SS) 
"My mother did not know AJSL, but when she married my father, who was deaf, he taught her AJSL so that they could communicate. Father showed and taught my mother all the time, all the signs, pepper, tomato, potato, frying... That's how my mother learnt all the signs and sentences" (ES)

ZM says that she learnt and acquired AJSL by observing YZ's deaf family.

"In the beginning I looked at YZ and his brother but I did not understand one word of AJSL. YZ's mother loved me very much. I looked at how she signed and I learnt the sign language from her. Now our communication is good. In the beginning we communicated mainly by the use of lip reading and through speech, but even then her voice was very disrupted..." (ZM)

It is interesting that, in this signing community, many deaf members acquired AJSL not only from older deaf language models, but also from fluent hearing signers. This is particularly notable, since most urban sign languages are acquired by children not vertically, from hearing adults, but horizontally, from other deaf children (Quinn 2010: 479). This is due to the fact that in urban sign language communities such as the British Sign Language community described by Quinn (2010), most deaf children have no access to sign language using adults in their environment.

Unlike in urban sign languages with their transmission of the language mainly within generations, the transmission of AJSL seems to have functioned across generations, either within or outside the home (language transmission across generations is discussed further in Chapter 6 in relation to Fishman's (1991) model). For instance, although YZ's mother was hearing, she learned AJSL to communicate with her deaf children, so they acquired it naturally from her as well as from other community members. ZM, who is deaf, was not exposed to AJSL at home. She acquired the language from interactions with a hearing woman whose husband and children were deaf. These instances illustrate that hearing people played an important linguistic role along with deaf members of the Ghardaia Jewish community in the acquisition and evolution of this language.

\subsection{Conclusion: The AJSL-using community in Ghardaia}


In conclusion, the deaf people living in Ghardaia were integrated in the community in many ways, warranting a categorization of this community as an "assimilative deaf community" (Marsaja 2008) or a "shared signing community" (Kisch 2008). From the interviews conducted for this study, we can start to piece together a picture of the AJSL community in Ghardaia that serves as a basis for comparison with the situation after the move to Israel (Chapter 4).

It is argued here that the AJSL-using community in the mellah of Ghardaia can be regarded as a community of practice where the common use of a sign language by deaf and hearing members of the community was one of the important characteristics, including the patterns of transmission of AJSL over successive generations. As is argued in Chapter 4, the move to Israel resulted in changes and disruptions to this community, and consequently in the endangerment of AJSL.

The AJSL community in Ghardaia was characterized not only by use of a sign language, but also by the particular way in which deaf people functioned in the community. As communication was accessible to deaf people, they held ordinary jobs, got married, and occupied an economic situation and life circumstances that were similar to their hearing counterparts. In these respects, this community resembles other cases of village communities with hereditary deafness such as those reported in Nonaka (2012) for Thailand, Kisch (2012) for the Al-Sayyid Bedouins in Israel, Escobedo Delgado (2012) for Mexico, and Panda (2012) for India.

However, there are several respects in which deaf people's lives were significantly different from hearing people's lives. First, the issue of education casts a dark and painful cloud over the subject of equality; deaf boys did not attend schools while hearing boys did. Thus, the critical skills of reading and writing were denied them, damaging their ability to participate in Torah reading and later to blend into life in Israel. Second, parents preferred to give birth to hearing children rather than deaf children. Third, deaf people always married hearing spouses, whereas hearing people were not restricted in their choice of spouse. Finally, according to the local myth, deafness was considered a punishment to a sin (e.g., having sexual intercourse during menstruation). All in all, deaf 
people were integrated into the daily life of the community, but were not quite equal to the hearing members.

Another interesting aspect of the AJSL-using community in Ghardaia, which is logically linked to the co-use of sign language by deaf and hearing people, is the fact that there was no separate "Deaf community" that would be characterized by its own cultural practices as is the case for urban sign languages (cf. Padden \& Humphries 1988, for instance). Rather, the deaf were part of the whole Jewish community in Ghardaia, and the deep sense of religious commitment held by the whole community is evident from the interviews presented here. It seems that religious identity would have been of great significance to both deaf and hearing people in Ghardaia.

While in other "deaf villages" such as those mentioned above, there is no segregated deaf sub-community either, the details of marriage and professional patterns develop uniquely in each of these societies. On Martha's Vineyard, hearing community members did not try to avoid marrying deaf spouses or having deaf children, nor sought medical attention when a child was born deaf (Marsaja 2008:15). In the Al-Sayyid Bedouin tribe, until recently deaf people only married hearing spouses, as in Ghardaia, and deaf women were typically married as second or third wives. However, in recent years deaf men have begun to select deaf women for marriage (Kisch 2012). In the case of Adamarobe village in Ghana, the Ghanaian government had outlawed marriage between two deaf people, in an attempt to decrease the incidence of deafness, though ironically, most deaf children are born into families with two hearing parents. Deaf women seem to have no trouble getting married, especially in cases of polygamy, but deaf men often do not marry (Nyst 2007:28). Marsaja (2008:60) mentions that of the 407 families in the village of Bengkala in Bali, there are 13 deaf couples and two deaf-hearing couples. This pattern is distinct from patterns in Ghardaia, where deaf people only marry hearing spouses. In each of these signing communities, preference, gender, laws, and social norms result in a variety of marriage patterns between deaf and hearing members of the community. 
When the Jewish community of Ghardaia immigrated to Israel, their marriage, work, education, and communication patterns changed dramatically. This transition and the resulting situation of AJSL as an endangered language is the topic of the next chapter.

\section{CHAPTER 4: AJSL IN ISRAEL}

\subsection{Introduction}

This chapter examines the life of the Jewish deaf people who migrated from Ghardaia to Israel from several angles. Following their migration, the immigrants encountered considerable changes, as the Israeli lifestyle is very different from that which the immigrants were familiar with in Algeria in terms of adherence to religious norms, language, occupations and education.

This chapter starts with a description of the transition, the migration to Israel (section 4.1). Although this stage is not directly related to the formation of the AJSL community in Israel, it provides the background needed to understand the reasons for the immigration and its effects on the Ghardaian community. The relocation of the AJSL community meant that the unique sociolinguistic situation in Ghardaia was lost. Crucially, in Israel, the AJSL community was no longer confined to a mellah of the town, as it had been in Ghardaia. Rather, they dispersed in the country, no longer forming a closed community. This meant that the high density of deaf people disappeared, and the ratio of deaf to hearing people changed. In addition, deaf people met deaf people from other origins, and started becoming part of a new community, the Israeli Deaf community, and encountered also a different sign language, Israeli Sign Language. The encounter with the Deaf community in Israel was culturally challenging, since in Algeria deaf people had been integrated in the Jewish community, as opposed to being part of a specifically Deaf community. After migration, Deaf people from Ghardaia began to marry people who had immigrated to 
Israel from other countries, thus weakening the possibility of having deaf offspring. All of these factors had an impact on the transmission, acquisition and maintenance of AJSL.

The changes affecting the AJSL community after migration to Israel are addressed in the remaining sections of this chapter. I discuss the life of these immigrants in Israel from the three points of view represented Figure 2.4 in Chapter 2: Life in Israel (section 4.2); the Deaf community in Israel including the attitude towards the immigrants from Algeria and the attitude of the immigrants towards the Deaf community (section 4.3); and the use of sign languages in Israel - both AJSL and ISL (section 4.4). Section 4.5 presents the conclusion.

\subsection{Relocation of people and dispersion of the population}

In the years leading up to the end of the 1940s and during the first years of the 1950s, many Jews left Algeria. There was tension between Jews, Muslims, and Berbers, a tension that continued to grow towards the end of the World War II. Between the years 1943 and 1950, 500-600 Jews migrated to Israel and France (Briggs and Guede 1964). In 1947 the Jews from Ghardaia arrived in Israel on the ships "Yehuda Halevi" and "Shivat Zion" (Swartzfox 1989). A third ship failed to dock at the port, and dozens of people were stranded on the beach. In the end, these families arrived in Marseilles, France. Some of them settled there, while others eventually succeeded in migrating to Israel. In 1950-1951 the tensions in Algeria diminished to some extent and the Jews stopped leaving Algeria. Some immigrants who were unsatisfied with life in Israel returned to the M'zab region at that time (from the archives at Beit HaTfutsot \#73772).

In the 1950s, a second wave of Algerian Jews left Algeria, motivated both by the establishment of the State of Israel in 1948, and by the Algerian War of Independence with France (ibid). Although the war was between Algeria and France, it had a significant impact on the Jews of the region, as they were seen as French allies. As a result, the war was fought against them as well. The Jews felt increasingly unsafe in their homes and began to leave, again. The last wave of migration from Algeria to Israel was in 1962. No Jews remain in Algeria today (ibid.; see also Briggs and Guede 1964). 
The Algerian Jews thought of Israel as a holy land, a belief based on the Jewish bible. Therefore, many Algerian Jews aspired to immigrate to Israel, as is recounted by some of the interviewees:

"Mother woke up and told me that Israel is the holy country." (YZ)

"My father only ever spoke of Israel and wanted to move there already. He never gave up." (MS)

However, a large part of the community also immigrated to France. According to Nagel (2004), the wealthier Jews tended to move to France and to stay there instead of going to Israel. The less affluent Jews moved to Israel, first selling all they could to raise money for the move. The participants in this study shared moving stories of their immigration.

"We thought that we had to sell our bracelets and our gold and silver necklaces. We sold them and received a good price" (MS)

YZ's family not only raised money for the move and future life in Israel, but also needed funds in order to bribe an Arab driver so that they could flee from the city to the sea.

"At night it was silent. We took our belongings and sold everything... The Arabs beat us because it was not allowed for the Jews to flee. It was necessary to bribe people in order to leave." (YZ)

The deaf people sometimes remained in Algeria, waiting to move during later waves of immigration. This seems like there may have been an intentional selective immigration practice. YZ's mother worked with the Israeli Ministry of Interior in order to bring him to Israel. However, many waited for immigration permits for a long time, sometimes years.

"Mother had already sailed away, and Father was already there as well. Mother and her sister with her three hearing children sailed to Israel. My deaf brothers and I stayed in Algeria. I suffered terribly and cried a lot.... The deaf did not immigrate to Israel because they did not want us. They left us in Algeria." (YZ) 
"They did not want me and my three deaf brothers to move to Israel" (MS)

"I remained near the coast in Algeria for five years...Father hugged me and I stood back a little and did not recognize him because I had not seen him for a long time, it had already been 12 years..." (YZ)

The migration itself across the Mediterranean Sea was also difficult. Often the immigrants sailed on ships to France or Israel without understanding what was happening.

"It rained and strong winds blew. We swayed, it was really scary. The sea was noisy; we were careful at all times. All the Jews prayed. I sat quietly and asked my mother what was happening...Mother told me not to talk...." (MS).

However, the hardships did not end with the arrival of the immigrants in Israel. The encounter with the young country, its people, the different language and customs, all these were a source of continuing hardship (Section 4.2).

The relocation and dispersal of communities is one of the known factors leading to the loss of languages (e.g. Tsunoda 2006). Brenzinger (2007) includes studies of several cases, particularly in Western and Central Africa and in South America, where languages have become endangered due to the relocation of speaker communities. Such physical movement of populations can result in the disintegration of the sociolinguistic setting of the community, resulting in language endangerment, and the AJSL community has clearly been affected by a similar process.

\subsection{Life in Israel}

The first difficulty that the immigrants encountered in Israel was in maintaining a livelihood. As most of the interviewees told us, many families had difficulty in finding employment and found themselves in a state of poverty. They could not find jobs within their previous fields of expertise, and were forced to change their trades. While ZM's father had worked as a successful silversmith in Algeria, no such job was available in Israel, and he worked as a general welder. 
Poverty was not restricted to the newcomers, however. The Algerian immigrants arrived in Israel during a difficult economic period of time, known in Israeli history as the Period of Austerity. During this time, the Israeli government imposed strict economical budget policies in order to handle the mass absorption of immigrants. During the Period of Austerity all basic consumption products were strictly budgeted for all the citizens of Israel, existing residents and new immigrants alike. The Algerian immigrants, like all Israeli citizens, bought food with coupons provided by the government of Israel in order to purchase basic commodities, and they found this policy very foreign.

"The whole family had coupons. They provided us with tea, sugar, coffee, couscous, semolina, flour, and everything. We bought coffee from the Arabs. Today in Israel life is good and there is everything." (SS)

"We came to Israel, and I played outside. I was not content because there was nothing to do. The bed was not good and I could not sleep well. We received the coupons to buy food. They counted how many children there were in our family and we only received four coupons. The food was not good. We only ate bread and more bread all the time. Father ate everything and he didn't care. He ate everything with yogurt and bread. My mother was very thin. I was also thin because the food was not tasty. It was disgusting. We just threw up all the time. We did not eat food, just bread." (MS)

While poverty and difficulty in finding jobs characterized the Algerian immigrants (and migrants from many other countries) in general, deaf immigrants encountered special difficulties. In the 1960 s and 1970s there was no vocational school where the deaf immigrants were able to learn a trade. As a result, they attended the schools until the 8th grade. Afterwards they held various jobs such as transport of goods, agriculture, construction, and carpentry. The girls held positions only as seamstresses.

The Association of the Deaf ran vocational courses at boarding schools for the deaf immigrants to enable them to acquire a trade. These courses included sewing, carpentry, shoemaking and photography. In addition, there were small industries owned by deaf people, where the deaf were generally employed. 
Later, the Algerian immigrants were successful in integrating into most working class fields. YZ worked as a carpenter and ZM's father worked as welder.

"When I finished school I was 16 years old and I went looking for a job but could not find any. I looked high and low but there were no jobs. I began with carpentry; slowly I advanced and found myself where I am to this day." (YZ)

Another major change in the life of the Algerian immigrants was the radical change in the hierarchical structure of the family as it existed in Algeria. In Algeria, it was the father's responsibility to support the family, while the mother took care of the home. In Israel, it was often quite difficult for the father to be the sole provider, which meant that women sometimes found professions as well, instead of staying at home.

"My mother worked very hard all day in order to support my brother and myself." (MG)

Tradition and religious aspects of life also underwent changes upon arrival in Israel. Previously, the Algerian family life was dictated by religion and its customs. In Israel the adherence to religious practices was not as strict. The immigrants felt "less religious" although they continued to maintain selected customs and traditions.

"I do not usually go to synagogue. I go only on the Jewish holidays - on the New Year and on the Day of Atonement. I go to pray but only for a short while and not for a long time. I come to honour the tradition." (ZM)

"I maintain the traditions passed down by my Algerian family but I do not go to synagogue - only on the Day of Atonement. I go to events - Bar Mitzvahs and weddings. When I was young, I was very religious because I was close to my mother and I went with her everywhere. When I grew up and got married, I changed, but I still maintain the tradition on Fridays, on the Sabbath and on the Jewish holidays. I have to maintain the tradition for the sake of honouring it." (ES)

It seems that upon arrival in Israel, the deaf Algerian Jews encountered new and foreign realities, and experienced a cultural shock. Life in Israel was drastically different from the life that they were familiar with in Algeria in a number of ways. As pointed out above, 
some of the Jews in Israel were secular, whereas all Algerian Jews were observant. In Israel, women were not confined to the house; they had to find a job in order to help with supporting the family, since the jobs that the men found often did not allow for financial maintenance of the family. In addition, the immigrants struggled to learn a new language, Hebrew. They also encountered people from European and North African countries and cultures for the first time, and were introduced to the concept of special education for the deaf. Contact with deaf education, the Israeli Deaf community, and Israeli Sign Language subsequently had a profound impact on the usage patterns of AJSL, as detailed in the next section.

\subsection{The AJSL-using community in Israel}

The Deaf community in Israel developed in the late 1930s. In Israel there were no schools for the deaf until 1932. Before that time, wealthier families sent their deaf children to the deaf schools in Europe - Paris, Vienna and Berlin. The most distinguished school at that time was in Berlin, and several key figures in the establishment of the Israeli Deaf community attended the school in Berlin (Meir and Sandler 2008).

In November 1932, the first Hebrew school for the deaf was created in Jerusalem. The elected headmaster of this school was Richard Bezalel, who had been a teacher at the Jewish School for the Deaf in Berlin. Concurrently, small groups of deaf people formed, including new immigrants from European countries (especially Germany). These groups began to meet on a regular basis, thus creating the founding group of the Deaf community. This burgeoning group attracted more Deaf people.

In 1943 the temporary committee of the association was set up and the following year the Association of the Deaf was officially founded. The association building was used as a place for social gatherings of the Deaf, and as a place where group activities and trade courses were provided. In the 1950s and 1960s there were waves of immigration from many European, North African, and Arab countries. The time that the immigrants spent with the existing community contributed to the expansion and the variation of the structure and substance of the Israeli Deaf community (Meir and Sandler 2008). 
The deaf immigrants from Algeria joined the Deaf community in Israel, and contributed to its multi-culturalism. However, the encounter between the Algerian immigrants and the growing Deaf community was not unproblematic. As we learned from the interviews, the deaf Algerians felt that they were looked down upon, and consequently developed special attitudes towards the Israeli Deaf community, their language (ISL) and their original language (AJSL), as I discuss below. All these changes affected the vitality of the language. As pointed out in UNESCO (2003), the community members' attitudes towards their own language, as well as the domains in which the language is used and shifts in these domains are important factors to consider when evaluating the vitality of a language.

\subsubsection{The attitudes of the Deaf community towards Algerian deaf people}

The deaf research participants feel that they and their sign language were rejected by the mainstream Israeli Deaf community. They felt inferior when faced with the Israeli deaf people, who were better educated and better able to communicate, especially those from Europe. This caused some of the Algerian immigrants to seclude themselves, and AJSL was kept internal to the Algerian community alone. This may have been a crucial ingredient for preserving the uniqueness of AJSL.

"It is said that people of Algerian origin are dangerous. It is said that we are vengeful and stubborn, but this is not true. I prefer to use AJSL in private conversations on the side and not in front of everybody, so that the other deaf people don't get insulted or say that we are dangerous. I would very much like to explain to them about Algeria, although people have classified the Algerians in a negative way. Now I use the sign language naturally. I am not ashamed of my sign language. Everyone has their own natural language." (ZM)

Following these degrading attitudes, AJSL became a sort of secret language, similar to other stigmatized minority languages seen around the world where a government or community supports a majority language through policy, education, and attitude, thus weakening the continued viability of the minority languages (e.g. Ho $\mathrm{Ne}$ in China, Zhou 2003; many Native American languages in the USA, Krauss 1998; and numerous others around the world, Tollefson 1994). In Israel, people used AJSL exclusively amongst their 
family and close friends, when they wanted the other deaf people not to understand them, and only signed ISL with other friends and acquaintances.

Signed languages around the world have a history of persisting behind closed doors when the majority of society does not approve of languages in the visual-manual modality (cf. Neisser 1990 on the suppression of ASL in the mid-eighteenth century, and Plann 2007, for a discussion of the same in Spain). In Israel, sign languages were not banned, though they were not used in the educational system until the late 1970s. However, with in the Deaf community, AJSL was not accepted as a legitimate language of the community, and AJSL signers felt they had to conceal their native language. This caused a major shift in the domains in which the language was used. In Algeria AJSL was used to all domains of everyday life, and was used by all members of the community who knew the language. In Israel, AJSL was not used in the public domain; it was confined to the family, because it was regarded as inferior to the more prestigious sign language in the country, ISL. Dwindling domains of use are regarded as an important factor in reducing the vitality of a language (cf. Factor 4 in UNESCO 2003).

"When speaking in AJSL, we speak in secret. The other deaf people looked and asked what it is: 'Is the AJSL secretive?' I told them that this is just the way it is. This is the Algerian sign language" (ES)

It is important to mention that some of the members of the Israeli Deaf community liked AJSL, and even learnt it so as to communicate with the Algerians. ES's husband learnt and communicates in AJSL.

"My husband is Iraqi, and he loves my father. He is deaf and communicates with my father in AJSL. He knows AJSL very well, and finds it a very interesting language." (ES)

While the Algerian absorption into Israeli society faced serious challenges, many Deaf people from within the Israeli community accepted the immigrants, taught them ISL, and tried to improve their conditions. One such an accepting member of the Deaf Israeli community was Moshe Bamberger, the German-born Deaf man who was one of the founders of the community and the first teacher of sign language in Israel. MS told us that 
she still remembers her first visit to the Deaf club. As she and her older sister, also deaf, came into the club, Moshe Bamberger approached them and asked them their country of origin. When they signed 'Algeria', he said: "Oh, don't worry. I'll teach you our signs. You do 'mother' like that, we do it like this. Your sign for 'father' is this, ours is that." After a few more visits to the club, the two sisters felt much more at home, both socially and linguistically (Meir and Sandler 2008).

\subsubsection{The attitude of the Algerian immigrants towards the Deaf community in Israel}

The Algerian deaf felt inferior to the members of the Deaf community in Israel as a result of the differences in their educational, economical, and social status. They felt that their language was not acceptable and that it singled them out in a negative way. These feelings caused the immigrants to attempt to hide their language by not using it when other Deaf people were present. The Israeli Deaf, who did not understand AJSL, began to see the use of AJSL by the Algerian deaf as a threatening secret. They labelled the Algerian deaf people as "dangerous", "cursed", and "secretive". The deaf Algerians were insulted and continued to keep AJSL to themselves, only to be used when people of the community met or when they wanted to share something with each other privately.

"If I am standing with a deaf man who communicates in AJSL, I will communicate with him in this language. But I will only do so personally, or off to one side, so that other people don't get insulted, because this language is different." (ZM)

It seems that the attitude that people from Ghardaia held towards their own language had changed. In Algeria, AJSL was part of everyday life in the community. In Israel, it seems that less and less people were supportive of language maintenance. Furthermore, most deaf Algerians preferred to use ISL most of the time. The result is that most of the Algerian deaf became sign-bilingual: they used ISL with members of the Israeli Deaf community, and used AJSL among themselves. Both factors - the diminishing support of AJSL maintenance and the fact that most of its users became bilingual - are crucial in affecting the vitality of the language. According to the scale used in the UNESCO questionnaire on language vitality, a language whose users mostly do not support its 
maintenance is assigned a grade of 2 (severely endangered) on the 0-6 scale (UNESCO 2003, Factor 8). In addition, a language used only in multilingual contexts is more endangered than a language used as the only language in a community (ibid. Factor 4).

\subsubsection{Marriage patterns}

In addition to changes in linguistic behavior, the social patterns of the deaf Algerians also changed as a result of their immigration to Israel. One significant change was in marriage patterns. As opposed to the patterns found in Algeria, in Israel most of the Algerian deaf married other deaf people, not hearing people. In addition, most of them married people from other countries and not other Algerian immigrants. In other words, they became integrated into the Israeli Deaf community and they completely changed their marriage patterns. The fact that most Algerians are married to non-Algerians shows that the immigrants were able to integrate into the Israeli Deaf community in spite of the hard feelings of inferiority and suspicion towards their Israeli counterparts reported by many Algerian immigrants.

According to MG, a widespread conviction in the community was that if Algerians marry other Algerians, there is a high incidence of congenital deafness. Therefore, many Algerians preferred to marry deaf people from other countries and from other ethnic groups, in order to improve their chance of giving birth to hearing children. Indeed, among the deaf Algerians interviewed for this thesis, the four Algerian deaf women are married to non-Algerian husbands. This practice appears to have had the expected results, as most children born to these integrated couples have been born hearing.

The changes in the patterns of marriage within the Algerian immigrants altered the patterns of language use and transmission within AJSL signers. Since most AJSL signers married people who did not know the language, ISL became widely used by AJSL signers, and AJSL ceased to be used even within the nuclear family domain. ISL, the dominant language, started penetrating even home domains (UNESCO 2003, Factor 4), and AJSL in contrast, was not used for any new domains (ibid. Factor 5), thus diminishing the language's vitality. Furthermore, the intergenerational transmission of AJSL virtually 
stopped, and most children of deaf couples (whether deaf or hearing) were no longer exposed to AJSL. Intergenerational transmission is perhaps the most crucial factor for the continuing maintenance of a language, and a language that is no longer being learned as the mother tongue by children in the home is definitely endangered. The classification of language endangerment by Krauss (2007:1) relies centrally on this consideration of language transmission across generations, and this factor is also crucial for considering the future viability of AJSL (see Chapter 6).

\subsubsection{Deaf education, language and literacy}

The deaf Algerian immigrants, who had not previously acquired formal education, encountered a new situation in Israel. Education was mandatory, for hearing as well as for deaf children. The educational system for the deaf in the 1950s and early 1960s consisted of several schools, nursery schools and special classes for the deaf (in Jerusalem, Tel Aviv, Haifa, Beer Sheva and Nazareth Illit, Plaut 2007). The schools in Jerusalem and Tel Aviv were boarding schools with dormitories. There was also a vocational rehabilitation center in Tel-Aviv. Deaf children went to school, and learned to read and write.

Deaf Algerian children of school age went to school in Israel. Some of them immigrated to Israel at a relatively late age, between 10 and 12 years old. They were required to attend school, but since they had no previous schooling experience, they encountered many difficulties and frustrations. They were not accustomed to the specialized kind of discipline and as a result most of them did not succeed at learning to read and write. Many of the Algerian deaf express a continued frustration with formal education even today. In Algeria, deaf people did not normally read or write, and this situation was painful to them. However, the pain was intensified when they encountered a new reality in Israel - Deaf people knew how to read and write, in contrast to their own illiteracy. Consequently the immigrants suffered even more distress and anguish.

In addition, they were required to communicate in a new sign language, Israeli Sign Language (ISL). This created an additional challenge to their linguistic situation. 
"My friends and I attended Niv, the school for the deaf. I began to learn how to go to school. I slowly understood how to find my way into school. I sat quietly with a group of new immigrants. I am from Algeria, one immigrant was from Egypt and two were from Romania. All of us came here. The class consisted of a mixed audience. I stayed in the class and studied. My mother made an effort for me to study at the school for the deaf. I studied with four other friends in my class. I was a new immigrant and studied but I did not fully understand how to write on the blackboard A-B-C-D..." (YZ)

"Now I communicate in ISL. In my youth I attended Niv (the name of the school). Today finger-spelling is very common. This was too difficult for me in the beginning, but I slowly absorbed and understood the concept of spelling." (ZM)

As can be seen from these quotes, the sign language that was used in the schooling system was ISL. Although the schooling system for the deaf started off as strictly oral, the children themselves signed to one another, and they used ISL for this purpose. When signing was introduced into the educational systems (in the 1970s), it was ISL signs that were used by the teachers (Plaut 2007, Meir and Sandler 2008). Thus, any institutional support or recognition was towards ISL, whereas AJSL did not have any official recognition or protection at all. This low status adds further pressure to the vitality of the language, and on the UNESCO vitality scale, this kind of situation attracts the weakest score (UNESCO 2003, Factor 7).

\subsection{AJSL in Israel}

\subsubsection{Learning Israeli Sign Language}

When the Algerian Jewish community moved to Israel and its deaf members established contacts with the Deaf community in Israel, it is highly likely that they encountered many different language varieties, since deaf people emigrated from many different countries and brought their signing systems with them (Meir and Sandler 2008). However, the beginnings of a common language had already been formed, and ISL was developing. The 
research participants confirmed that, when they arrived in Israel, they had great difficulty in understanding the sign languages of the other deaf people that they met. In such a volatile linguistic environment, people are often 'forced to learn a common means of communication' (Tsunoda 2006:59), and this can lead to language attrition (Craig 1997:257).

Myhill (2004) emphasises the importance of immigration to the spoken language situation in Israel, whereby learning Modern Hebrew became part of the process of settling in the new country. He describes the importance that learning the mainstream language of the new country had for the younger generation:

'Typically (though not invariably), children who spoke only an immigrant language to their parents and with their small friends will not only learn the mainstream language when they attend school in it but before long they will begin speaking it even to peers who know the immigrant language as well... this is, in fact, a completely routine occurrence in immigrant families' (Myhill 2004:90).

It is clear that a similar process took place for ISL as well. M.S. said that she learnt Israeli Sign Language from Moshe Bamberger, a senior member of the Israeli deaf community:

'I did not learn ISL. When I came to the deaf club, Moshe Bamberger was my first teacher in Israel and taught me in ISL. I was 17 or 18 years old, and I arrived at the deaf club and did not understand what they were saying. Moshe Bamberger asked me if I was Algerian immigrant, and I said yes. He taught me ISL - "father", "mother", etc. - and I slowly learnt from him. After six months I learnt it all. Moshe told me that I should come to the club all the time so as to advance my ISL.'.

It is clear from the comments made by interviewees that the deaf club had emerged as a very important centre in the lives of many deaf immigrants. For example, the Helen Keller House in Tel Aviv (where the Deaf Association is located) provided classes, tutorials and professional training courses from 1953 onwards and immigrants joined these courses (Meir and Sandler 2008:193). The Algerian deaf learned ISL through their encounters with friends and at the deaf club gatherings. As a result they were able to communicate in two 
sign languages - Algerian and Israeli. However, hearing family members were not exposed to ISL since they were not part of the Deaf community. They continued communicating in AJSL and remained largely sign-monolinguals in AJSL. This caused a situation in which the deaf Algerians communicated in ISL with the Israeli deaf and in AJSL among themselves and with their hearing family members. AJSL has been preserved to this day because of this duality.

"The hearing use only AJSL because they don't know Israeli Sign Language... The hearing knew AJSL very well and conversed with us freely." (LP)

"To this day we use AJSL as well as ISL" (LP)

"To this day my mother signs in AJSL. She communicates with me only in AJSL; even when she is on the telephone, she translates for me in AJSL. I have seen that at times she uses ISL. It has to do with the hearing family members continuing to communicate in AJSL." (ES)

"I communicate only in ISL with friends at all times, but when I talk to my mother, I immediately switch to AJSL. I talk with my deaf sister in ISL but with my mother mainly in AJSL and sometimes in ISL. Every Saturday the whole family comes to visit my mother. There are two hearing brothers, one hearing sister, and five deaf brothers and sisters, and we all communicate in AJSL with a few word signs in ISL - a mixture of ISL and AJSL" (ES)

The children that were born to the Algerian immigrants in Israel were born into a language environment in which ISL was dominant. Most children acquired ISL and are not fluent in AJSL. This situation is mainly characteristic of children that were born to mixed families, with one non-Algerian parent. In these families the parents communicate among themselves in ISL. However, children born to two Algerian parents, who are now 20 years old and older, are usually also not fluent in AJSL, since they are part of the Israeli Deaf community, and use ISL as their main communication resource.

"I used to speak with my sisters in AJSL at all times, but today it is different because of my children (who only know ISL). Sometimes, depending when, we still speak in AJSL" (ES) 
"My eldest son knows quite enough AJSL but my other sons can't communicate in the language." (LP)

These are strong indications of the fact that the intergenerational transmission of AJSL has virtually stopped, and that the language is hardly acquired by children as their mother tongue or as an additional language. As pointed out above, a language no longer acquired by children is definitely endangered (Krauss 2001; UNESCO 2003, Factor 1).

\subsubsection{Recent changes in attitudes towards AJSL and ISL}

As we saw, the Algerian immigrants felt that they were looked down upon, and as a result, tried to keep their most salient characteristics, their language, to themselves. In recent years, however, there is a feeling of change towards AJSL and its users, both from the general ISL community and from AJSL users themselves. The interviewees for this study report that they feel less hostility from the wider Deaf community, and that they themselves have begun to take more pride in their language. A renewed interest in the language and traditions of Algeria has grown. People are no longer ashamed of being Algerian or of their sign language. They feel a responsibility to preserve the language since they realize that their generation is probably the last generation to use the language.

"Now I sign in my natural sign language [AJSL] and I am not ashamed of it." (ZM)

"The history and geography of Algeria is very interesting. In the future our heritage will disappear, AJSL will disappear and it is a shame. Very few people speak in AJSL" (ZM)

"I love using AJSL very much. To this day I use several signs from AJSL." (ES)

ES appeared to sign this with pride. In the past it was not thought of as a great achievement to be fluent in AJSL, which was thought of as a simple and inadequate language. Now that the perception of AJSL has begun to change, she shows pride in knowing both languages. 
All deaf interviewees who participated in the present study are bilingual, fluent in both AJSL and ISL, although there are still some other deaf people who did not integrate into the Israeli Deaf community and only know AJSL, as mentioned above. Largely speaking, ISL has been accepted as a second language and the deaf Algerians regard themselves as a bilingual people. Moreover, ISL became the main means for communication, as it is used not only with friends but also within the nuclear family - with spouses not of Algerian origin, and with the children who were born in Israel and who have acquired ISL.

ISL enjoys a higher prestige, as it is the main sign language in the country. In addition, all formal resources, such as courses for learning a sign language, use of signs by teachers and interpreters' training programs are all in ISL. With such strong prestige vis-a-vis AJSL, it is no wonder that AJSL signers reverted to use mainly ISL. This change in language practices threatens the vitality of AJSL .

"I only sign in ISL with my sister ES. My eldest son knows AJSL but the others do not know AJSL. All of them are hearing." (LP)

"I talk with my deaf husband - Shimon -- in ISL. Now we usually talk in ISL. If we are in front of a deaf person, I will talk with him in ISL." (ZM)

Today the younger generation of deaf people from Algerian families have become an integral part of the Deaf community in Israel and barely use AJSL. Surprisingly, it is the hearing people of the community who have continued to use AJSL the most, because they were, by and large, not exposed to ISL.

One deaf woman who I met but who was not one of the interviewees for the study, MI from Givat Shmuel, had never been exposed to ISL, did not participate in the meetings with the Israeli Deaf community, and as a result communicates solely in AJSL. Her hearing children, who were born in Israel and have no connection with Algeria, communicate with her using only AJSL. Hearing people who sign in AJSL, although they have never lived in Algeria, such as MI's children, are an interesting and unique phenomenon. To this day the hearing family members, regardless of age, use this language with their deaf relatives, but the number of children using AJSL is very small. 
Thanks to the Algerian Jewish Sign Language that connected the deaf and hearing people and bridged communication between them, it seems that strong and satisfying connections were maintained between family members after migration to Israel, as explained by ES, who relates how her mother would use AJSL to relate what her aunt had said to her in Arabic.

"My mother signs in AJSL to this day... Every time my aunt and my mother would talk to each other about different issues and gossip [in Arabic], I would cry. After, they would eat and my aunt would go home, my mother would call me over and say [in AJSL]: 'Let me tell you about all the different things that your aunt told me - about her quarrel with her husband, and about how her husband refused to give her money.' It was good for me to learn of these things from my mother, because we are very close and she tells me everything. This connection with my mother is very important to me. My mother shares with me everything from her heart." (ES)

Such narratives are important in the interview data because they show that AJSL continues to be used in Israel by hearing parents to communicate with their deaf children. For ES, this was an essential part of their relationship. Such usage patterns of AJSL can help to explain why AJSL has persisted in Israel until now, despite adverse factors resulting in its endangerment.

\subsection{Conclusion: AJSL in Algeria and in Israel}

From the data collected through the interviews, we learn that the AJSL using community in Algeria and in Israel differs significantly, both in terms of their social characteristics and practices and in terms of their linguistic characteristics.

AJSL has undergone many changes after migration of the user population to Israel. AJSL was the only sign language in Ghardaia, whereas in Israel both AJSL and ISL are used. In Ghardaia, mostly Algerian-Algerian marriages took place (commonly between deaf and hearing people), but in Israel, deaf Algerians tend to marry deaf people from other places who do not know AJSL. In Israel, AJSL users are dispersed, with a few small clusters of Algerian immigrants, and adherence to the Jewish religion and associated rituals is weaker 
than it was in Ghardaia. AJSL in Israel has been somewhat stigmatized outside the Algerian Jewish community and had very few new learners, whereas in Ghardaia, the language carried no stigma and was acquired by children from their parents and neighbours in open spaces; women used the language at home and men used it at work. In Israel, the use of AJSL is relegated to the home; only ISL is used in public.

AJSL has never had an official status, either in Ghardaia or Israel, but ISL does have such a status within Israel, and ISL resources are available. There was no school for the deaf in Ghardaia, so AJSL has not been used in formal education. In Israel, schoolchildren use ISL to socialize with their friends, though the schools themselves mainly use oral education or Total Communication.

The differences caused by migration may be seen in terms of the differences between the AJSL-using community of practice as it existed in Ghardaia and the community after its migration to Israel. Some of the points discussed above are in line with characteristics of communities of practice in terms of identity and linguistic behaviour. For instance, Wenger 1998: 78-84 mentions factors such as mutually defining identities, shared stories, and a shared discourse reflecting the community's perspective on the world. The differences between AJSL in Ghardaia and AJSL in Israel are further summarised in Section 6.1 (see also Table 6.1 in Section 6.1). 


\section{CHAPTER 5: LEXICAL COMPARISON OF AJSL AND ISL}

\subsection{Lexical comparison}

The massive migration of Algerian Jews to Israel took place in the middle of the twentieth century (all of the deaf interviewees moved to Israel between 1948 and 1962 - see Table 2.1). Since AJSL users arrived in Israel, there has been contact between AJSL and ISL, but the impact of this language contact has not yet been investigated. Chapter 5 presents the results of a comparison of a section of the lexica of AJSL and ISL, in order to discern the extent to which language contact with ISL has affected the lexicon of AJSL. This comparison will deepen knowledge of the history and current status of AJSL by indicating the impact that this language contact has had since the 1960 s.

In order to establish how far the lexicon of AJSL has been influenced by ISL, the signs of AJSL and ISL will be compared in several semantic domains, such as food, colour, religion and kinship terms (see section 5.2). Lexical comparison has been used many times in the history of sign language research, but some of the methods that have been employed are not suitable for the current investigation. Section 5.1.1 considers lexicostatistical studies to see why this method has been chosen by sign language linguists in the past, and how they have been carried out. Several problems with these methods are identified, and section 5.1.2 will outline the research method of the current study, showing how this links to the research questions.

\subsubsection{Previous studies that use lexical comparison}

Comparison of words in spoken language was pioneered by the anthropologist Morris Swadesh, who created several lists of lexical items for elicitation during his working life (Swadesh 1955). These words were chosen from the core vocabulary, which is purportedly 'relatively stable and resistant to change from borrowing' (Woodward 2010:40) - that is, these words were thought to be resistant to borrowing. Linguists have tried to discern the relationships between different spoken languages by categorising them as (i) the same 
language, (ii) different languages of the same language family, or (iii) different languages of different language families (cf. Crowley 1992).

In spoken languages, cognates are two words that are 'derived from a single original form with a single original meaning' (Crowley and Bowern 2010:81). For example, the English words 'mother', 'father' and 'friend' are cognates of the German words 'Mutter', 'Vater' and 'Freund' (Yule 2006:184). The presence of many such cognates in modern English and modern German suggests that there is a shared ancestor, which has been labelled the Germanic branch of Indo-European (Yule ibid).

The main exponent of lexical comparison in sign languages is James Woodward. Following his investigation of the historical relationships between American Sign Language and French Sign Language (Woodward 1978), Woodward pioneered these methods in Costa Rica (1991, 1992) and India, Pakistan and Nepal (1993). He has gone on to use the same methods in Thailand (1996) and Vietnam (2000, 2003). Woodward uses a modified Swadesh List, which takes into account the effects of iconicity by removing signs that refer to body parts and pronouns, which are identified indexically, with pointing (Woodward 2010:44). Subsequently, Al-Fityani and Padden (2011) conducted a comparison of all the signs from the sign language dictionaries of Jordanian Sign Language, Kuwait Sign Language, Libyan Sign Language, Palestinian Sign Language, and American Sign Language, and a filmed interview with a signer from the Al-Sayyid Bedouin community (see also Padden 2010, and the commentary on this work by Woodward 2010).

There are various problems with this approach. ${ }^{7}$ Signs in two different sign languages that appear to be cognates - genetically-related - may in fact have been borrowed from one sign language by the other. Contact-induced borrowing is very common - for example, ISL itself emerged in the second half of the twentieth century as a result of contact between the sign languages and home signs of deaf immigrants to Israel (Meir and Sandler 2008). Since there have been bilingual AJSL/ISL users for at least forty years (see sections 4.3 .2

\footnotetext{
${ }^{7}$ It seems that successful alternative approaches to lexical comparisons of sign languages for the purpose of deciding on historical relatedness have not yet been developed.
} 
and 4.4.2), it cannot be assumed that similar or identical signs in AJSL and ISL are indeed cognates, that is, of a common origin. Additionally, ISL has only been documented recently, and AJSL is only now starting to be documented. The absence of documentation of the language as it existed in the past makes it very difficult, if not impossible, to determine whether similar signs in AJSL and ISL are cognates or contact-induced borrowing.

There is a crucial third factor to consider. Signs may look the same in different sign languages not only because of genetic relationships and contact-induced borrowing, but because of iconicity. The iconic nature of many signs and structures in sign languages means that it is very possible for similar signs to appear in different sign languages, but independently of each other. In their comparison of Mexican Sign Language, Spanish Sign Language, French Sign Language and Japanese Sign Language, Guerra Currie, Meier and Walters (2002) found that the signs they examined in Japanese Sign Language and Mexican Sign Language were $23 \%$ similar. These two languages clearly developed independently of each other, as the two communities have no common history. The only satisfactory explanation for this finding is iconicity (Guerra Currie, Meier and Walters 2002:229). It is important, therefore, not to assume that similarity between signs in two or more sign languages is an indicator of a genetic relationship, or of contact-induced phenomena, as such similarity may be attributable to the role of iconicity.

To give an example from AJSL and ISL, the signs for 'knife' in each language, shown in Figure 5.1, are phonologically similar. Both are two-handed signs articulated in a neutral space in front of the body, with a similar movement whereby the dominant hand moves across the non-dominant hand. ${ }^{8}$ The main difference between the signs is in their hand configuration: the ISL sign for 'knife' is articulated with all four fingers of the dominant hand extended, while the AJSL sign has only the index and middle fingers

\footnotetext{
${ }^{8}$ Typically, a right-handed signer will produce more complex handshapes with their right hand, and if a sign requires the movement of only one hand, it will be the right hand. Conversely, a left-handed signer will move the left hand, and use it for more complex handshapes. Rather than describing signs in terms of 'right' and 'left' hands, the terms 'dominant' and 'non-dominant' are used here.
} 
extended.Importantly, the handshapes of the dominant hand iconically resemble the blade of a knife, and the movement of the dominant hand resembles the action of the knife as it cuts into the object represented by the non-dominant hand. There is no doubt that each of these signs is iconic, and similar signs can be found in other sign languages too, such as British Sign Language, which have no known relationship to ISL. It is very possible that these signs emerged independently of each other - rather than because of a genetic relationship, or contact-induced borrowing - and appear to be similar simply due to iconicity.
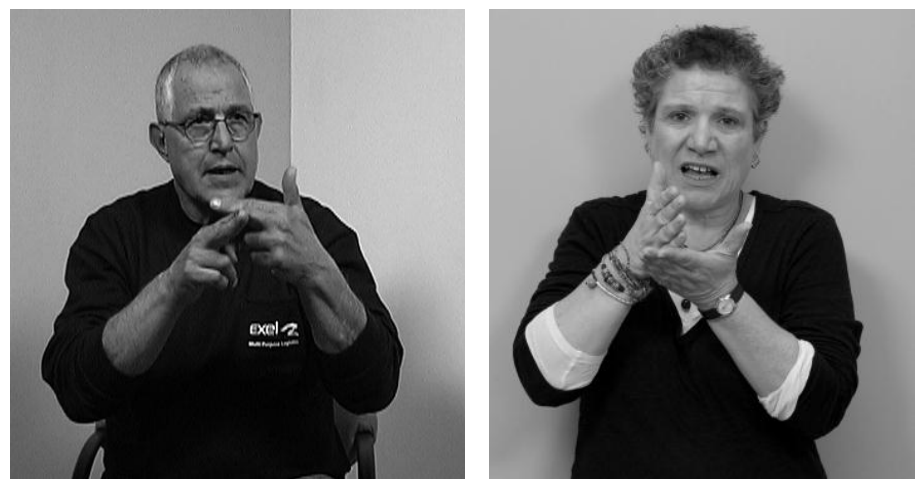

Figure 5.1 - Two similar signs: KNIFE in AJSL (left) and ISL (right)

\subsubsection{Comparison of the lexica of AJSL and ISL}

Due to the controversial nature of the lexicostatistical method, therefore, it has been decided only to make a comparison of the lexica of AJSL and ISL, looking at how similar a selection of signs are in a number of semantic domains. The results of this comparison will not be used to draw conclusions about the interrelatedness of AJSL and ISL, but rather to consider how different the lexicon of AJSL is from that of ISL.

The list that I compiled consists of words from semantic domains that refer to everyday objects and artifacts, actions and customs, as well as kinship terms, colours, and numerals. The complete list of concepts is given in Appendix B, and a sample of the AJSL signs that were compiled is presented in appendix $C$.

I conducted the comparison in the following manner: Using the filmed interviews as participants signed 300 words in AJSL, I analyzed the phonological structure of these signs 
according to the following features: handshape, orientation, number of hands, place of articulation, and movement features - direction of movement, type of movement, reduplication, contact, and internal movement. These features were necessary in order to give an accurate phonological representation of the signs. However, for the sake of comparing the AJSL and ISL lexica, only the main phonological features handshape, location, movement and hand orientation features -were used. These were determined according to McKee and Kennedy's (2000) method of comparison that was similarly used to study BSL, Auslan and NZSL. McKee and Kennedy compared the signs from a random list ${ }^{9}$ of signs from the three languages and concluded that all three are different dialects of the same language. Identical features were marked in blue, non-identical - in yellow. A screen capture showing part of the table that was used for this can be seen in figure 5.2.

\begin{tabular}{|c|c|c|c|c|c|c|c|c|c|c|c|}
\hline & Sign & handshape & orientation & $\begin{array}{l}1 \text { or } 2 \\
\text { hands }\end{array}$ & location & movement dire & movement $\mathrm{t}$ & t reduplication & Contact & $\begin{array}{l}\text { Internal } \\
\text { movement }\end{array}$ & Notes \\
\hline 240 & Taberlance- סוכות & B & side & 2 & arm & up and down & & single $\mathrm{M}$ & & & שמחת תורה \\
\hline 241 & Hannukah & G & down & 2 & $\mathrm{H} 2$ & down & & single $\mathrm{M}$ & & & \\
\hline 242 & Purim & bO-pay & out & 1 & neutral & away & & single $M$ & & & \\
\hline 243 & Passover 1 & B & up & 1 & neutral & up & & single $\mathrm{M}$ & & & ם עד היום הזה - קערה מעלה מoתובבת \\
\hline 244 & Passover 2 & B & down & 1 & $\mathrm{H} 2$ & away & & redup & & & \\
\hline 245 & Lag Bomer & B & side & 1 & neutral & side & & single M & & & דואית אש,חם ,אך B מפה למעלה \\
\hline 246 & Pentecost & $\operatorname{lax} 5$ & out & 1 & neutral & away & arc & single $\mathrm{M}$ & & & זוג באלג'ריה וטוניס'ה שופכ'ם מ'ם ברחובות \\
\hline 247 & $\operatorname{dog}$ & E & in & 1 & mouth & towards & & redup & continuous & & ;פוך בפה בתבנית טורפת כמו שס בדואית \\
\hline 248 & cat & curved V & down & 1 & neutral & down & & redup & & & \\
\hline 249 & mouse & curved V & down & 1 & neutral & down & & redup & & & \\
\hline 250 & donkey & V & in & 1 & $\mathrm{H} 2$ & away & & single $\mathrm{M}$ & & & \\
\hline 251 & stubborn & G & in & 2 & $\mathrm{H} 2$ & up and down & & redup & & & \\
\hline 252 & horse & bO-pay & side & 2 & neutral & up and down & & redup & & & \\
\hline 253 & bee & V & down & 1 & neutral & up and down & & single M & & & א "גזר ומתוק (נגיעה בפה בG נפופה) \\
\hline 254 & camel & V & down & 2 & $\mathrm{H} 2$ & up and down & & redup & & & \\
\hline 255 & sheep & "male" & side & 2 & $\mathrm{H} 2$ & up and down & & redup & & & \\
\hline 256 & goat & $\mathrm{V}$ & in & 1 & chin & towards & & redup & continuous & & הפוך ליג הסנטר V \\
\hline 257 & snake & G & down & 1 & neutral & down & & single $\mathrm{M}$ & & & \\
\hline 258 & cow & $\mathrm{s}$ & side & 2 & temple & up & & single $\mathrm{M}$ & & & \\
\hline 259 & eating forbidden & G & out & 1 & forehead & up & & single M & brushing & & ל \\
\hline 260 & devil & V & in & 1 & cheek & towards & & single $\mathrm{M}$ & brushing & & \\
\hline 261 & gas & G & side & 1 & nose & side & & redup & continuous & & \\
\hline 262 & alace & $\mathrm{B}$ & & 4 & noutral & awave & & cinglo M & & & \\
\hline
\end{tabular}

Figure 5.2 - Part of the table that was used for phonological analysis of signs in AJSL

Three degrees of relatedness were established (following Mc. Kee et al 2000): identical, similar and different. Two signs are considered 'identical' if all of the components are found to be identical, and 'similar' when the signs differ in one of the four components. When two or more of the components are different, they are considered 'different'. Figure 5.3 shows two identical signs, the signs for CHICKEN in the two languages.

\footnotetext{
${ }^{9}$ According to McKee et al. (2000) the use of a random list is supposed to prevent the exaggeration of the level of similarity between different languages as a result of the examination of signs only according to their basic concepts.
} 

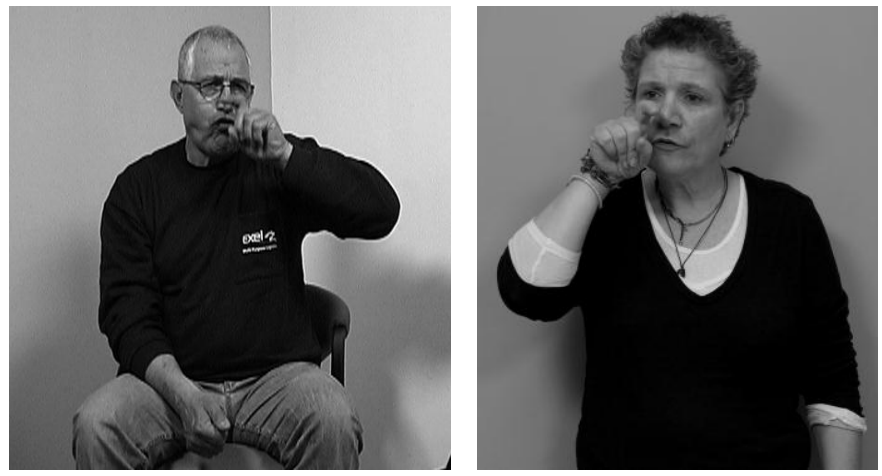

Figure 5.3 - Identical signs for CHICKEN in AJSL and ISL

Figure 5.1 shows two similar signs, KNIFE. They share location, orientation and movement, but differ in handshape. Figures 5.4 and 5.5 show two pairs of signs that are completely different in the two languages: MORNING and MOTHER. They differ on all 4 components. Figures 5.6 and 5.7 show pairs of signs that are quite similar, but since they differ in two parameters, they are not considered similar for the purpose of this study. The signs for WATER share movement and location, but differ in handshape and orientation. The signs for COW share location and orientation but differ in movement and handshape.

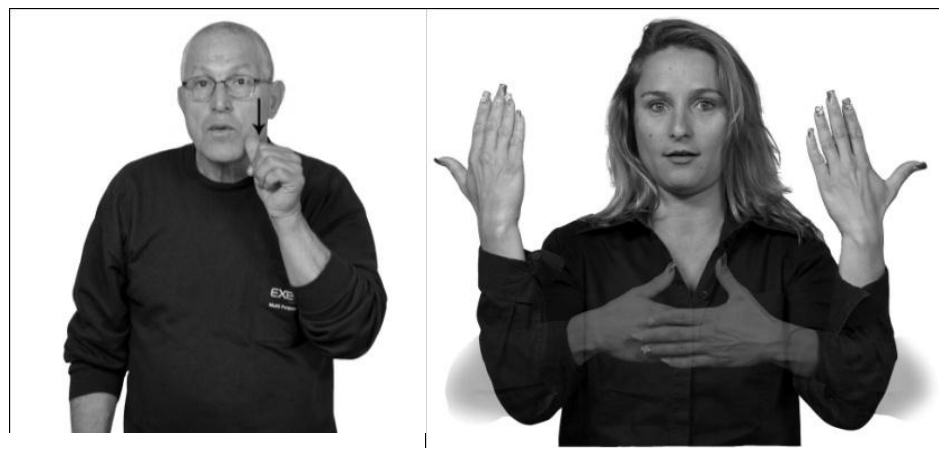

Figure 5.4 - Two entirely different signs for MORNING in AJSL and ISL
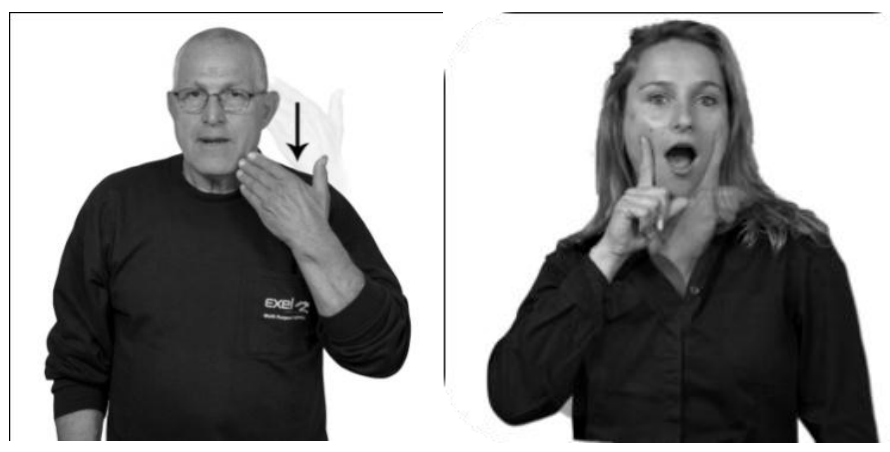

Figure 5.5 - Two entirely different signs for MOTHER in AJSL and ISL 


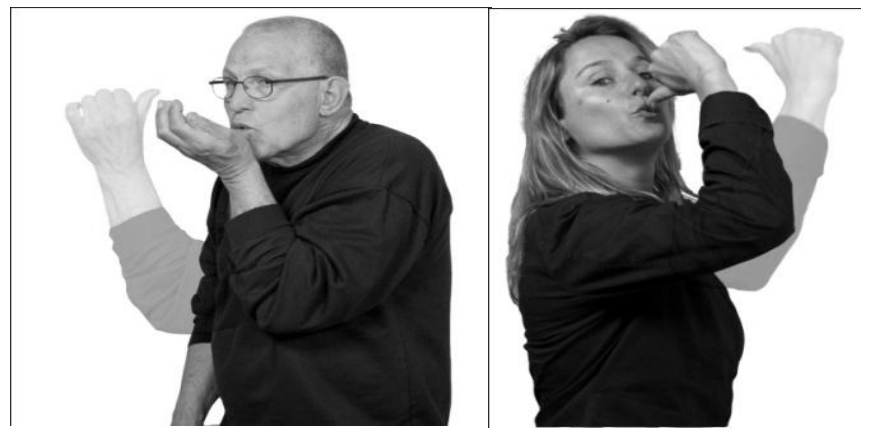

Figure 5.6 - Different signs for WATER in AJSL and ISL

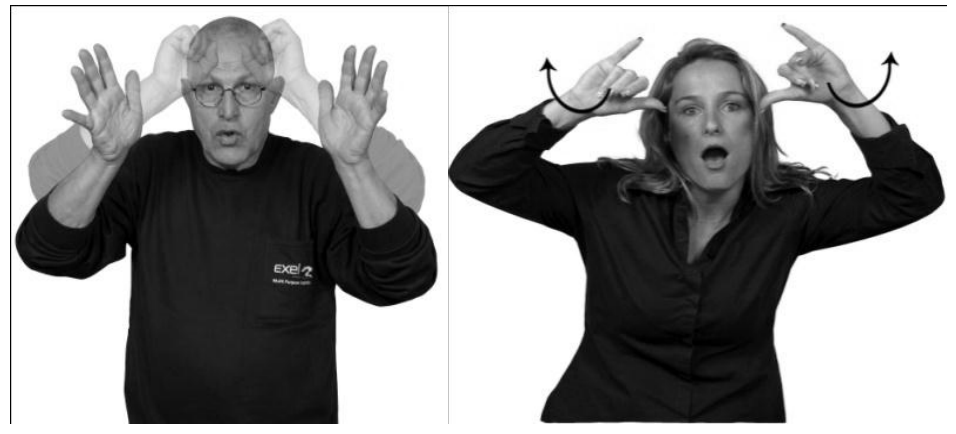

Figure 5.7 - Signs for COW in AJSL and ISL

A comparison of the elicited lexemes from AJSL with the corresponding lexemes in ISL shows that approximately $10 \%$ of the signs can be defined as identical and approximately $6 \%$ of the signs can be defined as 'similar' (though not identical). In total about $17 \%$ of the signs were found to be identical or similar.

Where a sign in AJSL and ISL are identical, there are several possible reasons for explaining this identity. Firstly, the similarity in form could be attributed to iconicity. The sign for SNAKE in both languages depict the motion of the snake in an S-like path; the sign for HEN depicts the pecking of the beak; FISH depicts the motion of a fish in water; and the sign for RED is signed by the mouth. Secondly, some signs are related to gestures that are commonly used by hearing people in the region, as the sign for SLOWLY/PATIENTLY (an O hand oriented upwards, with up and down movement). Finally, some similarities are the result of contact between the two languages. For example, the sign for CRAZY was borrowed from AJSL to ISL. 
Taking all this into consideration, the percentage of shared lexical items between the two languages is still low when compared to findings from other studies, such as the 23\% of overlap found for Mexican (LSM) and Japanese Sign Languages (JSL) mentioned above (Guerra Currie, Meier and Walters 2002), which is also considered quite low, and is to be expected since the two languages are historically unrelated. In comparison, the percentage of similar signs found in Israeli (ISL) and German Sign Languages (GSL), languages with a known and recorded historical connection, is approximately $37.5 \%$ (Meir and Sandler 2008). This low level of resemblance between the vocabularies of signs suggests that AJSL has persisted without a lot of influence from ISL, and that there has been little attrition of the AJSL lexicon.

\subsection{Sign from specific semantic domains within the AJSL lexicon}

In the first part of the chapter, I compared the vocabulary of Algerian Jewish Sign Language (AJSL) and that of Israeli Sign Language (ISL). The aim of the comparison was to examine if AJSL was influenced by ISL, or if ISL had no influence on AJSL and the two languages were completely different. The two languages contained identical or similar words in approximately $17 \%$ of cases. As this is a relatively low rate, one can infer that the two languages are completely different.

In the second part of the chapter, I attempt to formulate a qualitative comparison of specific aspects of the AJSL lexicon. First, I describe the system of numerals in AJSL, since it has some unique features. Then I describe several AJSL signs from specific semantic fields which are very much related to the cultural and social life of the AJSL community. I compare these signs to their ISL counterparts, as it is interesting to consider how cultural practices are reflected in the vocabulary of both communities.

The vocabulary of a language often reflects the unique customs and values of that society (Nettle and Romaine 2000). Consequently, AJSL signs may reflect cultural aspects that are unique to that society. By comparing these signs with signs that are used in ISL, one can compare and contrast these two distinct communities, that of the Algerian and Israeli deaf communities. 
I chose to focus on four semantic fields, all connected to daily life of the community: family, festivals, food and colours. In each field, I describe several signs in both languages, and I examine how the sign reflects the practices of the community in which it is being used. In addition, I looked at the signs "deaf" and "hearing", and analyzed if they represented a particular perception of deafness in society.

\subsubsection{Number in AJSL}

Different sign languages express cardinal numerals (e.g., one, two, three, ten seventeen, hundred...) in different ways. Some languages use only one hand to express all numerals (e.g. ASL, Humphries, Padden and O’Rourke 1980), while other sign languages may use two hands for numerals higher than 5 (e.g. ISL). Sign languages may also differ with respect to the number they use as a basis. Many sign languages have a ten-based system. Numerals higher than ten require additional number signs; that is, thirteen is signed as ten and three. In AJSL we find that the numeral 5 has a special form: a flat $O$ handshape. This special handshape then forms the basis for numerals 6-10. In that sense, 5 can be regarded as an operator (Fuentes and Tolchinsky 2004). Below I describe the system of cardinal numbers in AJSL.

1-4: Addition of fingers: index finger - middle finger - ring finger - little finger

5: Flat O pattern with repeated movements of attached fingertips

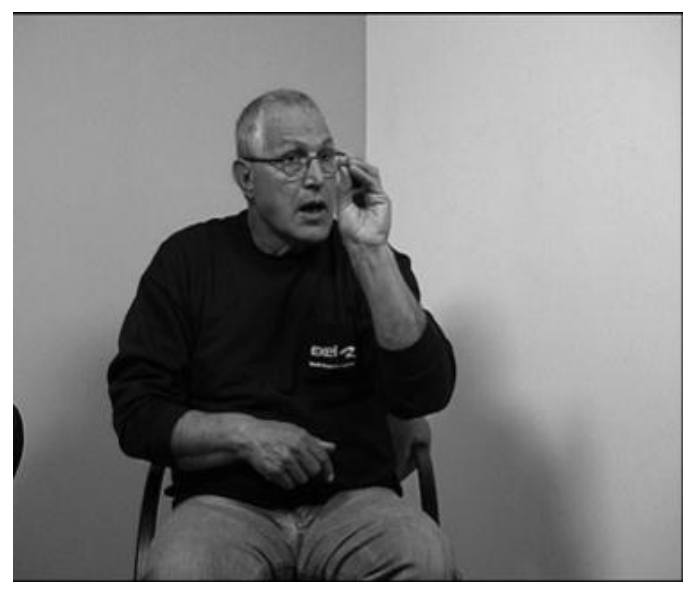

Figure 5.8 - The Number 5 in AJSL 
The numerals $6,7,8$ are used in relation to the numeral 5 . The non-dominant hand is the base, and the fingers of the dominant hand touch in repeated movement the fingertips of the non-dominant hand: index finger for 6 , index finger and middle finger for 7 , index, middle, and ring fingers for 8.

For the numeral 9, there are two possibilities: a. Use of the non-dominant hand for 5 with the pattern for 4 on the dominant hand (in repeated movements). b. Two open hands, one with five fingers extended and the other with four fingers, touching each other on the fingertips.

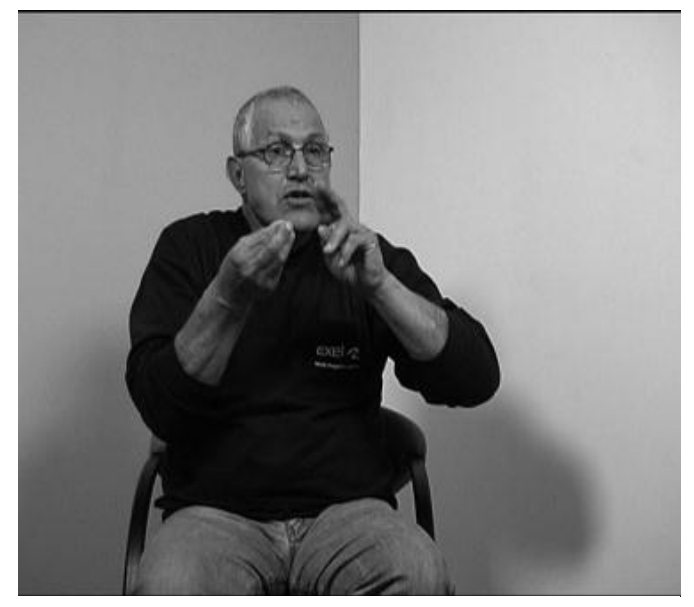

Figure 5.9 - The Number 7 in AJSL

The numeral 10 is signed as 5+5: the pattern for 5 in both hands (with or without repetitive motion).

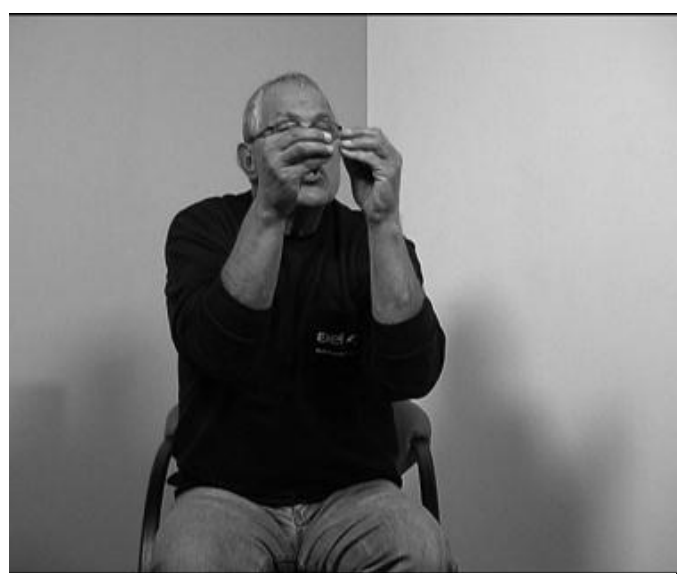

Figure 5.10 - The Number 10 in AJSL 

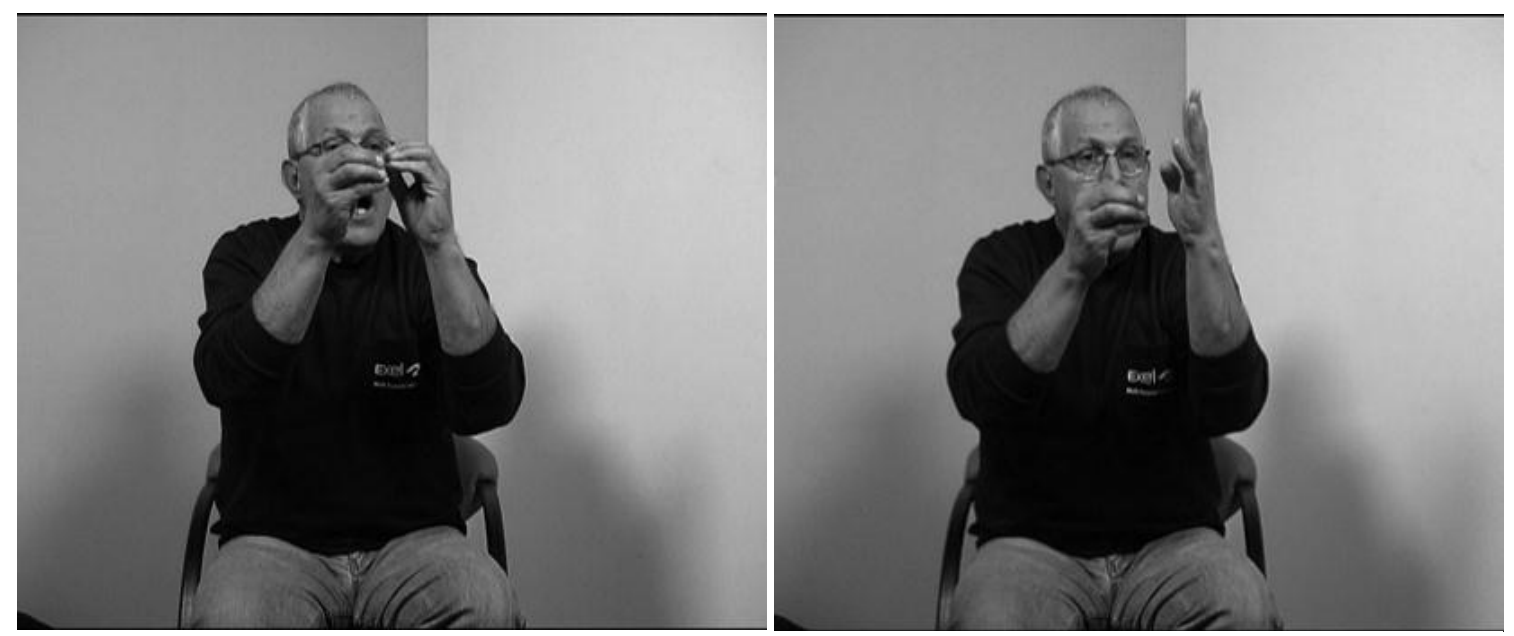

Figure 5.11 - The Number 14 in AJSL

11-19: The teens are composite signs: the sign for 10 , and then the number sign for the second digit.

The numeral 20 has two extended fingers (index and middle) with a repeated wrist movement. The numerals $30-50$ are signed in the same way, with three, four and five extended fingers respectively.

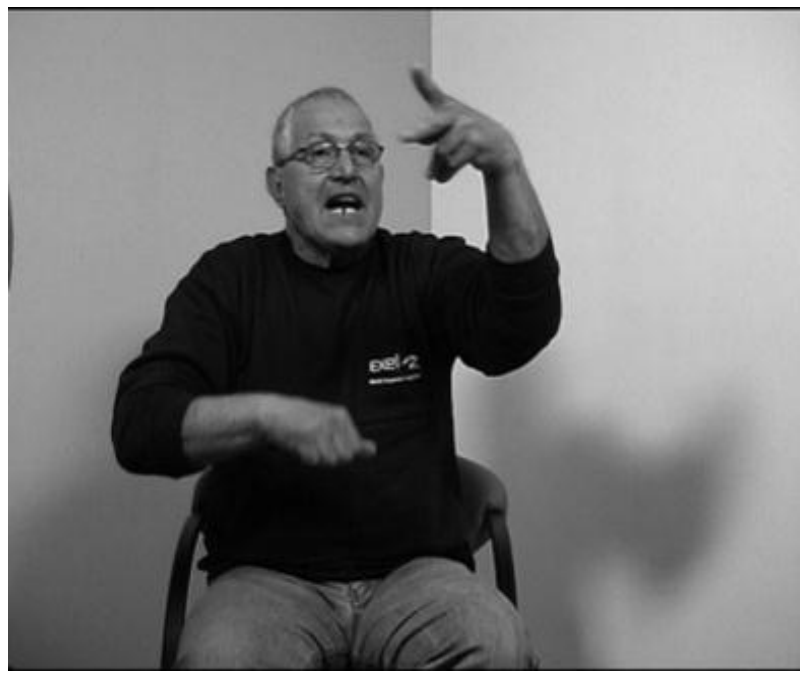

Figure 5.12 - The Number 20 in AJSL 
The numerals 60-90 are two handed: the non-dominant hand is an open 5 hand, and the dominant hand has 1-4 extended fingers, respectively. The movement is the same as in 20-50 above.

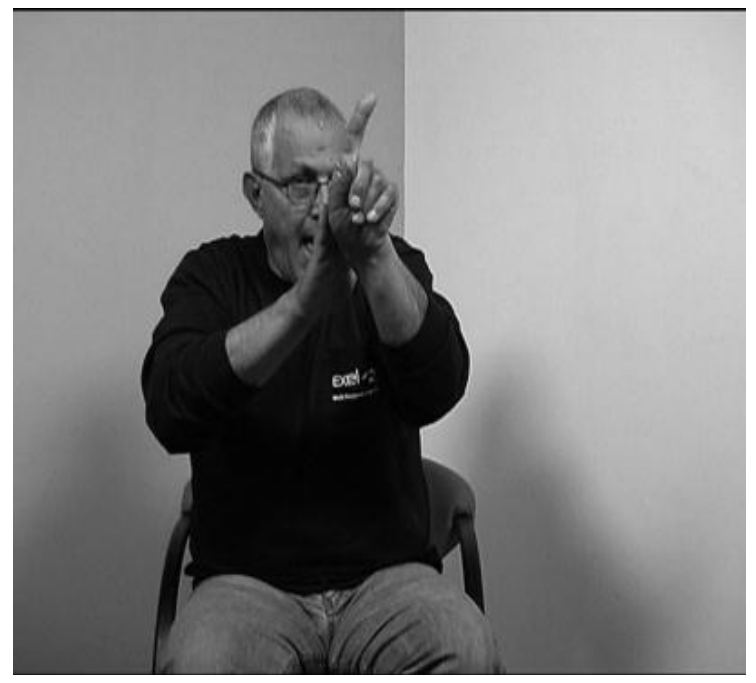

Figure 5.13 - The Number 100 in AJSL

Composite numerals (tens and ones, such as 29) are signed as composites, first the tens, then the ones.

The signs 100-500 are two handed: the non-dominant hand serves as the base, with a B handshape facing sideways; the dominant hand has one or more fingers extended (according to the amount of hundreds), and slides forward on the palm of the nondominant hand.

The main difference between the numeral system of AJSL and that of ISL is the form of the number 5: in AJSL it is a closed O handshape, in ISL - an open 5 (all fingers extended). The closed $O$ hand is the basis for the numerals 6-10, and for the teens (11-19). In larger numbers (tens and hundreds), this form is not used, and an open 5 hands is used instead (for 50 and 500), as in ISL. However, the movement of the tens and hundreds in the two languages is very different. In ISL there is a bending of the fingers in the tens and the hundreds. In AJSL, there is a wrist movement for the tens and a sliding movement for the 
hundreds. Therefore, although both systems are iconic, they are also very different, and do not seem to be related to each other.

\subsubsection{Family}

Signs indicating family members - "father", "mother", "boy", "girl" differ in the two languages. Below I describe the similarities and differences of these signs in more detail, and add some remarks as to their possible origins.

"Father": In AJSL, the sign for "father" is indicated by the sign "beard". The sign is believed to originate from the beards that the Algerian Jews wore. Therefore, the sign for "father" in AJSL was symbolized by a cultural/religious behaviour in the Algerian Jewish community, that of wearing a beard. According to traditional Jewish ritual laws (Halacha), it is forbidden for Jewish men to damage their side locks and beards with a razor or to shave in a form similar to that of idol-worshippers. This prohibition is based on the verse "You shall not round off the corner of your head, and you shall not destroy the edge of your beard" (Leviticus 19, 27). As a result of this it became customary for religious Jews to grow beards, and as a result of the custom, the sign of "father" is "beard". In ISL, "father" is signed by pointing to the forehead and to the chin. This sign also occurs in German Sign Language (although with an open hand rather than an extended index finger), and ISL could have borrowed it from GSL (Meir and Sandler 2008). In any case, its iconic origin is unclear.

"Mother": In AJSL, "mother" is signed by moving the side of the hand down the cheek, as a reminder of a headscarf. Religious Algerian Jewish women covered their heads with headscarves. According to Jewish ritual law, married women are obligated to cover their hair. In ISL, "mother" is signed by the pointing to the cheek. The origin of this sign is not clear. The cheeks are referred to in both languages, but since the origin of the ISL sign is not clear, it is not possible to claim that the signs reflect a similar concept. 

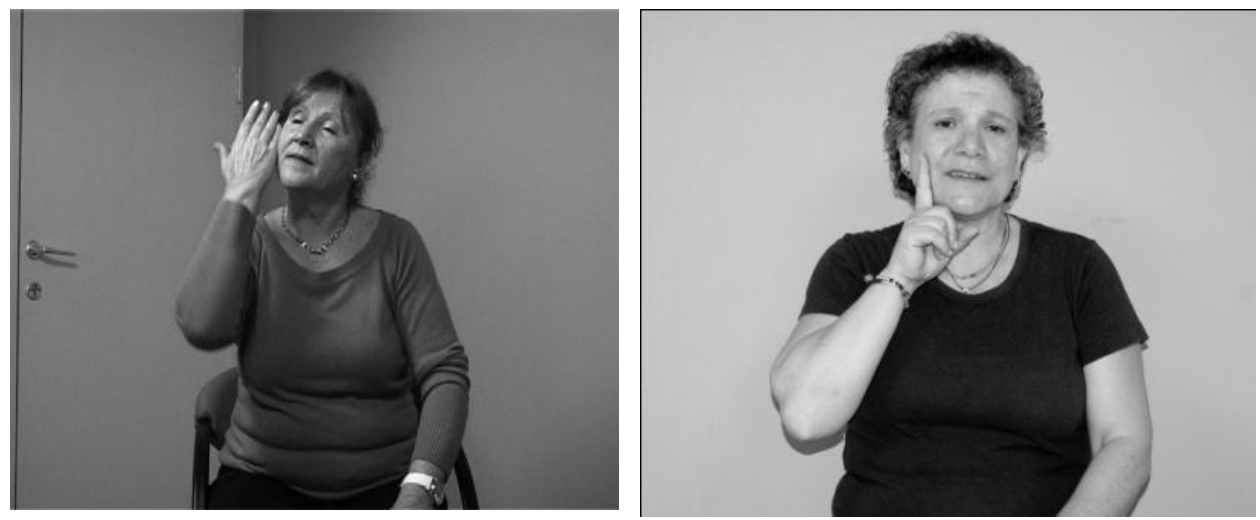

Figure 5.14 - The sign MOTHER in AJSL (right) and ISL (left)

"Boy": In AJSL, "boy" is signed according to the sex organ, the penis, to symbolize maleness. This sign also means "male". In ISL, "boy" is signed at the forehead. Here as well, the iconic origin of the ISL sign is unclear. Interestingly, the AJSL sign is used in several Arab communities in Israel and the vicinity, i.e., ABSL and Kfar Kasem (an Arab city in Israel with a large deaf community). In both AJSL and ISL, the sign for BOY is followed by the sign for CHILD when talking about a young boy.

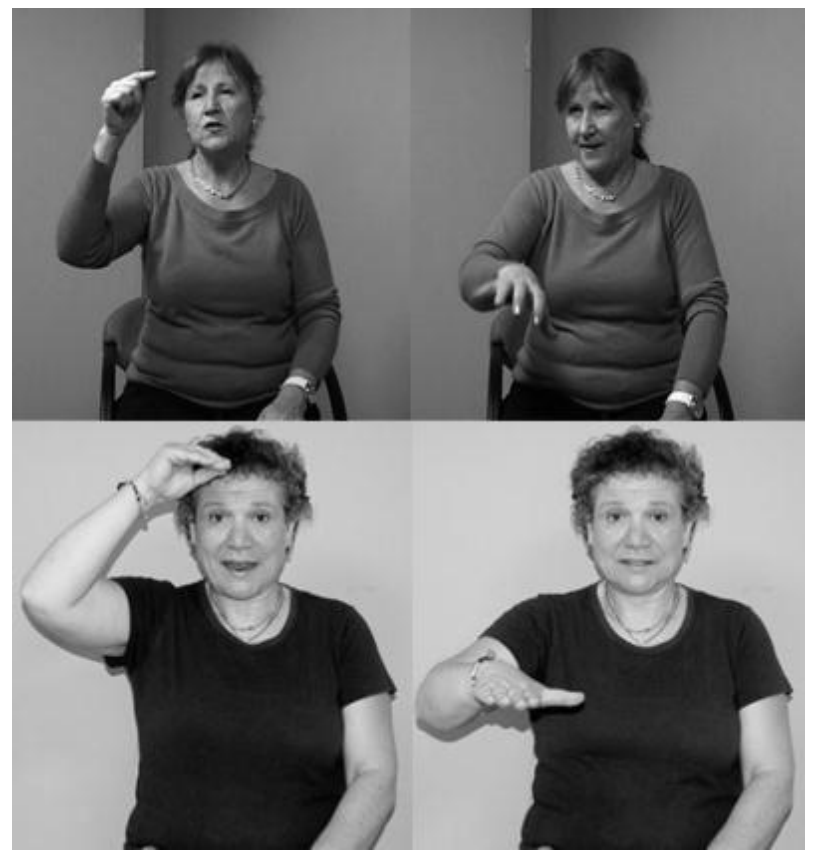

Figure 5.15 - The sign BOY in AJSL (top) and ISL (bottom) 
"Girl": When signing "girl" in AJSL, there is once again a strong reference to the sex organ, the vagina, as the defining symbol for femaleness, while in ISL the sign for 'female' has an F shape grasping the earlobe, as if referring to the earring. Here too, the sign for GIRL can be followed by the sign CHILD (in both languages), when referring to a young girl.

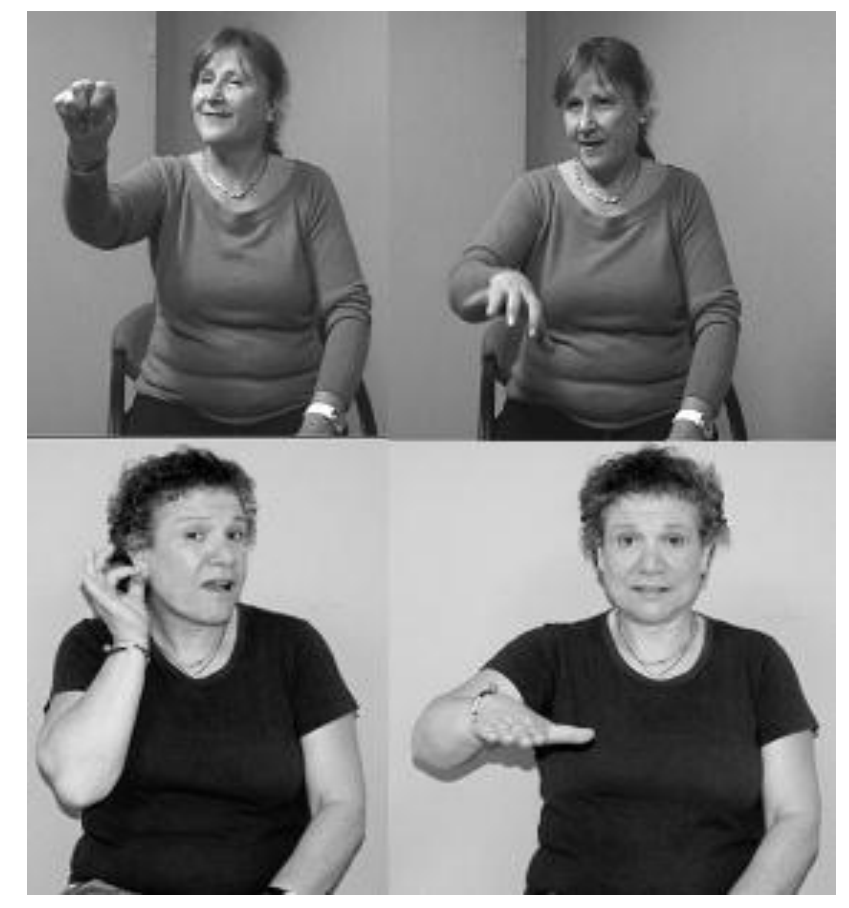

Figure 5.16 - The sign GIRL in AJSL (top) and ISL (bottom)

In the cases of both "boy" and "girl", the AJSL signs make use of an iconic symbol depicting the sex organ. In ISL such signs are considered unacceptable and rude; reference to a boy and a girl is done by using signs that are less iconic, and in any case, do not depict the genitalia in a straightforward manner.

"Wedding": In AJSL, "wedding" is signed by moving the tongue up and down in the mouth with the lips open, as if making loud vocal thrills, and shaking a "clawed" hand in front of the mouth while ululating with the tongue. At Algerian Jewish weddings, people would go into the streets and ululate in order to invite other residents to the wedding and to participate in the festivities. This custom is very common in many Arab societies and in Jewish communities in Arab countries, and indeed is the basis for the sign "wedding" in other sign languages in the region (e.g. ABSL). 
In ISL, "wedding" is signed by the fingers of the dominant hand touching the back of the non-dominant hand. A common folk etymology is that the sign placing the ring on the finger during the wedding ceremony, another common practice in weddings. However, this sign in ISL also means 'spouse' and 'married'. The AJSL sign for "wedding" does not have these extra meanings. AJSL has a different sign for 'spouse' - a brushing movement of the index finger on the nose.
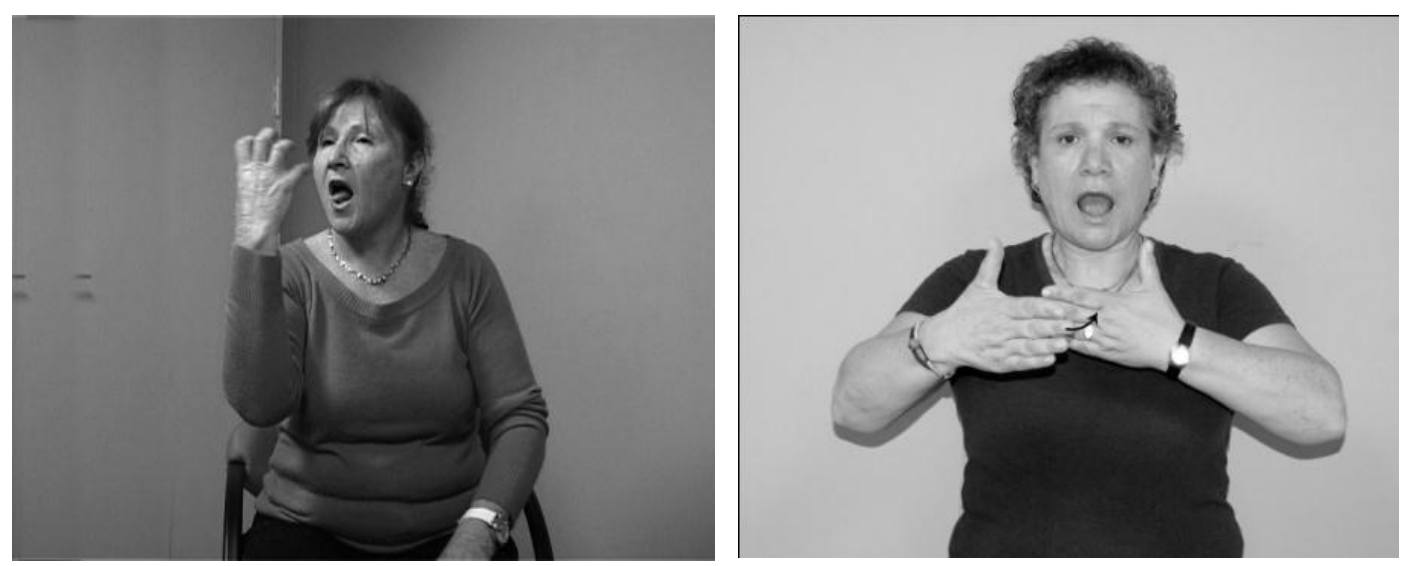

Figure 5.17 - The Sign WEDDING in AJSL (left) and ISL (right)

"Henna": The Henna ceremony is a custom in which the bride and groom paint their hands in reddish-orange colour made from henna leaves as a sign of good luck on the eve of their wedding. This ceremony is common among communities in the Middle East, North Africa and Western Asia. 

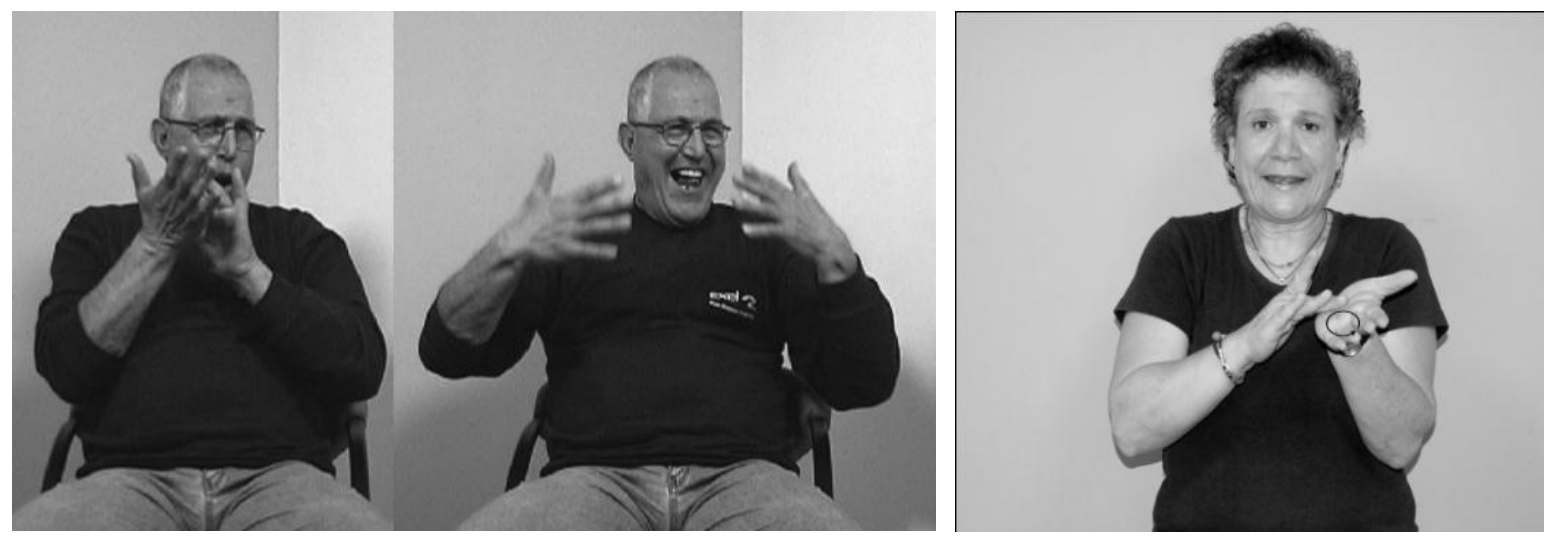

Figure 5.18 - The Sign for HENNA in AJSL (left) and ISL (right)

The sign for "henna" is similar in both languages - in both, "henna" is signed by miming the act of spreading henna on the palm of the hand.

\subsubsection{Jewish festivals}

Both the Algerian Jewish community and the general Jewish community in Israel celebrate the same religious festivals. Most of the customs that they practice are similar. However, Jewish communities in all parts of the world have developed special customs that are unique to them, and some of the signs for the festivals in AJSL reflect the community's distinct customs.
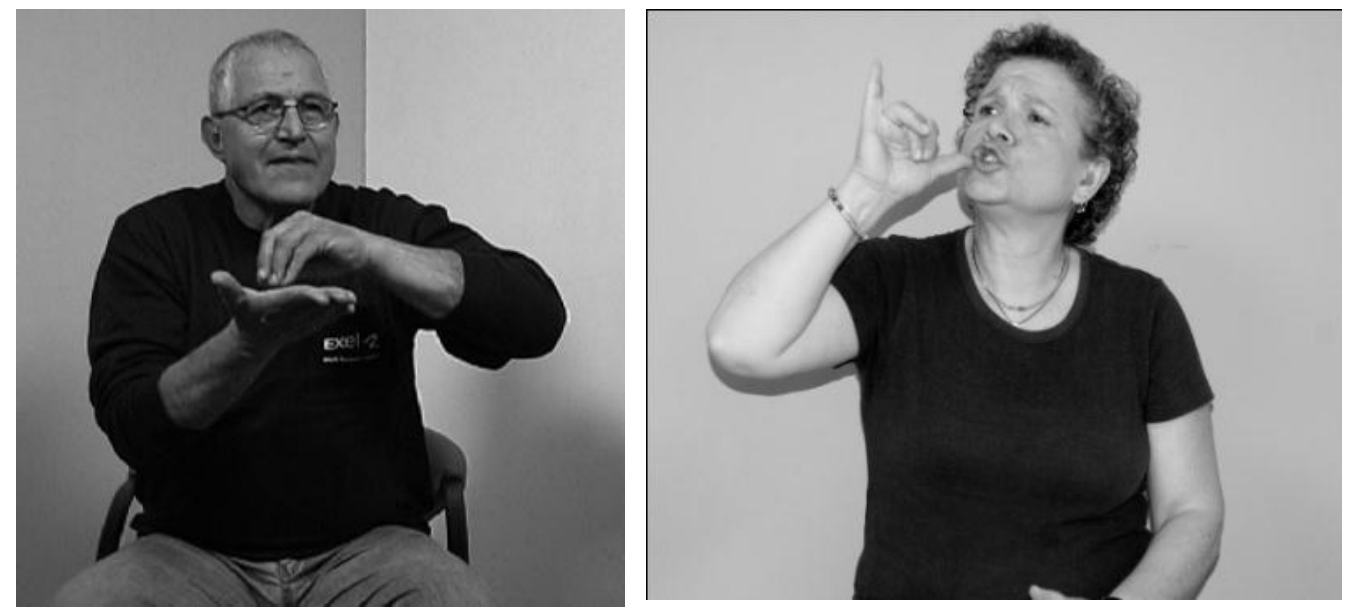

Figure 5.19 - The Sign ROSH HASHANA (Jewish New Year) in AJSL (left) and ISL 
"Rosh Hashanah" (Jewish New Year): Rosh Hashanah is an important Jewish holiday. In AJSL, "Rosh Hashanah" is signed by referencing the dipping of apple in honey, a custom practiced by all Jewish communities. In ISL, it is signed by iconic reference to another identifiable and important custom - the blowing of the Shofar (ram's horn). It is interesting that the Algerian community chose the sign of dipping apple in honey to symbolize Rosh Hashanah, while its Israeli counterpart chose shofar blowing, a more public custom executed in the synagogue. On the contrary, the custom of dipping apple in honey is carried out mainly in the home. An explanation for the symbolic difference in the signs in the two communities could be that in Israel the festival is celebrated and has more significance in the synagogue, and in Algeria it is considered more as a private family oriented festival.

"Yom Kippur" (Day of Atonement): Yom Kippur is one of the holiest days in the Jewish calendar. It is observed by praying and fasting. In AJSL the sign indicates closing of the mouth, while in ISL it is covering of the mouth. The two signs seem to reflect the same concept, but the hand patterns are different.
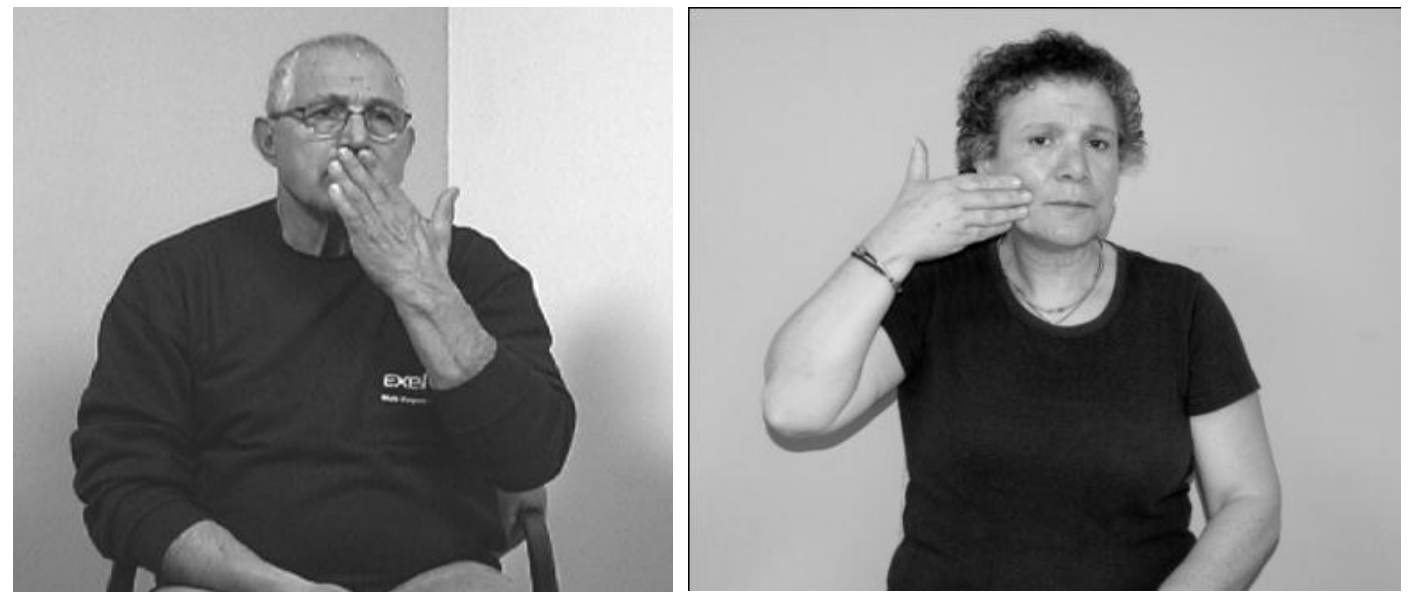

Figure 5.20 - The sign YOM KIPPUR (Day of Atonement) in AJSL (left) and ISL

"Hanukkah" (Festival of Lights): The main custom of this festival is the kindling of Hanukkah candles. In the Algerian community the sign for the festival looks like the act of "kindling of the candles". ISL uses several signs for "Hanukkah" depending on the period 
when the sign was developed:-1. "kindling of the candles" - this sign is identical to the one in AJSL. 2. "Hanukkah" - this sign describes the hanukkiah, a special candelabra that holds the Hanukkah candles. 3. "Hanukkah" - This is an initialized ${ }^{10}$ sign, in which the nondominant hand assumes the shape of the signed letter " $h$ " [for Hanukkah], while the dominant hand depicts a motion of kindling of candles.
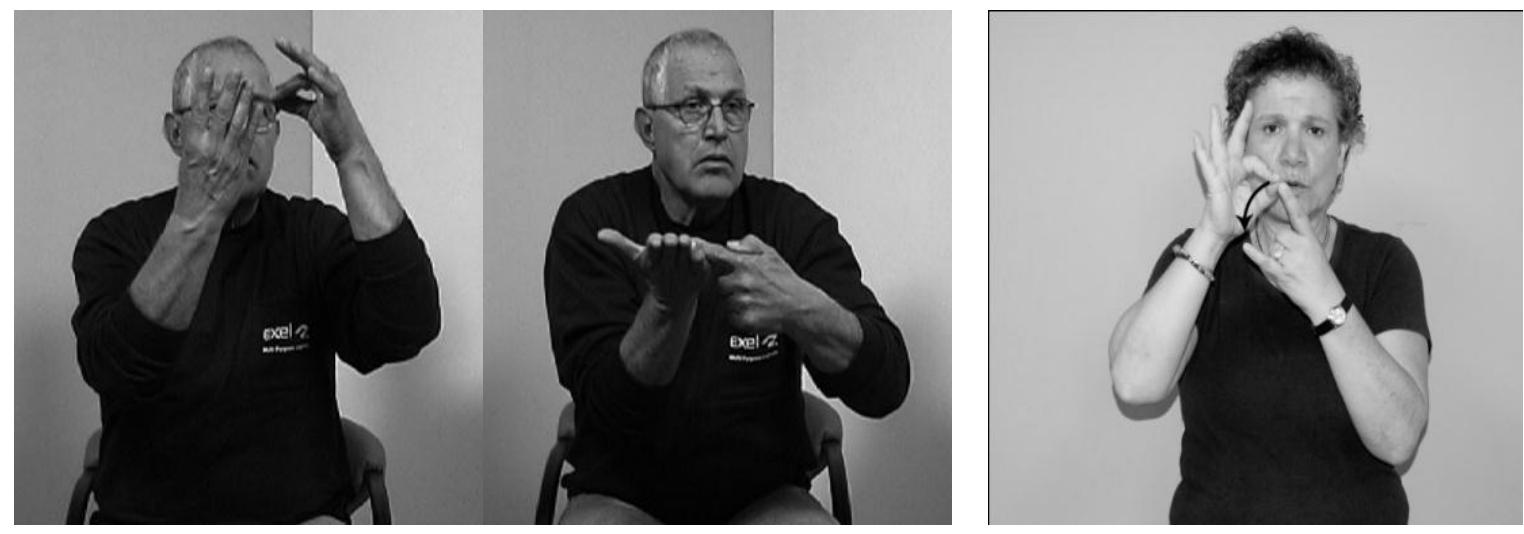

Figure 5.21 - The Sign for HANUKKAH (Festival of Lights) in AJSL (left) and ISL (right)

"Pessach" (Passover): The two dominant characteristics for this festival are the abstaining of eating leavened bread for seven days, and a ritual feast that takes place according to a specific order, night of order (leil seder), on the first night of the festival. Both languages reflect their own customs related to that night.

10 Initialized signs are a form of language borrowing. In this process, the handshape representing the fingerspelled initial of a word from the ambient spoken language (i.e. Hebrew) is combined with a movement and location to form a new sign. This often occurs when the sign language has one sign that represents concepts which are portrayed by multiple words in the ambient spoken language. Initialization is one means of differentiating between the signs. For more information on initialization in sign languages, see Meir \& Sandler (2008). 
The sign for "Passover" In AJSL reflects the Algerian custom of moving the special ceremonial plate of the feast over the participants' heads. Two signs exist for "Passover" in ISL - one is identical to one in AJSL and it may be that ISL adopted the sign from AJSL. The second sign is characterised by the custom of dipping the finger into the wine glass ten times to symbolise the "ten plagues".
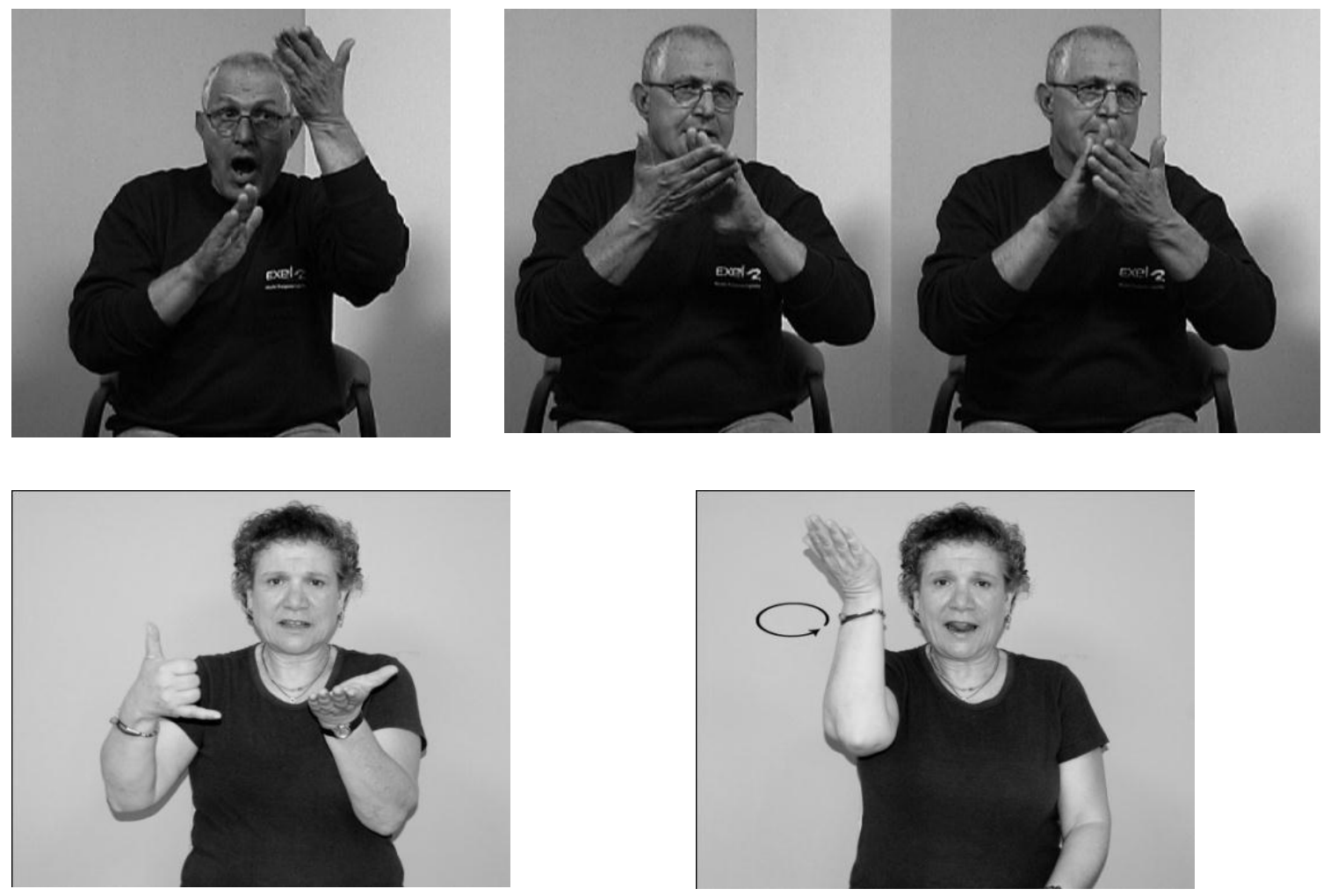

Figure 5.22 - Signs for PESSACH (Passover) in AJSL (top) and ISL (bottom)

"Shavuot" (Pentecost): The sign for "Shavuot" in AJSL is similar to the act of spilling water, reflecting a custom that was prevalent in North African communities - throwing waterbags on each other. In ISL, the sign indicates other customs - decorating the head with flower garlands and carrying baskets full of fruit on the shoulder. Recently, additional signs have entered the ISL lexicon, such as referencing the spilling of water. 

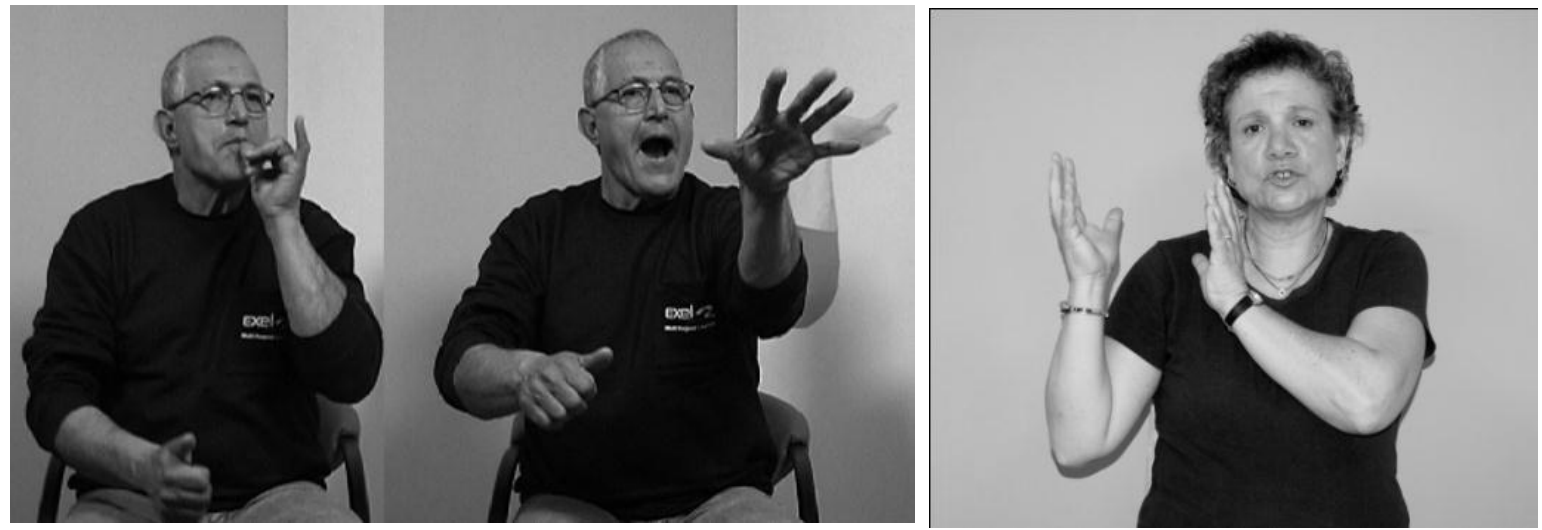

Figure 5.23 - The Sign for SHAVUOT (Pentecost) in AJSL (left) and ISL (right)

\subsubsection{Colours}

Signs for colours present an interesting challenge in the visual modality, since they don't have a visual property that can be directly represented iconically. There are two common sources for colour signs: (1) pointing to a body part that has characteristic colour. (2) signing the sign for an object that has a characteristic colour, such as 'sun' for yellow and 'grass' for green.

In AJSL, there are very few basic colour terms. If signers need to indicate a colour for which they do not have a sign, they point to an object in their vicinity with the relevant colour.

Colours that use body parts:
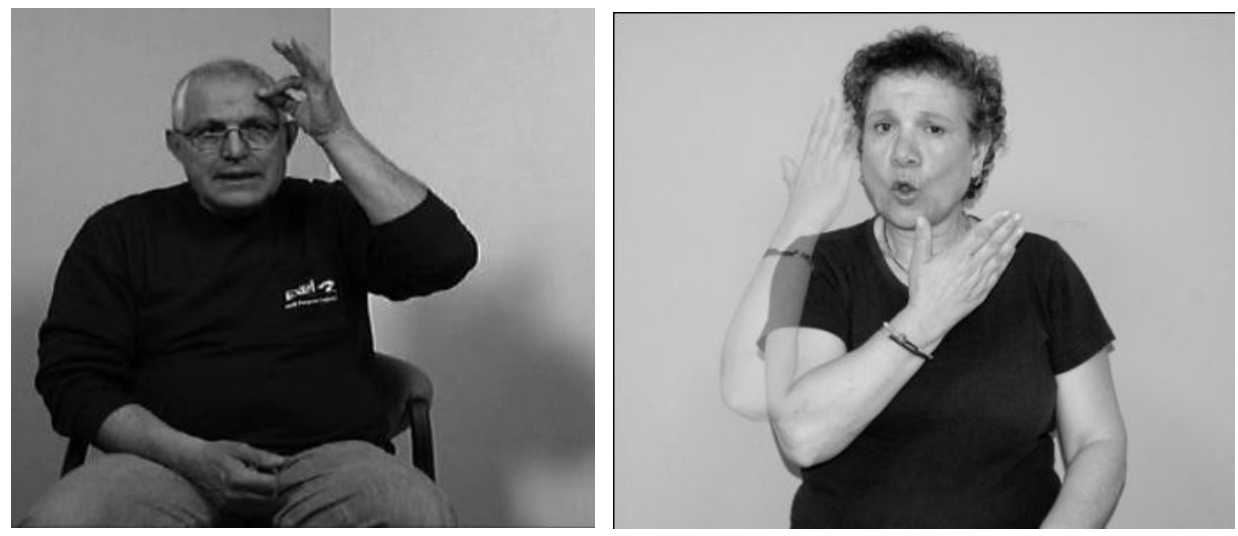

Figure 5.24 - The Sign BLACK in AJSL (left) and ISL (right) 
"Black": In AJSL there are two signs for "black': one is a grasping movement of the hair, the other is a two-handed sign with both hands using extended index and middle fingers, the dominant hand rubbing the back of the fingers of the non-dominant. The first sign is neutral, while the second sign has very strong negative connotations, and can be used to mean 'I don't want to see you ever again'.

In ISL, BLACK is signed with an open hand moving over the face. The iconic origin is less clear here, but once more, it is notable that German Sign Language uses the same sign.
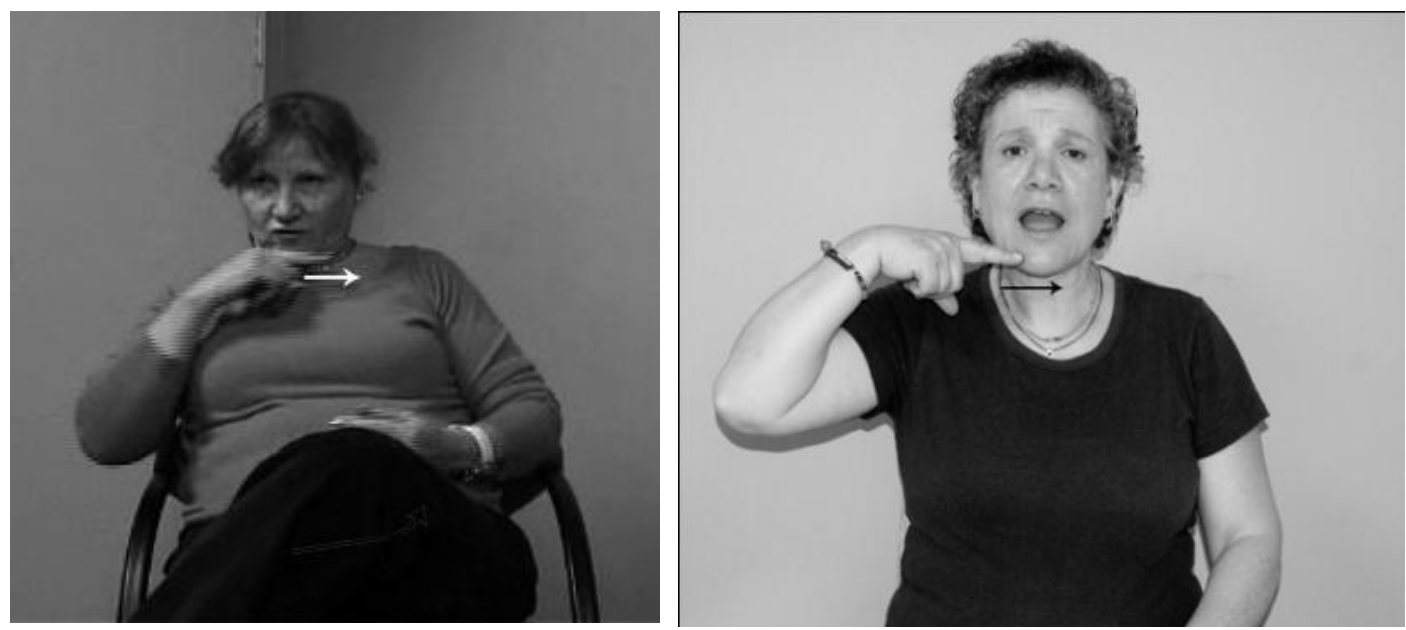

Figure 5.25 - The Sign RED in AJSL (left) and ISL (right)

"Red": Both AJSL and ISL use the mouth as the basis for the sign for "red"; there is an emphasis on the lips, a common motif for the colour red.
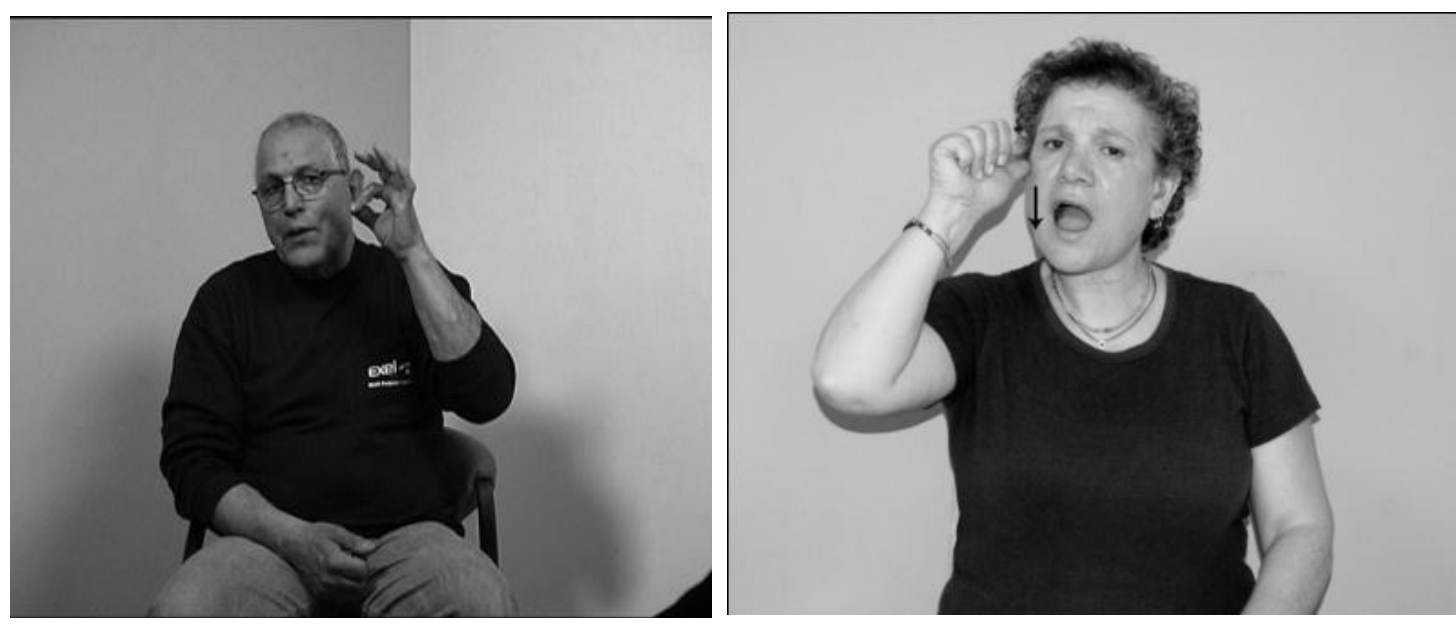

Figure 5.26 - The Sign WHITE in AJSL (left) and ISL (right) 
"White": In AJSL, the sign is signed in neutral space. The origin of the sign is unclear. In ISL the sign is signed on the cheek, maybe referring to the pale colour of the cheek. The AJSL sign is used also to mean 'clean' and 'new'.

Colour signs that refer to objects with a distinct colour:
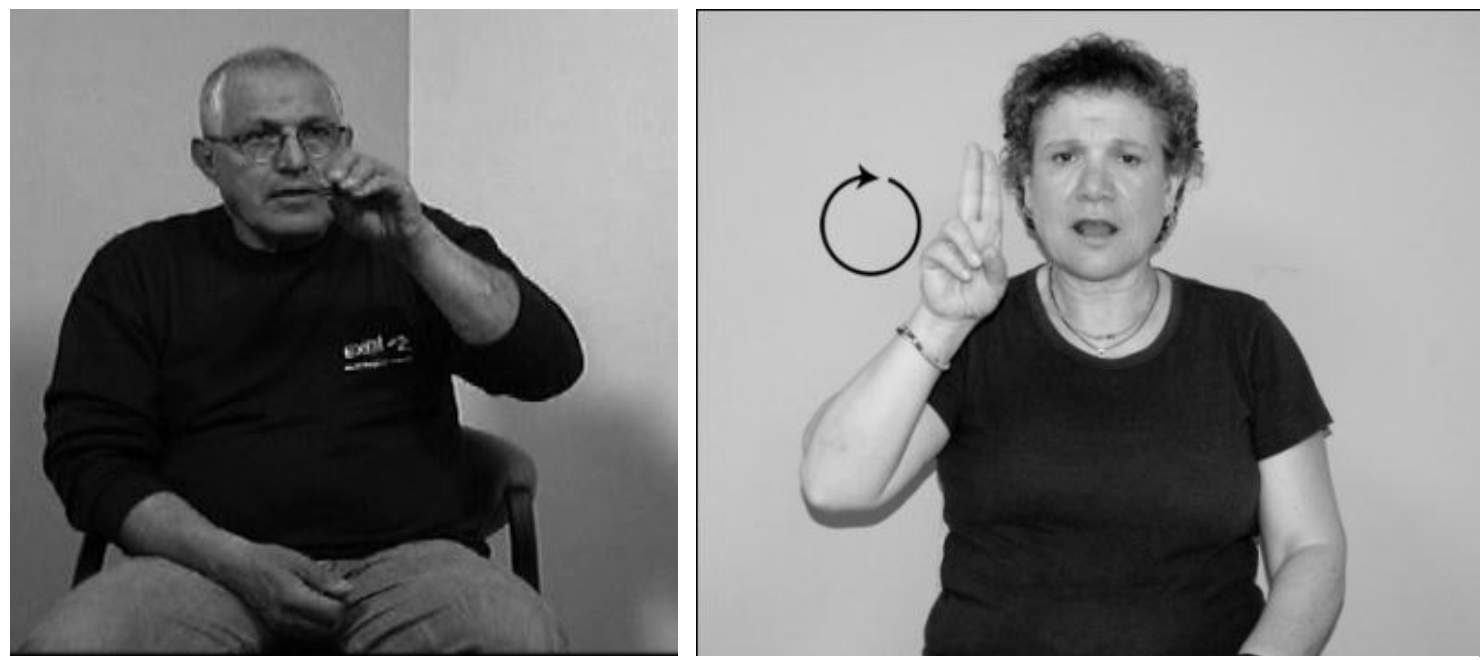

Figure 5.27 - The Sign BLUE in AJSL (left) and ISL (right)

"Blue": In AJSL, the sign might refer to the crushing to powder a substance used for blue eye shadow. In ISL, the sign is signed in the upper signing space, maybe referring to the colour of the sky.
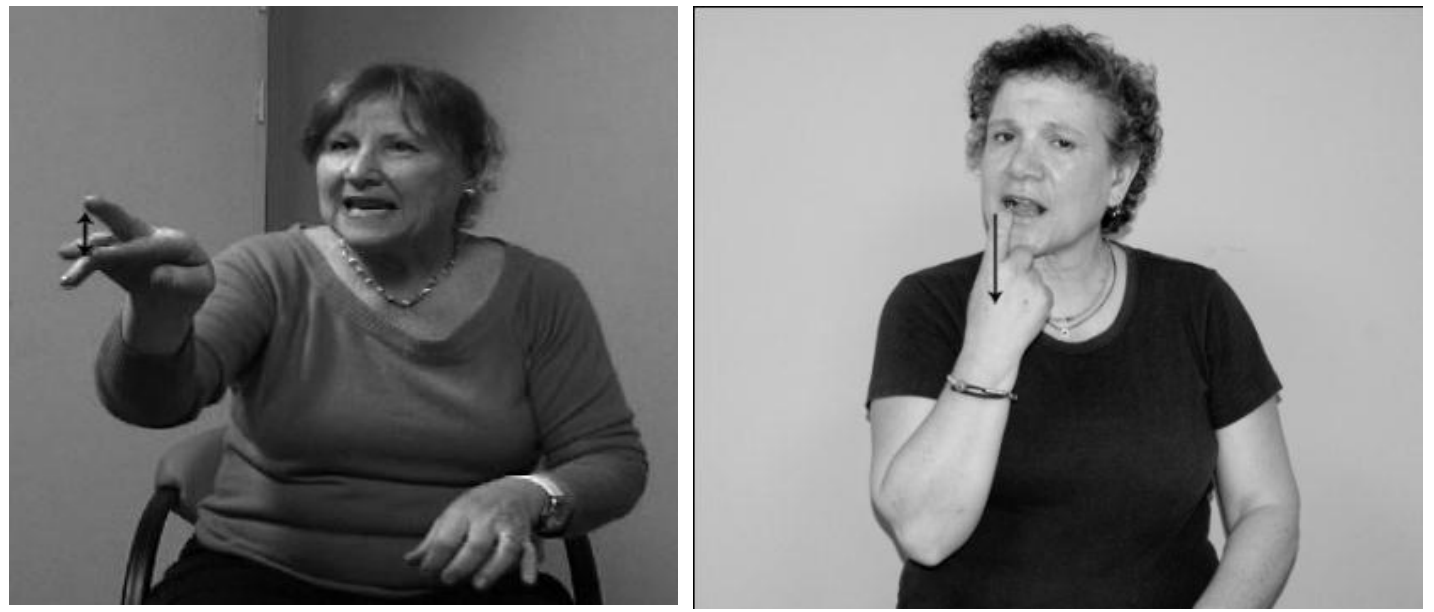

Figure 5.28 - The Sign ORANGE in AJSL (left) and ISL (right) 
"Orange": AJSL uses the sign for 'carrot' to refer to the colour orange. ISL uses an initialized word, whose handshape represents the letter $C$, which is the first letter in the Hebrew word 'orange'. There is no resemblance between the signing of this colour in the two languages since they each originate from a completely different source.
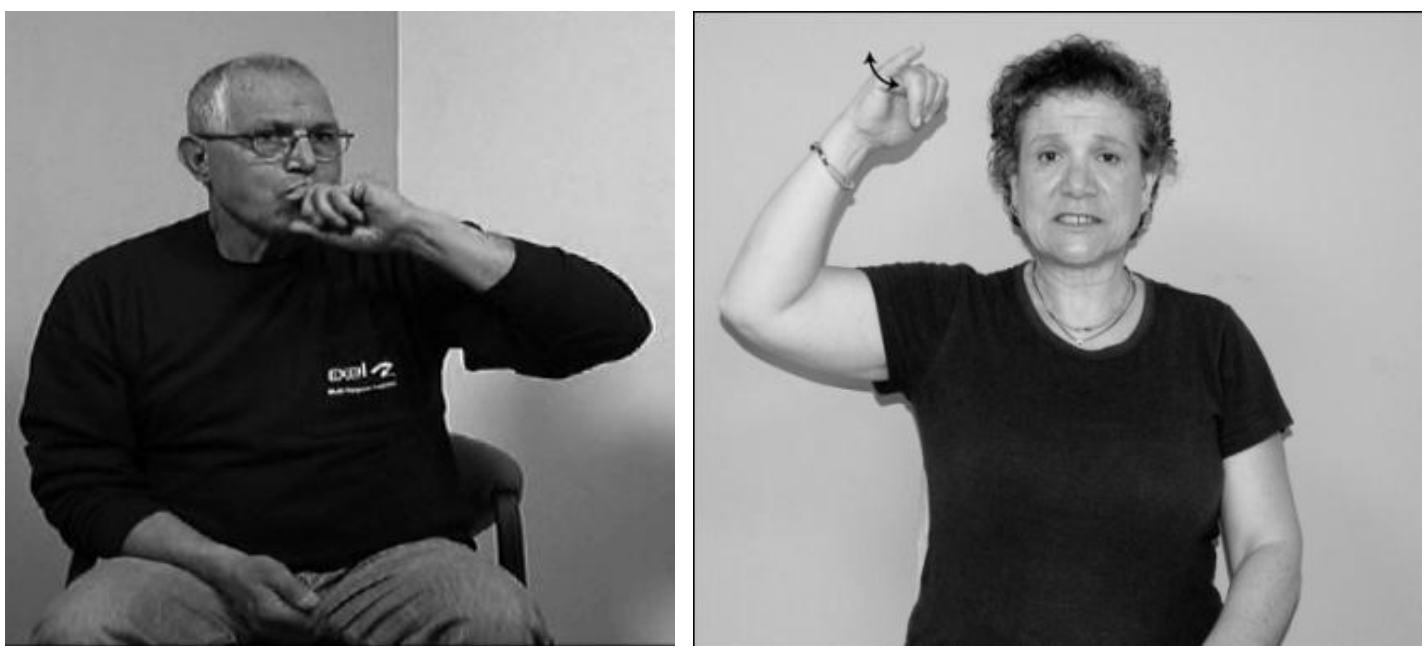

Figure 5.29 - The Sign YELLOW in AJSL (left) and ISL (right)

"Yellow": AJSL uses the sign for 'lemon' to indicate the colour yellow. ISL uses a sign whose origin is unclear.

In general, it appears that in AJSL, the iconic origins of the colour signs are much more apparent (except for the sign 'white'); they are based either on a body part with a predominant colour, or they use a sign for an object with a predominant colour. The origins of the ISL colour terms are less clear, but there is a larger colour vocabulary in the language. There are colour terms in ISL that have no counterpart in AJSL, such as 'pink', 'purple', 'green', 'brown'. 


\subsubsection{Food}

Every society has its own special foods, and therefore an examination of the vocabulary representing foods can reveal important aspects of community life. Here I relate three foods common in both cultures: bread, water, couscous.

"Bread": AJSL - the sign indicates the size of the particular kind of bread. For bigger breads, the palms of the hands move further apart. In ISL - the sign indicates the shape of a loaf of bread.

The signs in the two languages represent the bread shapes in two cultures. In Algeria, there are usually different sizes of breads, and the sign is derived from this fact - e.g. big bread, smaller bread, and very small bread. Israeli society refers to the different shapes or types of bread - e.g. bread loaves, pitas, buns - and for every type of bread there is a unique sign, reflecting the rich variety of breads in Israel. 

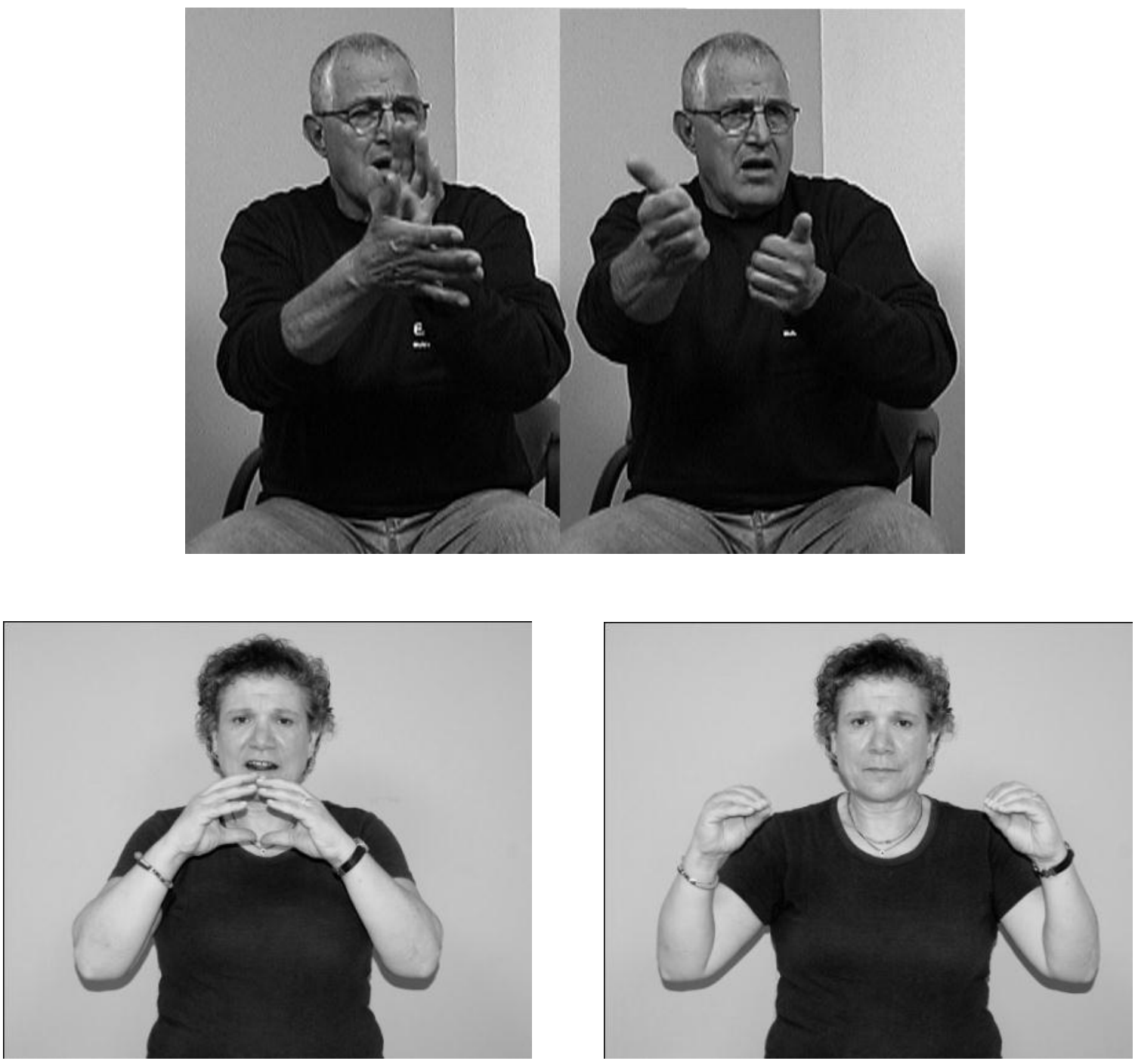

Figure 5.30 - The Sign BREAD in AJSL (top) and Two Signs for BREAD in ISL (bottom)

"Couscous": AJSL and ISL- rubbing of couscous

The sign is identical in both languages and indicates the main action of preparing couscous. Couscous is food that characterizes Oriental groups and it seems that the method of preparation of couscous is similar across cultures, and was selected by both AJSL and ISL as the most salient aspect of it. 
"Water": In AJSL water is signed as drinking from the cupped palm of the hand, as if one is drinking water from a well. It is interesting that a similar sign for "water" is found in many sign languages of Arab countries, where people drank water from the wells. Consequently, there is a resemblance between AJSL and Arab sign languages for the sign for "water" owing to their similar cultural backgrounds.
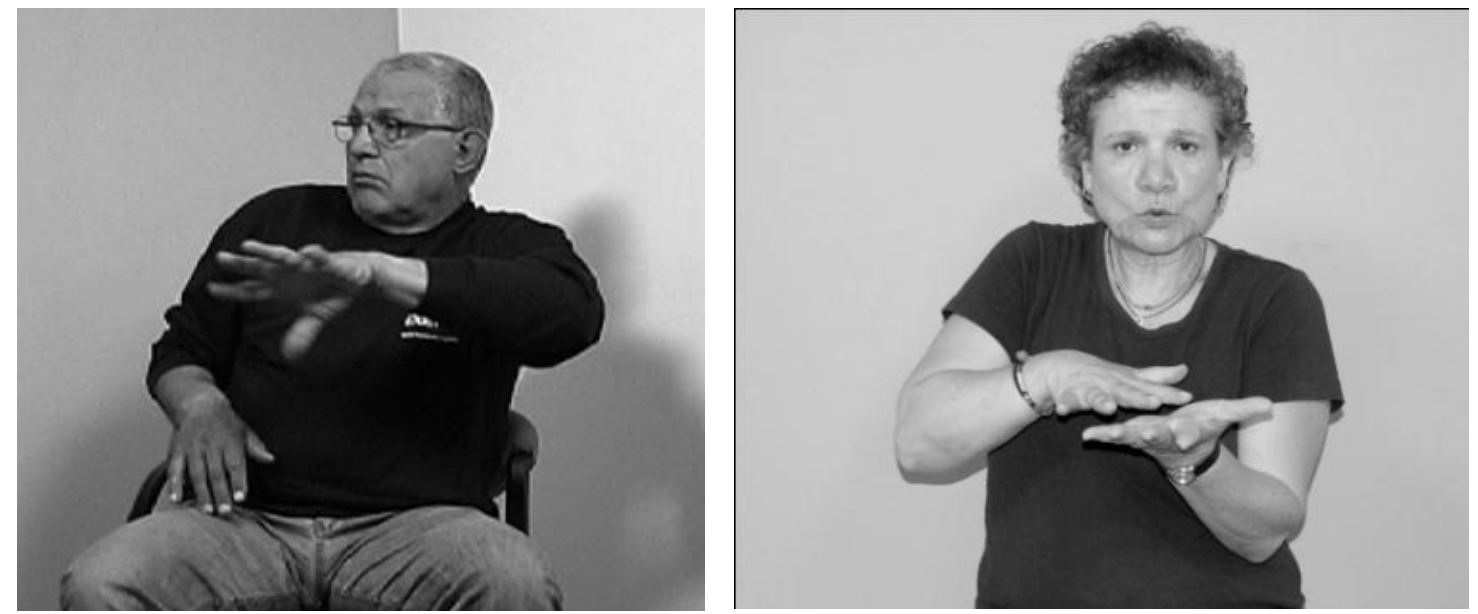

Figure 5.31 - The Sign COUSCOUS in AJSL (left) and ISL (right)
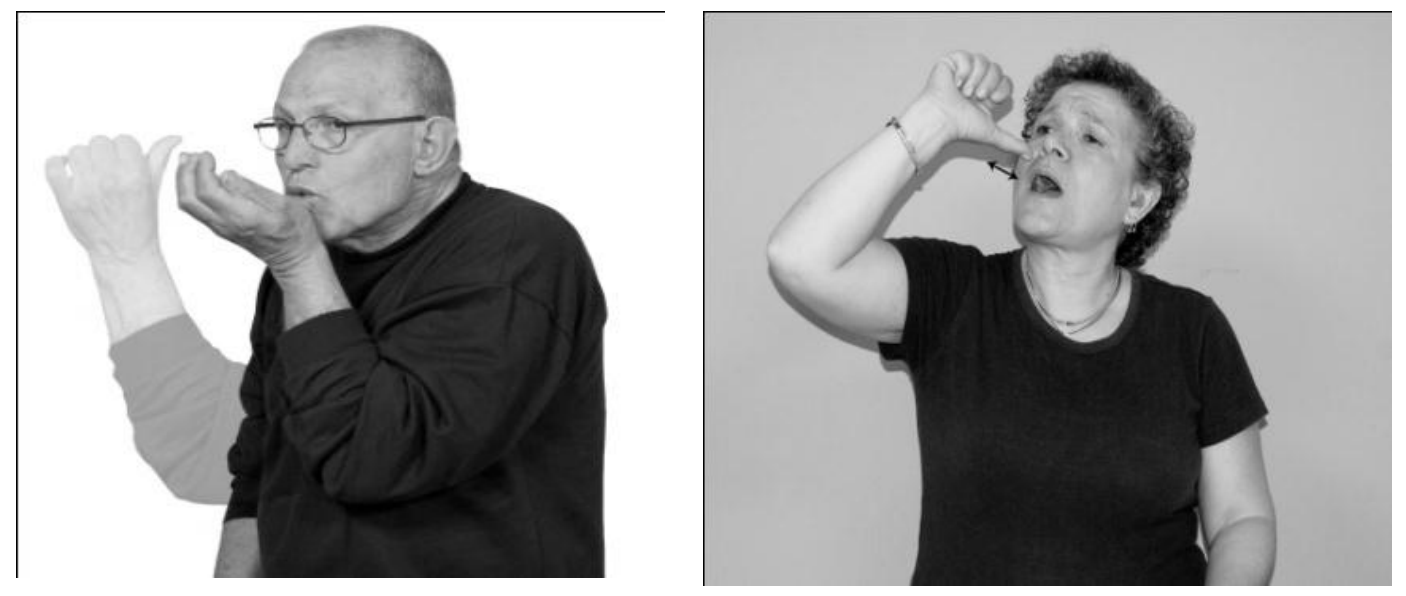

Figure 5.32 - The Sign WATER in AJSL (left) and ISL (right) 
Water in ISL is signed by a drinking action, from a cup or bottle. It is not customary for the contemporary Jewish community in Israel to drink water from wells thus ISL does not use the concept of "drinking from a well".

\subsection{6 'Deaf' and 'hearing'}

Different societies have different attitudes and relations to the deaf person: some cultures focus on loss of hearing, while other cultures focus on the lack of speech. The hearing person is perceived as a person with an ability - an ability to hear or ability to talk. The signs for "deaf" and "hearing" in both AJSL and in ISL reflect this perception.

"Deaf": AJSL signs "deaf" as "cut off the tongue", giving the impression that deaf people cannot speak. It is interesting to note that several Arab sign languages, as well as Alipur Sign Language - another village sign language, located in South India - express the sign for "deaf" in a similar way (Panda 2012). These signs do not highlight the ear as a damaged organ as is the case in many other sign languages, and it can be inferred that the background for this sign lies in the cultural conception of deafness - the deaf are considered unable to speak rather than unable to hear. It is possible that absence of schools for the deaf and lack of opportunities to teach the deaf to speak led to perception that the deaf person has been "cut in the tongue".
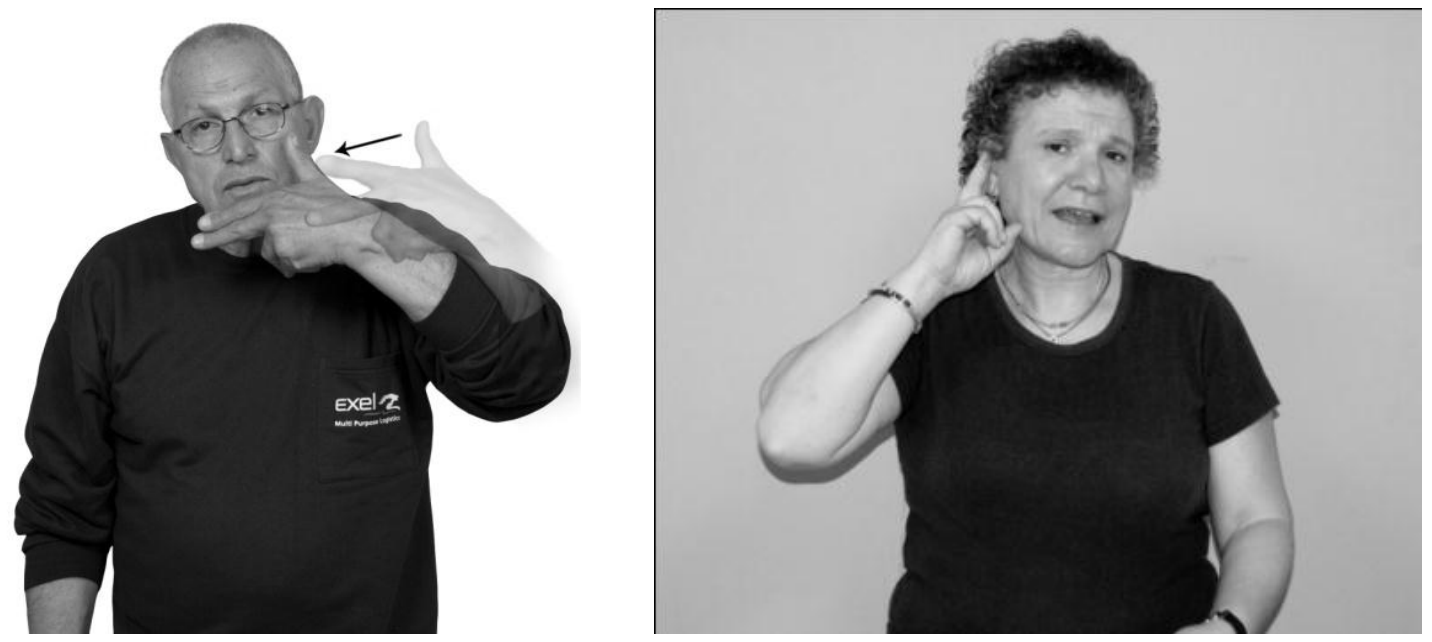

Figure 5.33 - The Sign DEAF in AJSL (left) and ISL (right) 
The ISL sign for "deaf" first touches the ear and then the mouth, showing that the person does not hear and does not speak. In the past, the society where ISL developed perceived deaf people as being "deaf and dumb". Though it is no longer considered politically correct to use this expression when referring to deaf people, the sign for DEAF, which is built on this perception, has persisted in the language.
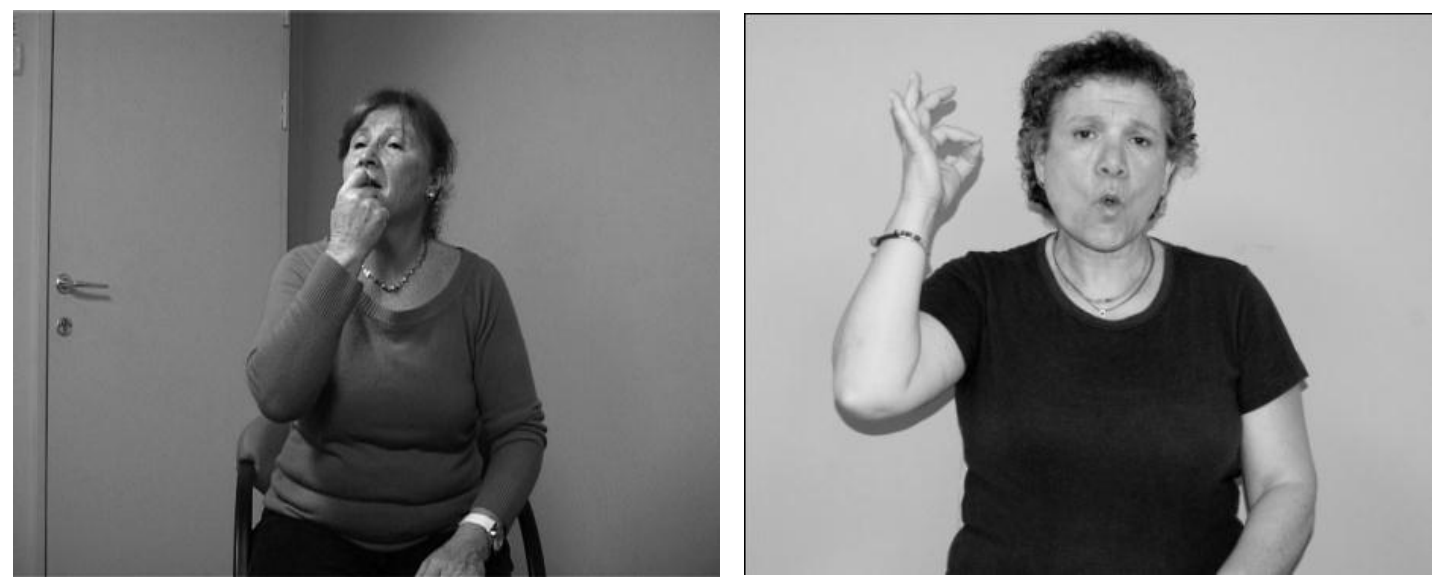

Figure 5.34 - The Sign HEARING in AJSL (left) and ISL (right)

"Hearing": In AJSL, "hearing" is signed by pointing to the mouth and describing speech action. This sign expresses the ability of the hearing person to speak, contrasting the sign "deaf" as an inability to speak - "cut the tongue".

In ISL, in contrast to AJSL, "hearing" is signed by pointing to the ear - to show that a person can hear. There is no reference to speech.

\subsection{Conclusion}

In this chapter I looked into the AJSL lexicon, and compared it to ISL. The comparison of 300 signs in both languages indicates that the lexicons of the two languages are different, and therefore we might conclude that the two languages are independent, and show no evidence for historical connection between them. Moreover, the low percentage of 
shared vocabulary indicates that AJSL has persisted as an independent language alongside ISL for about 50 years now.

When comparing signs in particular semantic domains, such as numbers, colours, kinship terms and food, some interesting differences arise. It seems that in many cases, the iconic origins of the signs are more apparent in AJSL than in ISL. This is most evident in colour terms, kinship terms and also in the sign for 'deaf'. Some of these iconic signs represent directly sex organs, and are considered impolite and even obscene to ISL signers, yet they are completely acceptable in AJSL, pointing to a difference in cultural norms. Many of the AJSL signs make use of metonymy, that is, there is an iconic motivation between the sign and a part of the concept that the sign conveys. For instance, the AJSL sign for "Hanukkah" referenced the lighting of candles, an important aspect of celebrating Hanukkah. Metonymy is a very common process in sign languages (cf. Taub 2001 on various types of iconicity in ASL).

In many cases, the iconicity of the AJSL signs reflects local customs that are almost on the verge of disappearing. Many of the customs of Jewish holidays, which were practiced in Algeria, are gradually falling out of use. The signs, then, form a live evidence for customs that are disappearing. As long as AJSL survives, the memory of these customs will survive in its signs. 


\section{CHAPTER 6: CONCLUSION}

\subsection{Summary of research findings}

In this chapter, I summarize this thesis and the conclusions derived from its studies. This research provides the first documentation of the sign language of a particular village community - the Algerian Jewish community from Ghardaia and the sign language that developed there. I became interested in studying this topic because of my personal background - being Algerian born and a daughter of an Algerian family consisting of deaf and hearing children; being acquainted with the Algerian Jewish deaf community in Israel; working in sign language research in general and village sign language research in particular; and being aware of the possibility of the extinction of Algerian Jewish Sign Language - all these elements led me to research this field.

The two central questions that I asked at the beginning of my research were:

1. What was the sociolinguistic situation of Algerian Jewish Sign Language (AJSL) before and after the migration of the AJSL community to Israel?

2. To what extent is AJSL now at risk of becoming displaced by Israeli Sign Language?

In order to answer these questions, I conducted interviews with nine members of the community, gathering information regarding personal details and their lives in Algeria and in Israel. I also consulted literary sources for obtaining information regarding the historical background of the Algerian Jewish community. As a first step towards the documentation of the language, I requested some of the interviewees to translate an initial word list consisting of 300 words into AJSL. Methodological consideration were discussed in chapter 2. 
The historical investigation revealed that AJSL was created within Jewish Algerian families in Ghardaia and other towns in the area, in which high numbers of deaf children were born. The need of the hearing and deaf family members to communicate with each other naturally gave rise to a sign language, Algerian Jewish Sign Language, as has happened in other small communities, such as Desa Kolok, Ban Khor and Adamarobe (see Section 1.3 for descriptions of these signing communities). This language was used by both deaf and hearing members of the community. Deaf Algerians learnt AJSL as their first language and the hearing people learnt it as second language. The communication between the deaf and hearing family members was fluent. They used the language to communicate about everyday issues, such as family life and social life. It was convenient for the family members to communicate in sign language, and the deaf did not feel exceptional. AJSL was a community characteristics that was shared by deaf and hearing. It was the creation of deaf and hearing members of the community together. For example, one interviewee (ES) reported that some AJSL signs were created by hearing people. Again, this characterizes other village sign languages too. The term "shared signing community" (Kisch 2008) refers to this special social setting (see Chapter 1). As in other shared signing communities, the deaf did not form a separate community. The common language between deaf and hearing members enabled the integration of deaf people in the larger hearing community.

These socio-linguistic characteristics changed drastically when the Jewish community left Ghardaia, and migrated to other countries, mainly France and Israel. In this thesis, I focused on the part of the community that migrated to Israel. The AJSL community of users in France is a topic that deserves future investigation, as I suggest in section 6.3.

Chapters 3 and 4 described the AJSL-using communities in Ghardaia and in Israel. A comparison between these two communities reveals that rhey differ significantly, both in terms of their social characteristics and practices and in terms of their linguistic characteristics.

In Algeria, the Jewish community of Ghardaia consisted of both hearing and deaf members. AJSL was used as a second language of this community. Both deaf and hearing 
users were sign monolinguals in AJSL. The hearing members used the local spoken Arabic dialect as their main language, and some of them used other languages such as French (e.g. in the schooling system) and Hebrew (for religious practices). In Israel, AJSL continued to be used by both deaf and hearing people. However, most deaf people became part of the Israeli Deaf community and acquired the dominant sign language, ISL. Hence deaf AJSL users became sign bilingual, whereas hearing users remained sign monolingual.

In Algeria, the Jewish community was a closed community. All community members shared a space with clear boundaries, the walls surrounding the mella. Most social interactions of members of the community, both hearing and deaf, were within the community. Though there were some social connections with Jewish communities in other places in Algeria (such as Aflou) and some financial interactions with the Muslim community of Ghardaia, the community within the mella was self-contained (Nagel 2004). Marriage was strictly within the community, for both deaf and hearing. Once in Israel, the Ghardaia community disintegrated. They were no longer settled in one place, but were rather located in several places in the country. Social interactions were not restricted to members of this community. Rather, the hearing people found it necessary to interact with people with other ethnic origins, - people in the various authoritative functions, in the job market and in the educational system. The deaf immigrants found themselves drawn into another sub-community in Israel, the Deaf community. The encounter with the Deaf community entailed several changes: first, deaf Algerians met deaf people not from their own community, who used another language. Second, the encounter with the Deaf community drew a line between deaf and hearing members of the Ghardaia community: deaf people formed a connection with a community that was not available to the hearing members. Hearing and deaf AJSL users did not share all of their social interactions and connections any more. This also caused a major difference in the marriage patterns: deaf Algerians married other deaf people, not necessarily from Algeria. Finally, deaf members were in contact with another sign langue, ISL, and became sign bilingual, unlike hearing AJSL users. In Israel, then, as opposed to Algeria, there were many differences between deaf and hearing AJSL users. 
The socio-linguistic changes in the status of deaf Algerians is represented graphically in Figure 6.1:

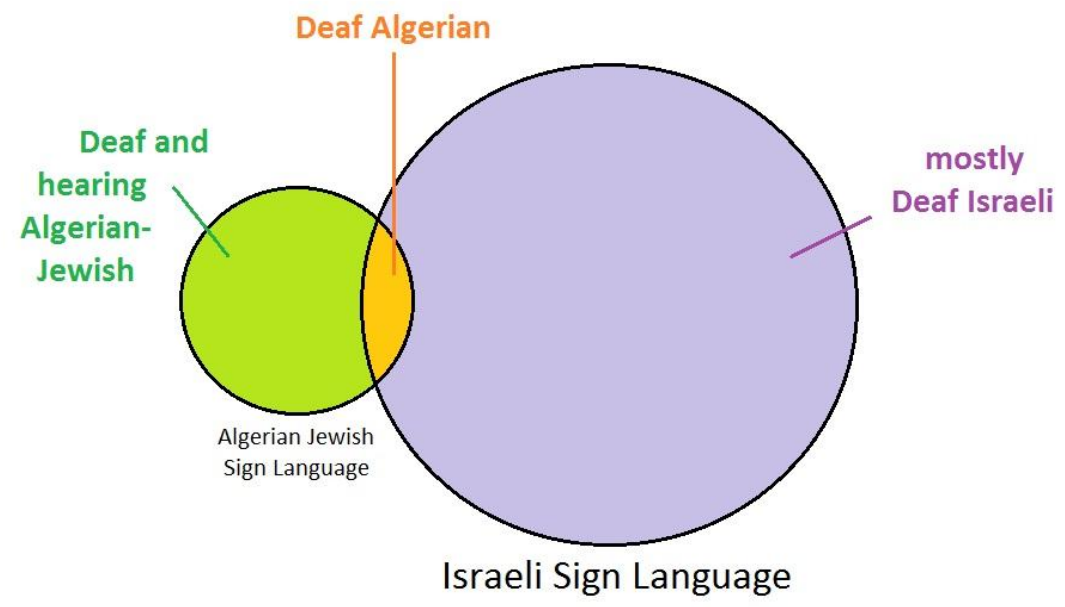

Figure 6.1: The changing socio-linguistic situation of deaf AJSL users in Israel

The illustration in Figure 6.1 has two larger communities: the Israeli Deaf community and the community of migrants from Ghardaia. The Israeli Deaf community consists mainly of deaf members, who use ISL as their main means of communication. The Ghardaian immigrant community consists of both hearing and deaf members. They share a language - AJSL. However, the hearing members are speakers of Arabic, French and Hebrew. That is, they are multilingual in terms of spoken languages, and monolingual in terms of sign languages. The deaf members of the Algerian community belong to both communities: they are part of the Algerian community and part of the Israeli Deaf community. They are sign bilingual, using both sign languages in their daily communication, though for different purposes and with different people. AJSL is restricted to communication with members of the Algerian community, while ISL is used for communication with Deaf Israelis. This bilingualism caused a change not only in language practices, but also in language attitudes.

In Algeria as well as in Israel, deafness was not a taboo, and sign language was not banned. However, in Israel, AJSL was not the only sign language in use, and it was looked down upon by users of the dominant sign language, ISL. So AJSL became stigmatized not 
by hearing people, but rather by deaf people, members of the Israeli Deaf community. Therefore, while in Algeria AJSL was used in every social domain where deaf people were involved, in Israel AJSL became confined to the nuclear families of Algerian origin. In Israel, any public resources towards a sign language were geared towards ISL. This includes the use of signing in the education system, the establishment of courses to learn ISL, the publication of dictionaries (Cohen, Namir and Schlesinger 1977; Namir, Sella, Rimor and Schlesinger 1977) and later the establishment of interpreters' training courses. AJSL was marginalized, and did not enjoy any prestige at all.

These social and linguistic changes affected also the transmission of AJSL. In Algeria, AJSL was transmitted from one generation to another, within the family. As I learned from the interviews, hearing members played an important role in this intergenerational transmission. Deaf children often learn the language from hearing adults (usually parents) as well as from deaf adults. There was also intra-generational transmission, usually between spouses. Non-signers who married deaf spouses learned the language from them. In Israel these patterns of language transmission changed. Most deaf Algerians married deaf people of other origins, and stopped using AJSL with their spouses; that is, the intra-generational transmission no longer took place. As a consequence, their children were not exposed to the language on a daily basis, and they do not use the language at all. Some of the children understand it to some extent, but they hardly use it themselves. Therefore the language is not transmitted to younger generations, and is highly endangered, as I discuss in the following section. 
The main points of comparison are summarized in Table 6.1.

\begin{tabular}{|c|c|}
\hline ty in Ghardaia & ty in Israel \\
\hline $\begin{array}{l}\text { - shared, clear space with boundaries } \\
\text { (walls) } \\
\text { - deaf and hearing use AJSL } \\
\text { - AJSL is the only sign language } \\
\text { - deafness is not taboo within the } \\
\text { community } \\
\text { - neutral attitudes towards sign } \\
\text { language }\end{array}$ & 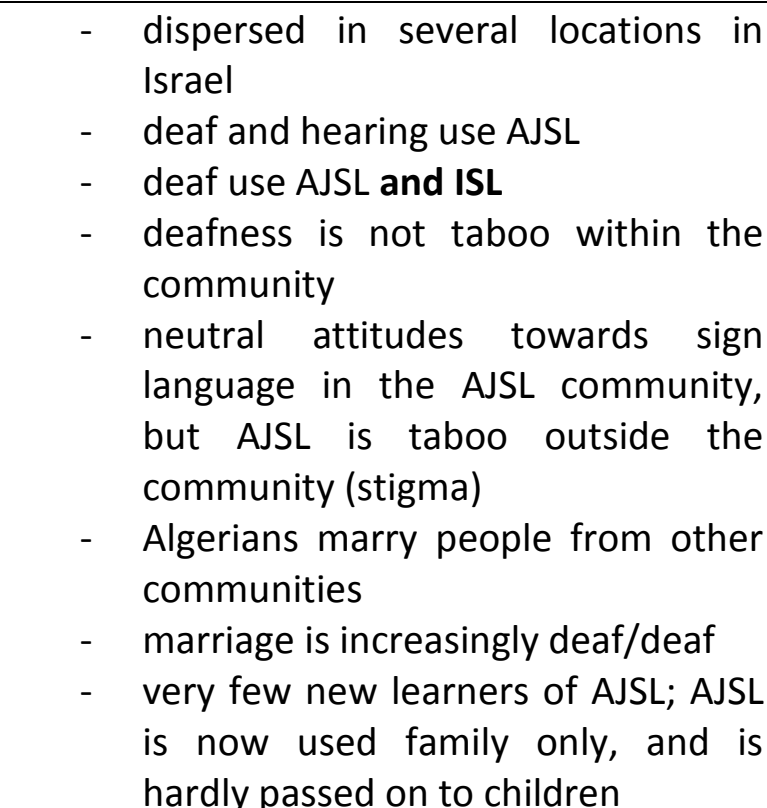 \\
\hline
\end{tabular}

Table 6.1: A comparison between the AJSL-using community in Ghardaia and in Israel

\subsection{The status of AJSL as an endangered language}

As is clear from section 6.1, the socio-linguistic situation of AJSL has changed significantly as a result of the migration and relocation of the community of AJSL users. In Israel, on the one hand it has succeeded in persisting for about 50 years alongside the dominant sign language, ISL. On the other hand, it seems that, by now, AJSL is highly endangered. In section 6.2.1 I examine the vitality of AJSL as it exists today, according to the major evaluative factors of vitality presented in UNESCO (2003). I then use two scales of language endangerment (Fishman 1991 and Krauss 2001) in section 6.2.2 to determine the degree of endangerment of AJSL.

\subsubsection{Evaluating the linguistic vitality of AJSL}

UNESCO (2003) lists nine factors that contribute to the vitality of a language. These encompass several important domains, including the number of speakers, language use, and language documentation, and are presented below in Figure 6.2. 


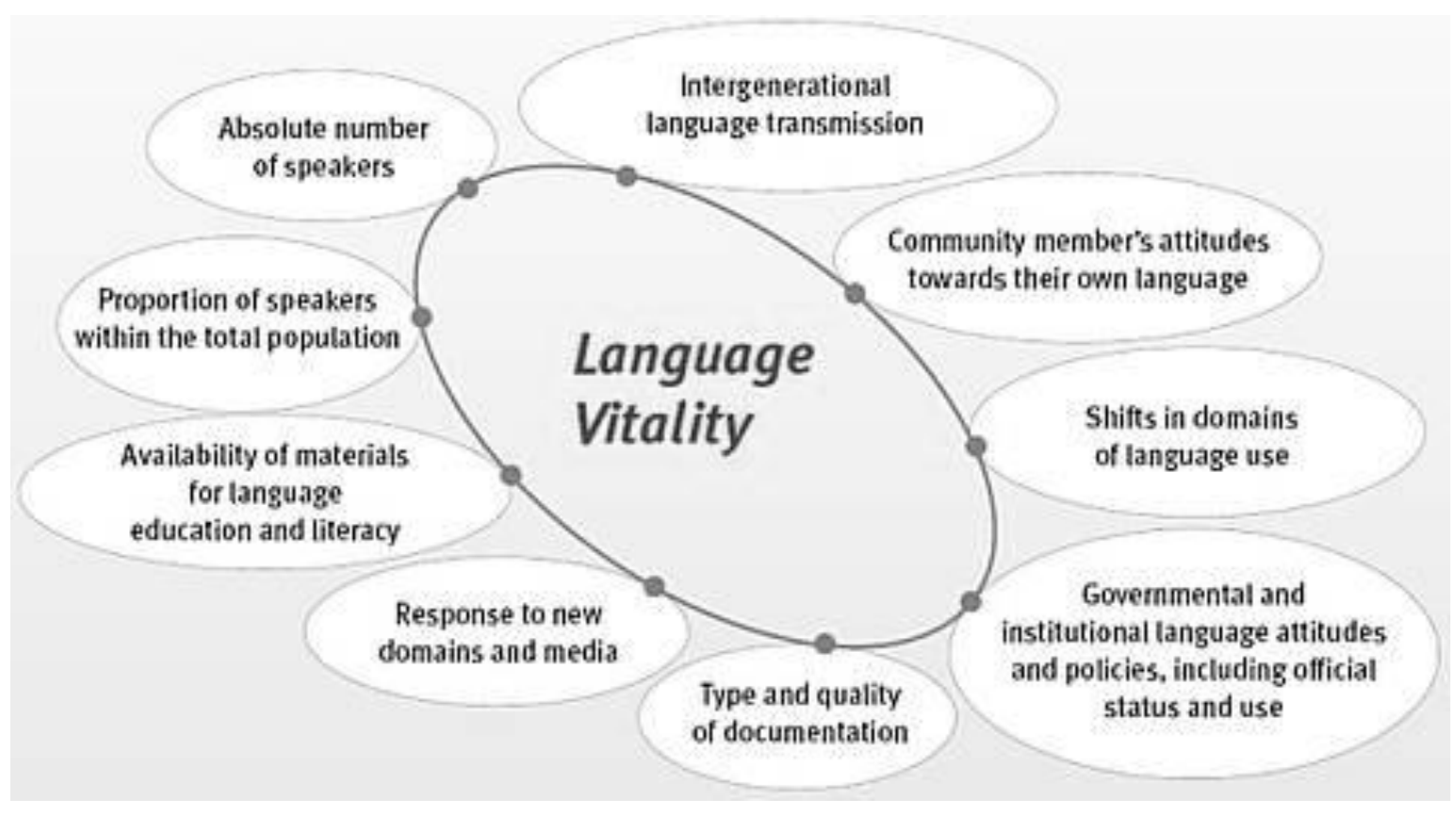

Figure 6.2 - UNESCO's nine major evaluative factors of language vitality (from www.unesco.org/new/en/culture/themes/endangered-languages/language-vitality)

Additionally, UNESCO (2003) sets down a grading system for eight of these factors - for all factors except 'absolute number of speakers', for which real numbers are used (ibid:19) and a scale from 0-5 is used alongside criteria to determine the degree of endangerment. Using this grading system, an assessment of the vitality of AJSL, according to UNESCO's nine factors, is presented below.

\section{Factor 1: Intergenerational Language Transmission}

AJSL is used mostly by older generations - grandparents and parents, rather than children (Grade 3, definitely endangered).

\section{Factor 2: Absolute Number of Speakers}

We have no definite figure concerning the number of AJSL users. With the help of the research participants, I have constructed a list of about 50 people who use AJSL. There are probably more than this, but the overall number is still very low.

Factor 3: Proportion of Speakers within the Total Population 
It is clear that even within the signing population in Israel, AJSL is used by a minority, and is therefore severely endangered (Grade 2, severely endangered).

Factor 4: Shifts in Domains of Language Use

AJSL is used in limited social domains and for several functions (Grade 2, limited or formal domains).

\section{Factor 5: Response to New Domains and Media}

The language is not used in any new domains (Grade 0 , inactive).

\section{Factor 6: Materials for Language Education and Literacy}

No orthography is available to the community (Grade 0).

\section{Factor 7. Governmental and Institutional Language Attitudes}

AJSL is neither recognized nor protected (Grade 1, forced assimilation).

Factor 8. Community Members' Attitudes toward Their Own Language

Here we see a positive change: while in the past very few members, if at all (Grade 1), supported language maintenance, now there are a few more people supporting it (Grade 2).

\section{Factor 9: Amount and Quality of Documentation}

Here as well, there is a slight positive change. The research presented in this thesis is a first step towards a documentation of the language. The grade for this factor has hence changed from Grade 0 (undocumented) to Grade 2 (fragmentary), since video recordings now exist, alongside an elicited word-list (see Chapter 5).

On average, AJSL scores between 1 and 2 on UNESCO's grading system, which means that AJSL may be considered to be a moribund language, lying between 'endangered' and 'extinct' on the continuum that runs from healthy to extinct (see section 1.6.2). 


\subsubsection{The function and transmission of AJSL}

Further evidence of the moribund status of AJSL is considered in this section (6.2.2), with a particular focus on two domains: language function, and language transmission. Having assessed the socio-linguistic situation of AJSL before and after the migration of AJSL users from Ghardaia to Israel in Chapters 3 and 4, it is clear that the function of the language changed considerably. For example, prior to migration, AJSL was used in the workplace, the home and the community (see section 3.4).

Following the migration, however, AJSL was restricted to use at home for many years, and was not used outside of the AJSL community (section 4.3). Consequently, the function of AJSL has narrowed considerably, and as mentioned in section 6.2.1, AJSL is now used by older people. Table 6.2 presents a scale based on criteria proposed by Fishman (1991:87109, described in Tsunoda 2005:10), for use in language endangerment. Whereas once AJSL may have been in stage 3 - used in the lower work sphere - according to this scale it is now in stage 7 (as highlighted in table 6.2), since the people who use the language are now older.

\begin{tabular}{|c|c|}
\hline (:) Stage 1 & used in higher education, employment, upper level government and media \\
\hline (:) Stage 2 & used in the lower level government and mass media \\
\hline :) Stage 3 & used in lower work sphere \\
\hline :) Stage 4 & used in lower education (according to the law) \\
\hline :) Stage 5 & used in the home, school, community \\
\hline :) Stage 6 & used informally between generations \\
\hline : Stage 7 & people use the language are older ('beyond child-bearing age') \\
\hline (:) Stage 8 & most speakers are 'socially isolated old folks' \\
\hline
\end{tabular}

Table 6.2: A scale for language function (based on the scale proposed by Fishman 1991:87-109, as described by Tsunoda 2005:10).

As described in section 4.3.3, the transmission of AJSL has been severely affected by changes to marriage patterns, which occurred once the Jewish community migrated from Ghardaia to Israel. Language transmission of AJSL virtually stopped, since most children born of one Algerian and non-Algerian parents are hearing. Table 6.3 presents the scale proposed by Krauss (2001:22-23, described in Tsunoda 2005:10). Given that AJSL is no 
longer being acquired as a first language, it is clear that AJSL is moribund, as far as Krauss's scale is concerned, and this is highlighted in Table 6.3.

\begin{tabular}{|c|l|}
\hline$:)$ safe & Most likely to be still used by (at least some) children in 2100 \\
\hline$:)$ endangered & Will cease to be learned by children in the twenty-first century \\
\hline$: 0$ moribund & No longer acquired as a first language now, in 2012 \\
\hline
\end{tabular}

Table 6.3: A scale for language transmission (based on scales proposed by Krauss 2001:22-23, as described by Tsunoda 2005:10).

To summarise, having considered both the UNESCO evaluative factors of vitality, and scales that have been proposed by Fishman and Krauss concerning language function and transmission, respectively, it is concluded here that AJSL is now a moribund language. The final part of this chapter (section 6.3) presents a brief discussion of the future of AJSL, alongside ideas for much-needed and timely further research.

\subsection{Further research and the future of AJSL}

What future can be expected for Algerian Jewish Sign Language? Having considered the history of AJSL, and its current state, it remains to reflect upon the future of AJSL and the possibilities for research that it offers.

The first point to consider is the impact of the research on the AJSL community. This research project has led to increased interest in AJSL among its speakers and among the broader deaf community in Israel. Awareness of AJSL has aroused interest and changed values regarding the language in the greater Israeli deaf community, beginning a change away from the previous perception of the language as a "dangerous and inferior" language. For the members of the deaf Algerian community, this research was a source of pride. Before the research was carried out, most of the community members were ashamed of their language and considered it a simple, rudimentary language in comparison to ISL, but this research has afforded them acceptance and support that their language has its equal place among all languages. Members of this community were witnesses to the procedures of this work - videotaping, photographing, documenting, dictionary building and arranging of studies at the University of Haifa, which included a 
special lecture on AJSL. This created much pride and an elevated status for AJSL and its users. Therefore, even if this research project will not halt the disappearance of the language, it still fills its users with pride about their unique cultural creation.

Secondly, a major contribution of this research project is that it established the first documentation of this language. Since the language has not been previously documented, an important goal of this thesis was to lay the foundations for documenting it. To this end, I collected a vocabulary of 300 words. The detailed comparison of these signs with those in ISL reflects that AJSL is an independent language, and that mutual influence between these two languages is minimal. AJSL has a wide vocabulary used in daily life and in life particular to the community, for example, Jewish festivals - Passover, Hannukah, Jewish New Year, etc. The signs signify essential elements and main customs in the community. Appendix C contains a sample of AJSL signs, which will serve as a basis for the dictionary. The documentation of the AJSL lexicon ensures that the special cultural and linguistic characteristics will be available for future studies.

As mentioned in chapter 4, some of the members of the Ghardaia community migrated to France, including some deaf members. I know from reports of some of the interviewees (ES, SS and ZM) that these people use AJSL in France till today. It might be that in France there is a larger number of AJSL users and therefore the language there is less endangered. If this is indeed the case, the French AJSL community might offer possibilities for investigating and documenting the linguistic structure of AJSL that are no longer possible in Israel. It is also important to investigate whether the socio-linguistic circumstances of the use of AJSL in France are similar to or different from those in Israel. Such a comparison will shed light on language maintenance and endangerment.

Finally, this study is relevant for the academic field of language endangerment studies in that it highlights the situation of a signed language and the particularities that can be involved when looking at endangered sign languages, such as, in this case, the patterns of sign bilingualism / sign multilingualism, and the possible role of hearing people in the vitality of a sign language. 
Although AJSL is severely endangered, and it is not clear that this thesis can reverse this fate, it at least provides some points for hope. The study of AJSL in France, as suggested above, might provide new findings about the language and its vitality. Secondly, this thesis promoted linguistic pride in the language among its users and among some members of the Israeli Deaf community. It is hoped that this pride and interest will promote more cooperation from other AJSL users, which, in turn, will enable more comprehensive documentation of the language and the special socio-linguistic characteristics that gave rise to the language and its existence in both Ghardaia and Israel. 


\section{APPENDIX A: QUESTIONNAIRE}

SECTION 1: Biographical details

1. Name:

2. Age:

3. Place of birth in Algeria:

4. Year of migration to Israel:

5. Place of residence in Israel (Have you lived in more than one place in Israel?)

6. Is anyone else in your family deaf? (Parents, siblings, children, grandparents, uncles/aunts): If so, please list them clearly and in detail, preferably with their names and ages.

7. Is your spouse deaf? If so, does he/she know AJSL? If not, why? If so, how did he/she learn?

8. Who do you use AJSL with? Please list these people in detail, both deaf and hearing, with their names if possible.

9. Do you participate in meetings of the deaf association in Israel? If so, where?

10. Do you know ISL?

11. Who do you use ISL with?

SECTION 2: AJSL and the AJSL community in Ghardaia and Israel

12. Do you enjoy using AJSL?

13. Is AJSL important to you? 
14. Is there any reason you would prefer not to use AJSL?

15. Do you think that there is anyone who is embarrassed when using AJSL?

16. What do you think what people in the Israeli deaf community think of AJSL?

17. Do deaf Algerians attend synagogue? Is sign interpretation available for them if they do?

18. Do the deaf pray and celebrate the Jewish holidays? Is it customary for family members to interpret for the deaf?

Life in Algeria

19. What do you remember about your place of birth in Algeria?

20. Did the Jews only use AJSL with each other, or was the language used to communicate with the Muslim population as well? Was there any contact between Jews and Muslims?

21. Did the deaf attend synagogue? Did they read from the Torah?

22. Were there any elderly deaf people in the village? How old were the oldest deaf people you knew?

23. What kind of professions did the deaf have? Were they the same as those acquired by the hearing?

24. Were the hearing people in the village literate (both men and women)? What about the deaf?

25. Did deaf boys have a Bar-Mitzvah ceremony?

26. Which was preferable - marrying a deaf or a hearing person? 


\section{APPENDIX B: ELICITED LEXEMES (277)}

\begin{tabular}{|c|c|c|c|}
\hline adult & black pepper & cheap & day of atonement \\
\hline airplane & blue & chicken & dead \\
\hline alive & bottle & chocolate & deaf \\
\hline all day & bowl & clean & devil \\
\hline alone & boy & clever & difficult man \\
\hline apricot & bread & coffee & diligent \\
\hline Arab & broom & cold & dirty \\
\hline baby & brother-in-law & comb & doctor \\
\hline bad & brown & cotton wool & dog \\
\hline banana & bus & cow & doll \\
\hline bank & cabbage, lettuce & crazy & donkey \\
\hline barber & camel & cream cheese & doughnut \\
\hline beautiful & car, taxi & cry & eating forbidden \\
\hline bee & carpenter & cucumber & egg \\
\hline big & carpet & curious & eggplant \\
\hline big, giant & carrot & dark & empty \\
\hline birth & cat & daughter & engaged \\
\hline black & cauliflower & day after tomorrow & evening \\
\hline
\end{tabular}




\begin{tabular}{|c|c|c|c|}
\hline every day & goat & hot, summer & luck \\
\hline expensive & gold & hungry & many \\
\hline family & good & husband & market \\
\hline far & grandfather & injection & married \\
\hline fast & grandmother & injured & match \\
\hline fat & green & Jewish, Israel & meal \\
\hline father & guilty & juice & mess \\
\hline film & Hannukah & jump & milk \\
\hline fish & hard & kettle & Monday \\
\hline flour & hard life & knife & month \\
\hline food & hard work & Lag Bomer & more \\
\hline forget & hate & laugh & morning \\
\hline fork & healthy & lazy & mother \\
\hline Friday & hearing & lemon & mouse \\
\hline fridge & heavy & light & must \\
\hline funeral & henna & little & near \\
\hline game & honey & loan & nervous \\
\hline gas & horse & long time ago & new \\
\hline girl & hospital & look for & new year \\
\hline glass & hot & love & night \\
\hline
\end{tabular}




\begin{tabular}{|c|c|c|c|}
\hline no place & pink & rich & slow \\
\hline noisy & pita & run & small \\
\hline not on speaking & plate & salty & smelly \\
\hline terms & policeman & same & snake \\
\hline nothing & poor & satiated & soap \\
\hline nuts & post office & Saturday & socks \\
\hline oil & potato & scared & soldier \\
\hline old & pregnant & school & sometimes \\
\hline olive & prison & sea & son \\
\hline onion & pomegranate & sheep & sound \\
\hline operation & prostitute & shiny & soup \\
\hline orange & Purim & ship & sour \\
\hline pain & purple & shoemaker & spoilt \\
\hline Passover & quarrel & shoes & spoon \\
\hline patient & quiet & shop & stand \\
\hline pea & rain & short & stingy \\
\hline Pentecost & red & sick & strong \\
\hline people & remember & sign language & stubborn \\
\hline picture & restaurant & single & stupid \\
\hline pig & rice & sister-in-law & sugar \\
\hline
\end{tabular}




\begin{tabular}{|c|c|c|}
\hline Sunday & trousers & wife wine \\
\hline sweet & truck & work, profession \\
\hline synagogue & Tuesday & year \\
\hline Tabernacle & twist bread-halvah & yellow \\
\hline table & ugly & yesterday \\
\hline tailor & Uncle/Aunt & Youth \\
\hline talk & university & \\
\hline talkative & use & \\
\hline tall & vegetable & \\
\hline tea & vinegar & \\
\hline teaspoon & want & \\
\hline theatre & watermelon & \\
\hline thief & weak & \\
\hline thin & weaving & \\
\hline think & wedding & \\
\hline Thursday & Wednesday & \\
\hline tomato & week & \\
\hline tomorrow & white & \\
\hline towel & wide & \\
\hline train & widow/er & \\
\hline
\end{tabular}


APPENDIX C: DOCUMENTATION OF SELECTED AJSL SIGNS

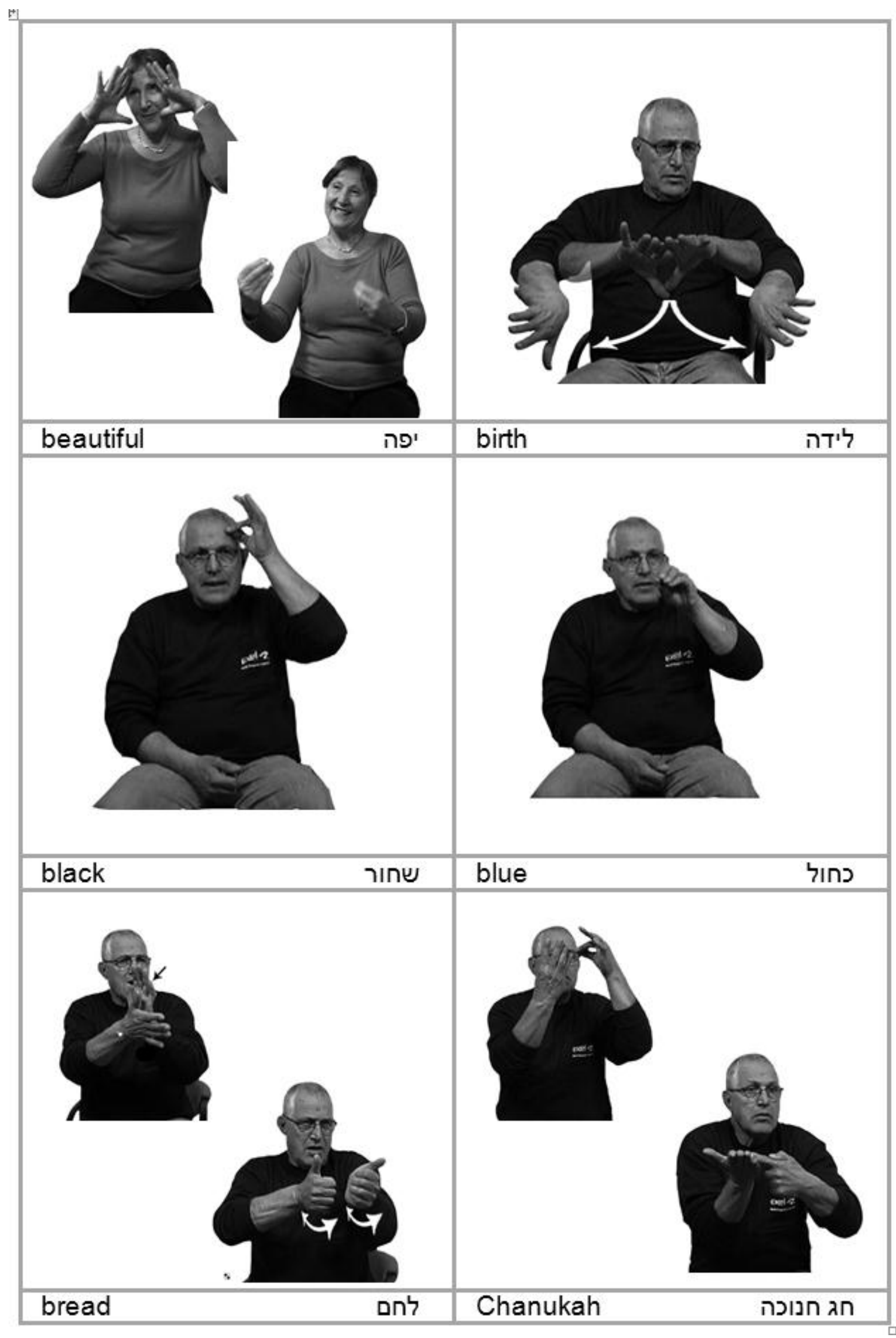




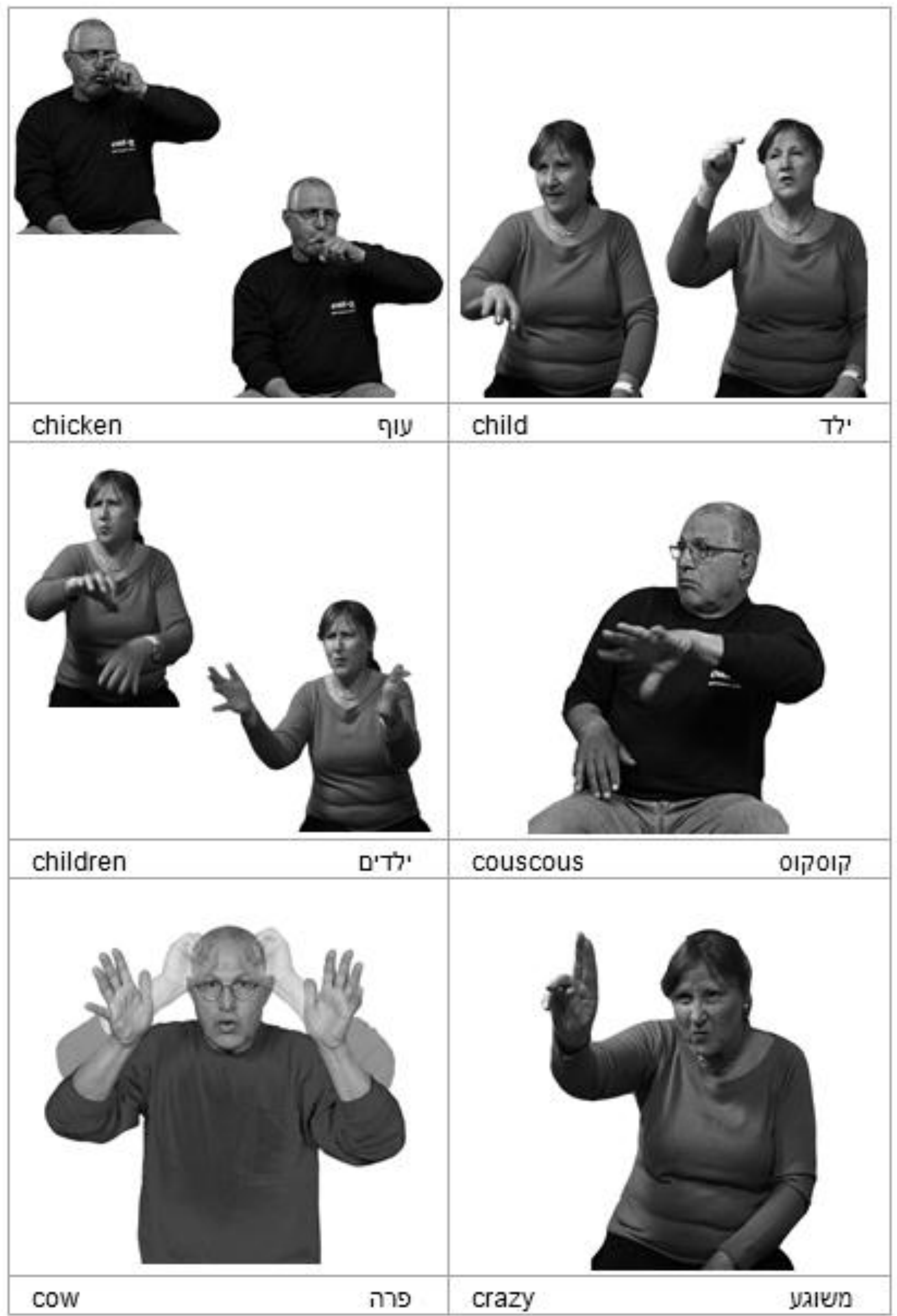




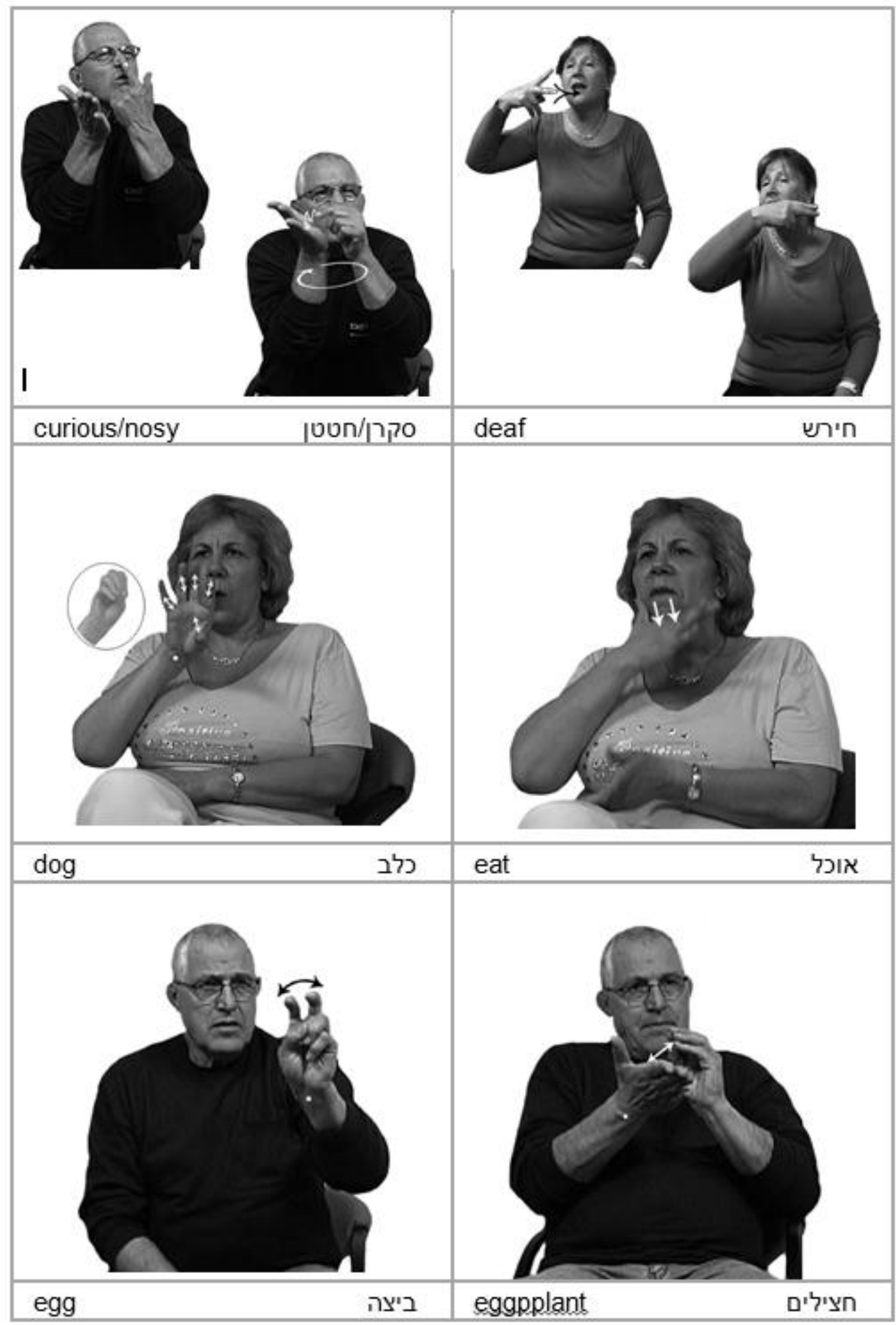




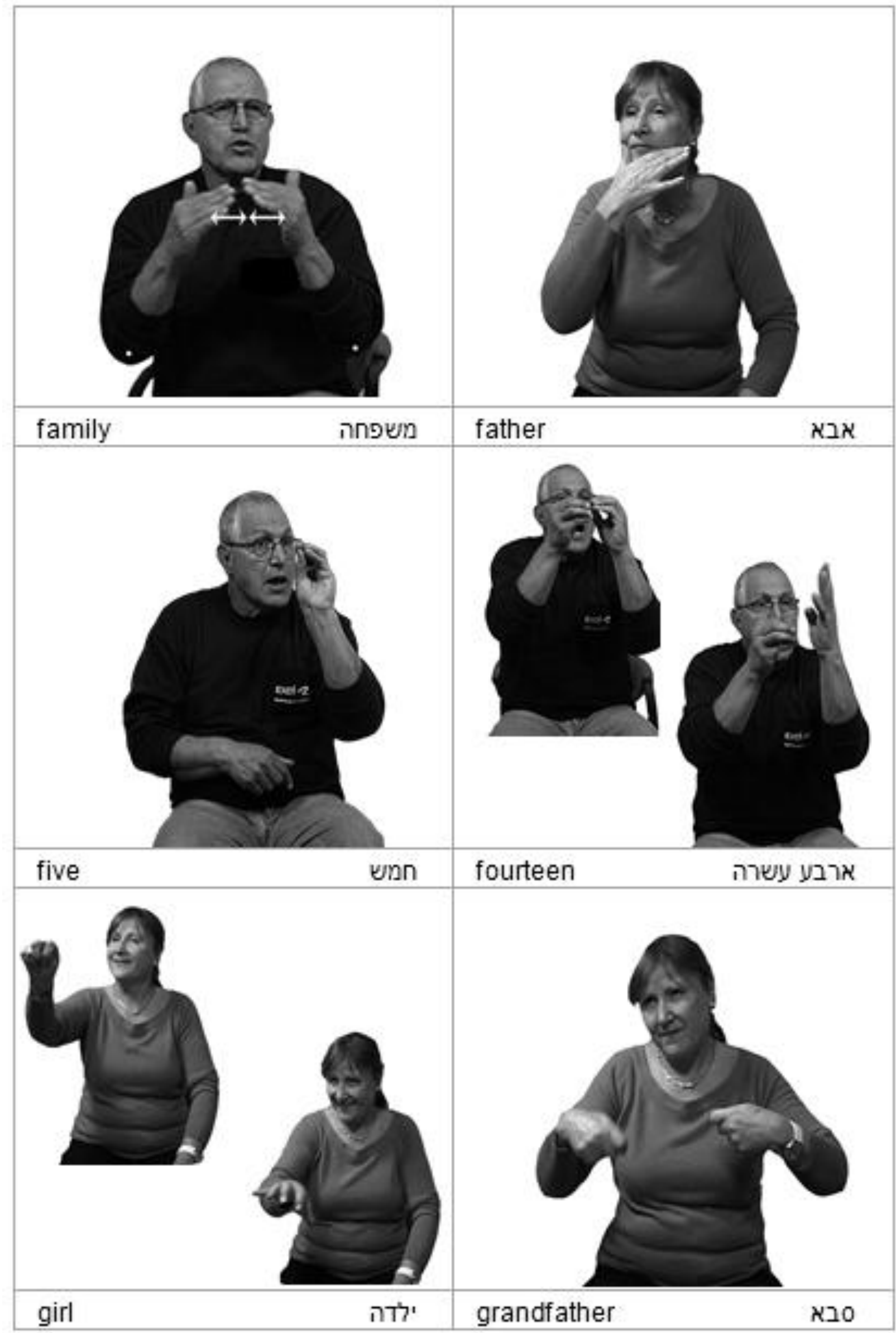




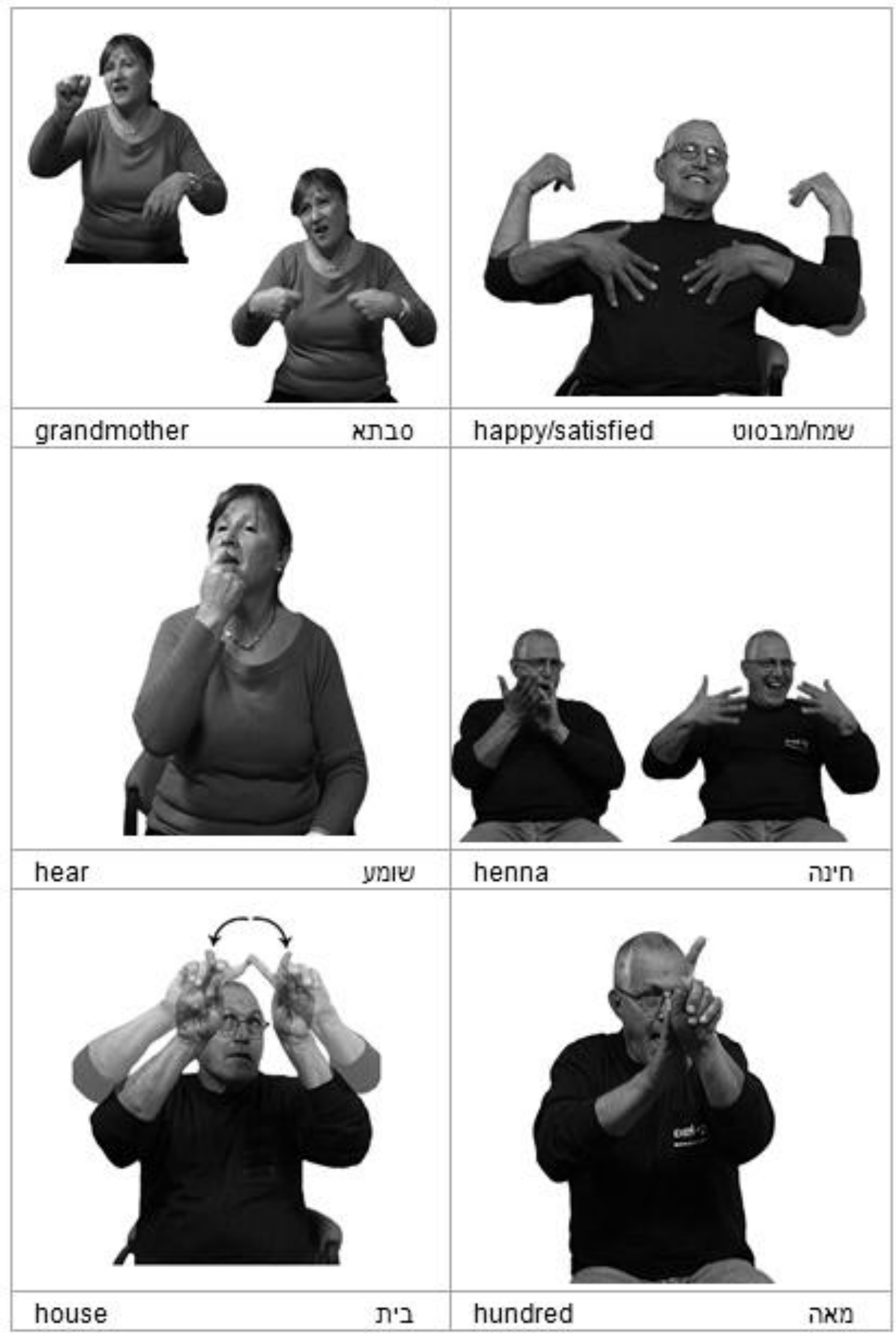




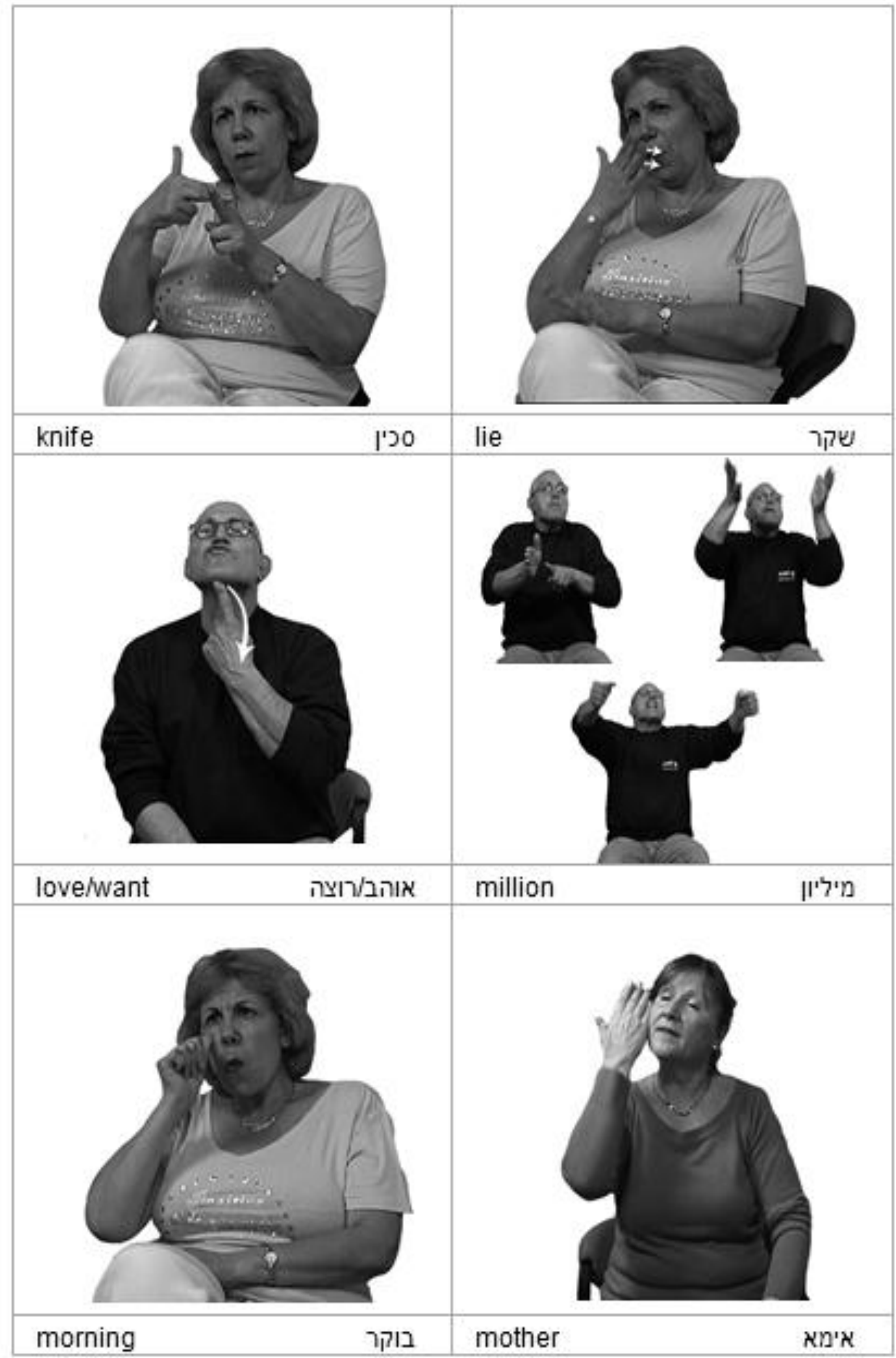




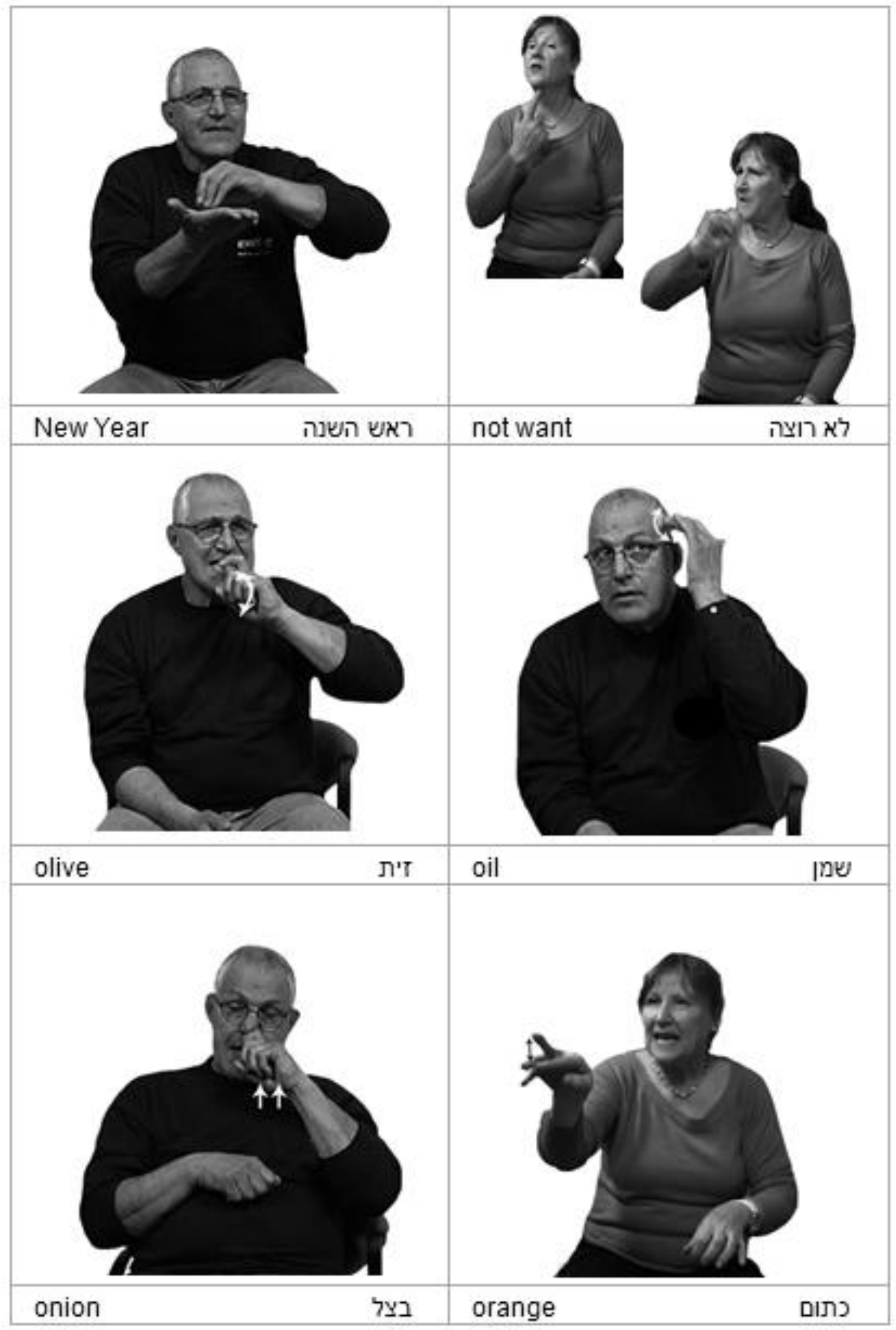




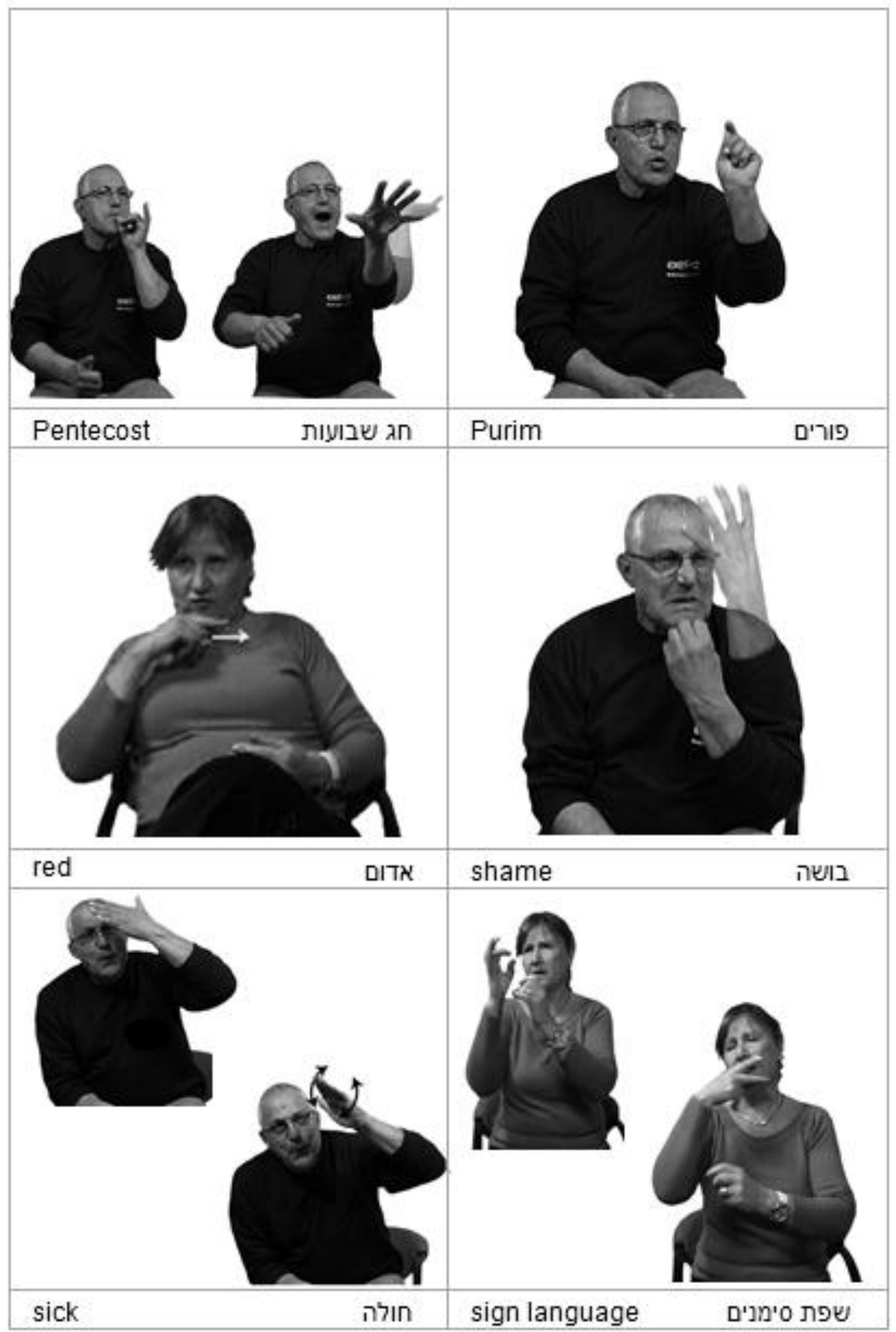




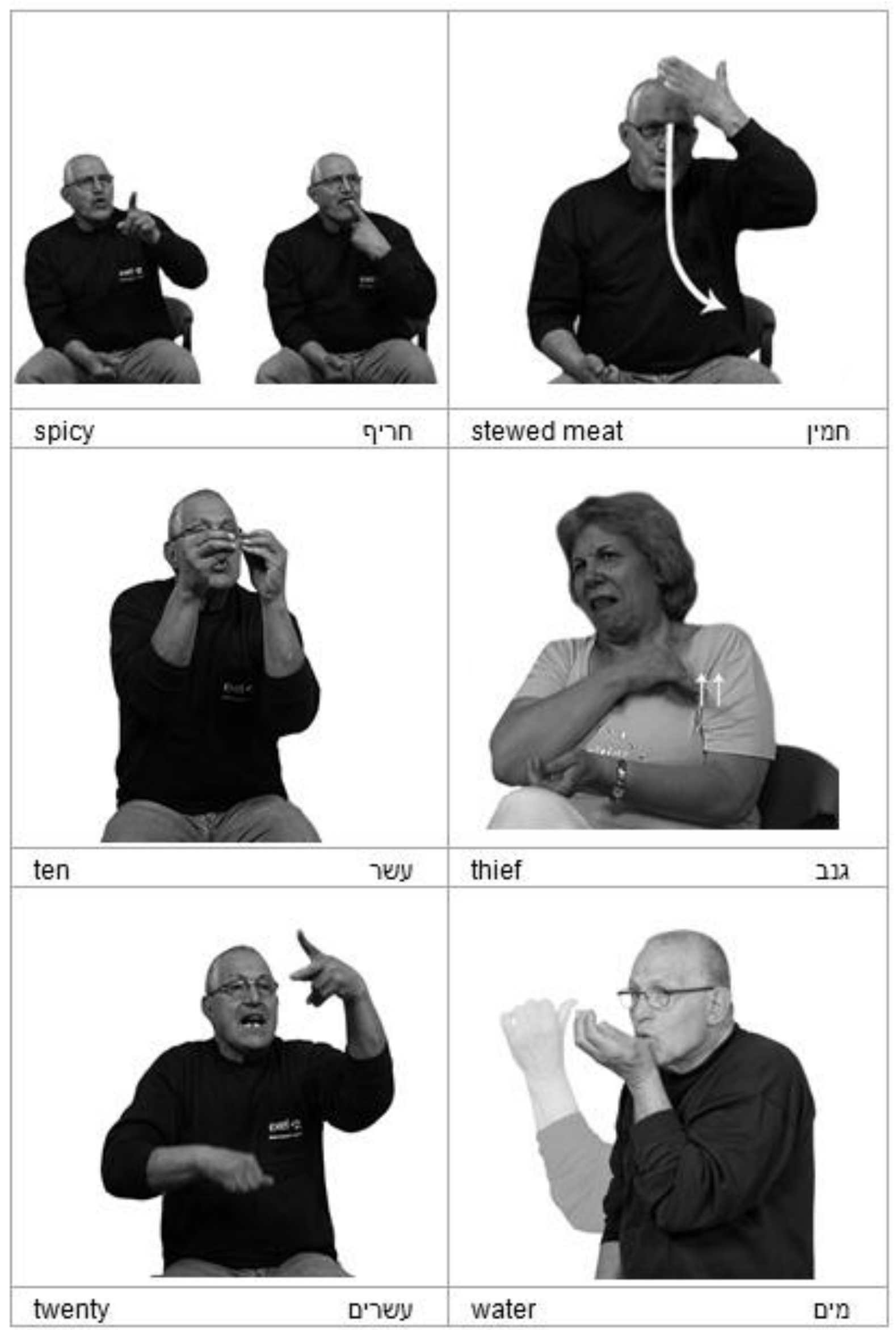




\section{BIBLIOGRAPHY}

Al-Fityani, K. (2007). Arab sign languages: A lexical comparison. Technical Report. Center for Research in Language Newsletter 19(1): 3-13.

Al-Fityani, K. \& Padden, C. (2011). Sign languages in the Arab world. In: Brentari,

D. (ed.). Sign Languages: A Cambridge Language Survey. New York, NY: Cambridge University Press, p. 433-450.

Aronoff, M., Meir, I., Padden, C. \& Sandler, W. (2008). The roots of linguistic organization in a new language. Special Issue of Interaction Studies on Holophrasis, Compositionality and Protolanguage 9(1): 133-153.

Batibo, H.M. (2009). Language documentation as a strategy for the empowerment of the minority languages of Africa. In: Matondo, M., McLaughlin, F. \& Potsdam, E. (eds.) Selected Proceedings of the 38th Annual Conference on African Linguistics. Somerville, MA: Cascadilla Proceedings Project, p. 193-203.

Boyes Braem, P. \& Sutton-Spence, R. (eds.) (2001). The Hands are the Head of the Mouth: The mouth as articulator in sign language. Hamburg, Germany: SignumVerlag.

Brentari, D. (1998). A Prosodic Model of Sign Language Phonology. Cambridge, MA: MIT Press.

Brenzinger, M. (ed.) (2007). Language Diversity Endangered. Trends in Linguistics: Studies and Monographs No. 181. Berlin, Germany: Mouton de Gruyter.

Briggs, L.C. \& Guede, N.L. (1964). No More Forever: A Saharan Jewish town. Cambridge, MA: The Peabody Museum.

Cohen, E., Namir, L. \& Schlesinger, I.M. (1977). A New Dictionary of Sign Language: Employing the Eshkol-Wachmann movement notation system. The Hague, Netherlands: Mouton.

Craig, C.G. (1997). Language contact and language degeneration. In: Coulmas, F. (ed.). The Handbook of Sociolinguistics. Cambridge, MA: Blackwell Publishers Ltd, p. 257-270. 
Crowley, T. (1992) An Introduction to Historical Linguistics. Oxford: Oxford University Press.

Crowley, T. \& Bowern, C. (2010). An Introduction to Historical Linguistics. New York, NY: Oxford University Press.

Crystal, D. (2000). Language Death. Cambridge, UK: Cambridge University Press.

Guerra Currie, A.M., Meier R., \& Walters, K. (2002). A cross-linguistic examination of the lexicons of four signed languages. In: Meier, R.P., Cormier, K. \& QuintoPozos, D. (eds.) Modality and Structure in Signed and Spoken Languages. Cambridge, UK: Cambridge University Press, p. 224-236.

Dachkovsky, S. (2008). Facial expression as intonation in Israeli Sign Language: the case of neutral and counterfactual conditionals. In: Quer, J. (ed.). Signs of the Time: Selected Papers from TISLR 2004. Hamburg, Germany: Signum Press, p. 61-82.

De Vos, C. (2012). The Kata Kolok perfective in child signing: Coordination of manual and non-manual components. In: Zeshan, U. \& De Vos, C. (eds.) Village Sign Languages: Anthropological and linguistic insights. Berlin: De Gruyter Mouton \& Nijmegen: Ishara Press.

Eckert, P. \& McConnell-Ginet, S. (1992). Think Practically and Look Locally: Language and Gender as Community-Based Practice. Annual Review of Anthropology 21: 461-490.

Eichmann, H. (2009). Planning Sign Languages: Promoting Hearing Hegemony? Conceptualizing Sign Language Standardization. Current Issues in Language Planning 10(3): 293-307.

Emmorey, K. (2002). Language, Cognition and the Brain: Insights from sign language research. Mahwah, NJ: Lawrence Erlbaum and Associates.

Escobedo Delgado, C.E. (2012). Chican Village Sign Language. In: Zeshan, U. \& De Vos, C. (eds.) Village Sign Languages: Anthropological and linguistic insights. Berlin: De Gruyter Mouton \& Nijmegen: Ishara Press.

Erting, C. (ed.) (1994). The Deaf Way: Perspectives from the international conference on deaf culture. Washington, DC: Gallaudet University Press. 
Evans, N. \& Levinson, S. (2009). The myth of language universals: Language diversity and its importance for cognitive science. Behavioral and Brain Sciences 32: 429-492.

Fischer, S. \& Gough, B. (1978). Verbs in American Sign Language. Sign Language Studies 18(7): 17-48.

Fishman, J.A. (1991). Reversing Language Shift: Theoretical and empirical foundations of assistance to endangered languages. Clevedon, UK: Multilingual Matters.

Friedman, L. (1975). Space and time reference in American Sign Language. Language 51(4): 940-961.

Fuentes, M. \& Tolchinsky, L. (2004). The subsystem of numerals in Catalan Sign Language: Description and examples from a psycholinguistic study. Sign Language Studies 5(1): 94-117.

Groce, N. E. (1985). Everyone Here Spoke Sign Language: Hereditary deafness on Martha's Vineyard. Cambridge, MA: Harvard University Press.

Hale, K., Krauss, M., Watahomigie, L.J., Yamamoto, A.Y., Craig, C., Masayesva, L.J. \& England, N.C. (1992). Endangered languages: On endangered languages and the safeguarding of diversity. Language 68(1): 1-42.

Himmelmann, N., Gippert, J. \& Mosel, U. (eds.) (2006). Essentials of Language Documentation. Trends in Linguistics: Studies and monographs 178. Berlin, Germany: Mouton de Gruyter.

Hockett, C. (1960). The origin of speech. Scientific American 203: 88-96.

Humphries, T., Padden, C. \& O’Rourke, T.J. (1980). A Basic Course in American Sign Language. Silver Spring, MD: T. J. Publishers.

Jones, M. \& Ogilvie, S. (eds.) (forthcoming). Language Endangerment: Documentation, pedagogy, and revitalization. Cambridge, UK: Cambridge University Press.

Kisch, S. (2000). Deaf Discourse: The social construction of deafness in a Bedouin community. MA Thesis, Tel-Aviv University, Israel (in Hebrew).

Kisch, S. (2008). The social construction of deafness in a Bedouin community. Medical Anthropology 27(3): 28-313. 
Kisch, S. (2012). Al-Sayyid Bedouin Sign Language. In: Zeshan, U. \& De Vos, C. (eds.) Village Sign Languages: Anthropological and linguistic insights. Berlin: De Gruyter Mouton \& Nijmegen: Ishara Press.

Klima, E. \& Bellugi, U. (1979). The Signs of Language. Cambridge, MA: Harvard University Press.

Krauss, M. (1998). The condition of Native North American languages: The need for realistic assessment and action. International Journal of the Sociology of Language 132(1): 9-22.

Krauss, M. (2001). Mass language extinction, and documentation: The race against time. In: Saiyama, O. \& Fubito, E. (eds.). Endangered Languages of the Pacific Rim Series C002. Lectures on Endangered Languages:2 Kyoto 2001. Suita, Japan: Faculty of Informatics, Osaka Gakuin University, p. 19-39.

Krauss, M. (2007). Classification and terminology for the degree of language endangerment. In: Brenzinger, M. (ed.) Language Diversity Endangered. Trends in Linguistics; Studies and Monographs No. 181. Berlin, Germany: Walter de Gruyter, p. 1-8.

Kusters, A. (2010). Deaf utopias? Reviewing the sociocultural literature on the world's "Martha's Vineyard Situations". Journal of Deaf Studies and Deaf Education 15(1): 3-16.

Labov, W. (1971). The study of language in its social context. In: Fishman, J.A. (ed.). Advances in the Sociology of Language, Vol 1. The Hague, Netherlands: Mouton.

Lanesman, S. \& Meir, I. (2010). Initial survey of sign languages and signing systems in Arab communities in Israel. In: Panda, S. (ed.) Sign Languages in Village Communities. Ishara Signed Publications No.2. Nijmegen: Ishara Press.

Lanesman, S. \& Meir, I. (2012). The survival of Algerian Jewish Sign Language alongside Israeli Sign Language in Israel. In: Zeshan, U. \& De Vos, C. (eds.) Village Sign Languages: Anthropological and linguistic insights. Berlin: De Gruyter Mouton \& Nijmegen: Ishara Press.

Lave, J. \& Wenger, E. (1991). Situated Learning: Legitimate peripheral participation. Cambridge, UK: Cambridge University Press. 
Lewis, M. Paul (2009) (ed.) Ethnologue: Languages of the World, 16 ${ }^{\text {th }}$ edition. Dallas, TX: SIL International. Online version: http://www.ethnologue.com/

Lüpke, F. (2009). At the margin - African endangered languages in the context of global endangerment discourses. African Research and Documentation 109: 15-41.

Marsaja, I. G. (2008). Desa Kolok: A deaf village and its sign language in Bali, Indonesia. Nijmegen: Ishara Press.

McKee, D. \& Kennedy, G. (2000). Lexical comparisons of signs from American, Australian, British and New Zealand Sign Languages. In: Emmorey, K. \& Lane, H. (eds.) The Signs of Language Revisited: An anthology to Honor Ursula Bellugi and Edward Klima. Mahwah, NJ: Erlbaum, p. 49-76.

McWhorter, J. (2001). The Power of Babel: A natural history of language. New York, NY: Times Books.

Meier, R.P., Cormier, K. \& Quinto-Pozos, D. (eds.) (2002). Modality and Structure in Signed and Spoken Language. Cambridge, UK: Cambridge University Press.

Meir, I. (1998). Syntactic-semantic interaction in Israeli Sign Language verbs: The case of backwards verbs. Sign Language and Linguistics 1: 3-33.

Meir, I. (2004). Question and negation in Israeli Sign Language. Sign Language and Linguistics 7(2): 97-124.

Meir, I. \& Sandler, W. (2008). A Language in Space: The story of Israeli Sign Language. New York, NY: Lawrence Erlbaum Associates.

Meir, I., Sandler, W., Padden, C. \& Aronoff, M. (2010). Emerging sign languages. In: Marschark, M., Spencer, P.E. \& Nathan, P.E. (eds.) The Oxford Handbook of Deaf Studies, Language, and Education. Oxford, UK: Oxford University Press, p. 267280.

Moseley, C. (ed.) (2010). Atlas of the World's Languages in Danger, 3rd edn. Paris, UNESCO Publishing. Online version:

http://www.unesco.org/culture/en/endangeredlanguages/atlas [accessed 27 April 2012].

Mufwene, S. (2008). Language Evolution: Contact, competition, and change. Wiltshire, UK: Cromwell Press. 
Myhill, J. (2004). Language in Jewish Society: Towards a new understanding. Clevedon, UK: Multilingual Matters Ltd.

Nagel, R.L. (2004). Jews of the Sahara. Einstein Journal of Biological Medicine 21: $25-32$.

Namir, L., Sella, I., Rimor, M. \& Schlesinger, I.M. (1977). Dictionary of Sign Language of the Deaf in Israel. Jerusalem, Israel: Ministry of Social Welfare.

Neisser, A. (1990). The Other Side of Silence: Sign language and the Deaf community in America. Washington, DC: Gallaudet University Press.

Nespor, M. \& Sandler, W. (1999). Prosodic phonology in Israeli Sign Language. Language and Speech 42(2-3): 143-176.

Nettle, D. \& Romaine, S. (2000). Vanishing Voices: The extinction of the world's languages. Oxford, UK: Oxford University Press.

Nonaka, A.M. (2004). The forgotten endangered languages: Lessons on the importance of remembering from Thailand's Ban Khor sign language. Language in Society 33(5): 737-767.

Nonaka, A.M. (2007). Emergence of an indigenous sign language and a Speech/Sign community in Ban Khor, Thailand. Unpublished University of California, Los Angeles.

Nonaka, A.M. (2011). Language endangerment and language socialization. In: Duranti, A., Ochs, E. \& Schieffelin, B. (eds.) Handbook of Language Socialization. Oxford, UK: Wiley-Blackwell Press, p. 610-630.

Nonaka, A.M. (2012). Ban Khor Sign Language. In: Zeshan, U. \& De Vos, C. (eds.) Village Sign Languages: Anthropological and linguistic insights. Berlin: De Gruyter Mouton \& Nijmegen: Ishara Press.

Nyst, V. (2007). A Descriptive Analysis of Adamarobe Sign Language (Ghana). Utrecht, Netherlands: LOT.

Osugi, Y., Supalla, T. \& Webb, R. (1999). The use of word elicitation to identify distinctive gestural systems on Amami Island. Sign Language and Linguistics 2(1): 87-112.

Padden, C. (1988). Interaction of Morphology and Syntax in American Sign Language. New York, NY: Garland Publishers. 
Padden, C. (2010). Sign language geography. In: Mathur, G. \& Napoli, D.J.: Deaf Around the World: The impact of language. Oxford: OUP, p. 19-37

Padden, C. \& Humphries, T. (1988). Deaf in America: Voices from a culture. Cambridge, MA: Harvard University Press.

Padden, C. \& Humphries, T. (2005). Inside Deaf Culture. Harvard University Press.

Panda, S. (2012). Alipur Village Sign Language. In: Zeshan, U. \& De Vos, C. (eds.) Village Sign Languages: Anthropological and linguistic insights. Berlin: De Gruyter Mouton \& Nijmegen: Ishara Press.

Pietikäinen, S., Huss, L., Laihiala-Kankainen, S., Aikio-Puoskari, U. \& Lane, P. (2010). Regulating multilingualism in the North Calotte: The case of Kven, Meänkieli, and Sámi languages. Acta Borealia: A Nordic journal of circumpolar societies, 1503-IIIX, 27(1): 1-23.

Plann, S. (2007). The Spanish National School: Portraits from the nineteenth century. Washington, DC: Gallaudet University Press.

Plaut, A. (2007). The History of Educational Frameworks for Students with Hearing Impairments in Israel 1932-2005. The Mofet Institute. [In Hebrew].

Quinn, G. (2010). Schoolization: An account of the origins of regional variation in British Sign Language. Sign Language Studies 10(4): 476-501.

Rathmann, C. \& Mathur, G. (2002). Is verb agreement different cross-modally? In: Meier, R., Cormier, K. \& Quinto, D. (eds.). Modality and Structure in Signed and Spoken Languages. Cambridge, UK: Cambridge University Press, p. 370-404.

Sandler, W. (1999). The medium is the message: Prosodic interpretation of linguistic content in sign language. Sign Language and Linguistics 2(2): 187216.

Sandler, W. \& Lillo-Martin, D. (2006). Sign Language and Linguistic Universals. Cambridge, UK: Cambridge University Press.

Sandler, W., Meir, I., Padden, C. \& Aronoff, M. (2005). The emergence of grammar in a new sign language. Proceedings of the National Academy of Sciences 102(7): 2661-2665. 
Sankoff, G. (2001). Linguistic outcomes of language contact. In: Chambers, J.K., Trudgill, P. \& Schilling-Estes, N. (eds.) The Handbook of Language Variation and Change. Oxford, UK: Blackwell Publishing, p. 638-668.

Schmidt, A. (1990). The Loss of Australia's Aboriginal Language Heritage. Canberra, Australia: Aboriginal Studies Press for the Australian Institute of Aboriginal and Torres Strait Islander Studies.

Scott, D.A., Carmi, R., Elbedour, K., Duyk, G.M., Stone, E.M. \& Sheffield, V.C. (1995). Nonsyndromic autosomal recessive deafness is linked to the DFNB1 locus in a large inbred Bedouin family from Israel. The American Journal of Human Genetics 54(4): 965-968.

Senghas, A., Kita, S. \& Özyürek, A. (2004). Children creating core properties of language: Evidence from an emerging sign language in Nicaragua. Science 305: 1779-1782.

Skutnabb-Kangas, T. (2003). Linguistic diversity and biodiversity: The threat from killer languages. In: Mair, C. (ed.) The Politics of English as a World Language. New Horizons in Postcolonial Studies. New York, NY: Rodopi, p. 31-52.

Stokoe, W., Casterline, D.C. \& Croneberg, C.G. (1965). A Dictionary of American Sign Language on Linguistic Principles. Washington, DC: Gallaudet University Press.

Swadesh, M.H. (1955). Towards greater accuracy in lexicostatistic dating. International Journal of American Linguistics 21: 121-137.

Swartzfox, S. (1989). The immigration to Israel from North Africa after the occupation of Algeria by France. Pe'amim 38: 109-123. [In Hebrew].

Tagliamonte, S. (2006). Analysing Sociolinguistic Variation. Cambridge, UK: Cambridge University Press.

Taub, S. (2001). Language from the Body: Iconicity and metaphor in American Sign Language. Cambridge, MA: Cambridge University Press.

Tollefson, J. (1994). Planning language, planning inequality. Teaching English as a Second or Foreign Language 1(1): 234.

Tsunoda, T. (2006). Language Endangerment and Language Revitalization. Berlin, Germany: Mouton de Gruyter. 
Turin, M. (2005). Language endangerment and linguistic rights in the Himalayas. A case study from Nepal. Mountain Research and Development 25(1): 4-9.

UNESCO Ad Hoc Expert Group on Endangered Languages. (2003). Language

Vitality and Endangerment. Online version:

http://unesdoc.unesco.org/images/0018/001836/183699E.pdf [accessed 27 April 2012].

Van Steenwyk, I. (2008). Going, going, but not gone: The impact of social and technological influences on the Australian Deaf community. Anthropology Matters 10(2).

Vaux, B. \& Cooper, J. (1999). Introduction to Linguistic Field Methods. Munich, Germany: Lincom Europa.

Wheatley, M. \& Pabsch, A. (2010). Sign Language Legislation in the European Union. Brussels: European Union of the Deaf.

Wilbur, R. (2000). Phonological and prosodic layering of non-manuals in American Sign Language. In: Lane, H. \& Emmorey, K. (eds.) The Signs of Language Revisited: Festschrift for Ursula Bellugi and Edward Klima. Hillsdale, NJ: Lawrence Erlbaum, p. 213-241.

Woodward, J. (1978). Historical bases of American Sign Language. In: Siple, P. (ed.). Understanding Language through Sign Language Research. New York, NY: Academic Press, p. 333-348.

Woodward, J. (1991). Sign language varieties in Costa Rica. Sign Language Studies 73: $329-346$.

Woodward, J. (1992). Historical bases of New Costa Rican Sign Language. Journal of Philology and Linguistics of the University of Costa Rica 18: 127-132.

Woodward, J. (1993). The relationship of sign language varieties in India, Pakistan, and Nepal. Sign Language Studies 78: 15-22.

Woodward, J. (1996). Modern Standard Thai Sign Language: Influence from ASL, and its relationship to original Thai sign varieties. In: Sign Language Studies, 92, p. 227-252.

Woodward, J. (2000). Sign languages and sign language families in Thailand and Vietnam. In: Emmorey, K. \& Lane, H. (eds.). The Signs of Language Revisited: An 
anthology in honor of Ursula Bellugi and Edward Klima. Mahwah, NJ: Lawrence Erlbaum, p. 23-47.

Woodward, J. (2003). Sign languages and deaf identities in Thailand and Vietnam. In: Monaghan, L., Schmaling, C., Nakamura, K. \& Turner, G.H. (eds.) Many Ways to Be Deaf: International variation in Deaf communities. Washington, DC: Gallaudet University Press, p. 283-301.

Woodward, J. (2010). Response: Some observations on research methodology in lexicostatistical studies of sign languages. In: Mathur, G. \& Napoli, D.J. Deaf Around the World. The Impact of Language. Oxford: OUP. p. 38-53.

Yoel, J. (2007). Evidence for first-language attrition of Russian Sign Language among immigrants to Israel. In: Quinto-Pozos, D. (ed.) Sign Languages in Contact. Washington, DC: Gallaudet University Press, p. 153-191.

Yule, G. (2006). The Study of Language. Cambridge, UK: Cambridge University Press.

Zeshan, U. (2002). Towards a notion of 'word' in sign languages. In: Dixon, R.M.W. (ed.). Word: A cross-linguistic typology. Cambridge, UK: Cambridge University Press, p. 153-177.

Zeshan, U. (2012). UNESCO Survey: Linguistic vitality and diversity of sign languages. Unpublished Ms.

Zeshan, U. \& De Vos, C. (eds.) (2012). Sign Languages and Village Communities: Anthropological and linguistic insights. Berlin, Germany: Walter de Gruyter.

Zhou, M. (2003). Multilingualism in China: The politics of writing reforms for minority languages 1949-2002. Berlin, Germany: Mouton de Gruyter. 